Canadian

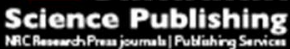

Canadian Geotechnical Journal Revue canadienne de géotechnique

\title{
Design of ballasted railway track foundations using numerical modelling Part II: Applications
}

\begin{tabular}{|r|l|}
\hline Journal: & Canadian Geotechnical Journal \\
\hline Manuscript ID & cgj-2016-0634.R1 \\
\hline Manuscript Type: & Article \\
\hline Date Submitted by the Author: & 18 -Apr-2017 \\
\hline Complete List of Authors: & $\begin{array}{l}\text { Sayeed, Md. Abu; Curtin University, Civil Engineering } \\
\text { Shahin, Mohamed; Curtin University, Civil Engineering }\end{array}$ \\
\hline Keyword: & $\begin{array}{l}\text { Finite elements, numerical modelling, ballasted railway track foundations, } \\
\text { dynamic amplification factor, high-speed trains }\end{array}$ \\
\hline
\end{tabular}

SCHOLARONE ${ }^{\text {MN }}$

Manuscripts 
1 Design of ballasted railway track foundations using numerical modelling

\title{
Part II: Applications
}

\author{
Md. Abu Sayeed \\ PhD Candidate, Department of Civil Engineering, \\ Curtin University, WA 6845, Australia \\ Mobile: +61404214238 \\ E-mail: sayeed.ce00@yahoo.com
}

\author{
Mohamed A. Shahin* \\ Associate Professor, Department of Civil Engineering, \\ Curtin University, WA 6845, Australia \\ Phone: +61-8-9266 1822; Fax: +61-8-9266 2681 \\ E-mail: $\underline{\text { M.Shahin@ } @ \text { curtin.edu.au }}$
}




\section{Design of ballasted railway track foundations using numerical modelling}

\section{Part II: Applications}

28 Abstract: This paper is the second of two companion papers in relation to a new design 29 method for ballasted railway track foundations. The development of the new design method 30 has been explained in the first paper (i.e., Part I: Development), and the procedures for using 31 the method and its practical application on some field case studies are presented in this paper. 32 Special feature of the proposed design method is that it considers the true impact of train 33 dynamic moving loads and number of repeated applications of the traffic tonnage. The 34 proposed method is then applied to four case studies of actual tracks and the results are 35 compared with field measurements and found to be in good agreement. It should be noted 36 that, although the proposed design method is able to overcome most shortcomings of the 37 existing methods and found to provide excellent outcomes, further verification for more field case studies is highly desirable.

39 Keywords: Finite elements, numerical modelling, ballasted railway track foundations, 40 dynamic amplification factor, high-speed trains. 


\section{Introduction}

43 A new method is developed for design of ballasted railway track foundations for determining

44 the granular ballast layer thickness required to prevent the railway track failures induced by

45 the repeated train (dynamic) moving loads. Two common track failure criteria are considered

46 to govern the new design method, namely the subgrade progressive shear failure and

47 excessive plastic deformation of track substructure. The process leading to development of

48 the new design method, including all affecting design parameters, are studied in detail and

49 presented in a separate companion paper, i.e., Part I: Development (Sayeed and Shahin 2017).

50 In this paper, the design procedures that need to be followed for using the new design method

51 is described and the applicability of the method is verified by conducting a comparison

52 between the method outcomes and field measurements, for some well-documented case

53 studies. The results obtained from the new design method are found to be in good agreement

54 with the field measurements, thus, the method can be used with confident in routine design

55 by practitioners.

\section{Description of design procedures of new proposed method}

57 This section presents detailed procedures for using the new design method of selecting a

58 granular layer thickness with the aid of the design charts developed in the companion paper

59 (i.e., Part I: Development). The method has two design procedures corresponding to two

60 different criteria of preventing railway track failures. One procedure is meant for preventing

61 the progressive shear failure at the top subgrade surface, while the other focusses on

62 preventing the excessive plastic deformation of the track. The thickness of the granular layer

63 that should be used for design should be the maximum thickness obtained from applying the

64 two procedures. It should be noted that if the subgrade is very stiff and dynamic wheel load is

65 low, the obtained design thickness might be very small and in such a case it is suggested to 
use a standard minimum thickness of granular layer equal to $0.45 \mathrm{~m}$, including $0.30 \mathrm{~m}$ of ballast plus $0.15 \mathrm{~m}$ of sub-ballast, as suggested by Li et al. (2016). However, if the subgrade is soft (e.g., $E_{s}=15 \mathrm{MPa}$, i.e., shear wave speed $\approx 54 \mathrm{~m} / \mathrm{s}$ ), before proceeding to calculate the granular layer thickness using the design charts, the practitioner needs to double check whether the design speed is higher than the critical speed of the train-track-ground condition at hand. To quantify the critical speed of the train-track-ground condition, readers are referred to Sayeed and Shahin (2016). If the design train speed is higher than the critical speed, the soft subgrade will be susceptible to failure and it is thus recommended to improve the subgrade (e.g., by chemical additives) so that the subgrade modulus can be increased and in turn the critical speed becomes higher than the train design speed.

\section{Design procedure for preventing progressive shear failure}

The design procedure for preventing the progressive shear failure is based on limiting the cumulative plastic strain at the subgrade surface below a threshold value. As discussed earlier, limiting the cumulative plastic strain is achieved automatically by limiting the deviatoric stress induced by the dynamic train moving loads. Li and Selig (1998a, b) developed a design procedure for preventing this mode of track failure; however, their method has several limitations discussed in the companion paper (i.e., Part I: Development). The intention of the proposed new design method is to overcome most of the current limitations of the available design methods including Li-Selig's method, by providing a methodology that suits the modern railway traffics.

Fig. 1 shows a flowchart that can be used for calculating the granular layer thickness needed to prevent the progressive shear failure. The flowchart has four main steps: (1) data collection and preparation; (2) determination of allowable deviatoric stress; (3) determination of 
89

90

allowable strain influence factor; and (4) selection of the granular layer thickness using the developed design charts. The above steps are described in some detail below.

Step 1: The designer should collect and prepare the following information:

- Loading conditions: this requires calculation of the design dynamic wheel load, $P_{d}$, and number of equivalent repeated application of wheel load in the subgrade layer, $N_{s}$, for a given design traffic tonnage. In order to establish the dynamic wheel load, $P_{d}$, it is required to determine the wheel spacing factor (WSF) corresponding to the wheel spacing, which can be obtained from Fig. 12(b) of the companion paper (i.e., Part I: Development). It is also required to determine the dynamic amplification factor (DAF) corresponding to the train speed, which can be obtained from Fig. 13 of the companion paper (i.e., Part I: Development) and best corresponds to the track-ground condition under consideration. The dynamic wheel load, $P_{d}$, can then be estimated using Equation (7) of the companion paper (Part I: Development), and the number of load repetitions in the subgrade layer can be calculated using Equation (9) of the companion paper (i.e., Part I: Development). If there are some major groups of wheel loads, the corresponding groups of dynamic wheel loads and number of repeated loads should be determined separately. Equations (10) and (13) of the companion paper (i.e., Part I: Development) have then to be employed to determine the total number of equivalent load applications in the subgrade, $N s$, of the wheel load, $P_{s}$.

- Design criterion: the design proceeds by selecting an acceptable level of the cumulative plastic strain at the subgrade surface, $\varepsilon_{\left(p_{-} s\right) a}$, for certain number of repeated loads (i.e., for the design traffic tonnage). 
111

112

113

114

$121 \quad \sigma_{\left(d_{-} s\right) a}=\left(\frac{\varepsilon_{\left(p_{-} s\right) a}}{a N_{s}^{b}}\right)^{\frac{1}{m}} \sigma_{s_{-} s} \times 100$

- Subgrade characteristics: this design item requires selection of the subgrade soil type and determination of the soil monotonic strength, $\sigma_{s_{-} s}$, from the unconfined compressive strength (UCS) test and soil modulus, $E_{s}$, obtained from the cyclic triaxial compression test under a confining pressure equal to $100 \mathrm{kPa}$.

- Granular material characteristics: the mechanical properties of the granular materials in the form of the ballast modulus, $E_{b}$, need to be determined from the cyclic triaxial compression test under a confining pressure equal to $100 \mathrm{kPa}$.

Step 2: The allowable deviatoric stress at the subgrade surface is determined using the following equation developed in the companion paper (i.e., Part I: Development):

122

123

$132 \quad I_{\left(\varepsilon_{-} s\right) a}=\frac{\sigma_{\left(d_{-} s\right) a} \times A}{P_{d}}$

where, $\sigma_{\left(d_{-} s\right) a}$ is the allowable deviatoric stress at the subgrade surface; $\varepsilon_{\left(p_{-} s\right) a}$ is the allowable cumulative plastic strain at the subgrade surface needed to prevent the progressive shear failure; $\sigma_{s_{-} s}$ is the soil unconfined compressive strength; $a, b$ and $m$ are material parameters pertinent to the subgrade soil type (see Table 2 of the companion paper, i.e., Part I: Development); $N_{s}$ is the total equivalent number of repeated applications of the design load obtained from Step 1.

Step 3: The allowable strain influence factor at the subgrade surface is determined, using the following equation derived in the companion paper (i.e., Part I: Development): 
133 where, $I_{\left(\varepsilon_{-} s\right) a}$ is the allowable strain influence factor based on the allowable deviatoric stress, $134 \sigma_{\left(d_{-} s\right) a}$, obtained from Step 2; $P_{d}$ is the design dynamic wheel load obtained from Step 1; 135 and the area coefficient, $A=1 \mathrm{~m}^{2}$.

136 Step 4: The required granular layer thickness needed to prevent the progressive shear failure 137 at the subgrade surface is determined, as follows:

- Using the design chart, calculate the granular layer thickness corresponding to the modulus of subgrade soil, $E_{s}$, and allowable strain influence factor, $I_{\left(\varepsilon_{-} s\right) a}$, obtained from Step 3.

\section{Design procedure for preventing excessive plastic deformation}

The design procedure for preventing the excessive plastic deformation of ballast layer is developed in this section. It should be noted that most exiting methods are limited to determination of the subgrade deformation only, although about $40 \%$ of the total track deformation may occur from the granular layer (Li et al. 2016; Stewart 1982). The key advantage of the current proposed design method is that the design procedure for preventing the excessive plastic deformation is based on limiting the total plastic deformation including both the ballast and subgrade layers. According to this design criterion and the above procedure, a flowchart for calculating the granular layer thickness is presented in Fig. 3. As it

152 is difficult to assume the exact value of the granular layer thickness initially, this procedure provides an optimum granular layer thickness after several repetitions following Steps 2-4, as follows: 
155 Step 1: Initially, the designer should collect and prepare the required design information, as 156 presented in the previous section, and some other information such as the thickness of the 157 deformable subgrade layer, $H_{s}$, ballast type, compressive strength of ballast at $50 \mathrm{kPa}$

158 confining pressure, $\sigma_{s_{-} b}$, and number of load repetitions in the ballast layer, $N_{b}$. The number of load repetitions in the ballast layer can be calculated using Equation (8) of the companion paper (i.e., Part I: Development). Similar to the load repetitions in the subgrade soil, if there are some major groups of wheel loads, the corresponding groups of the dynamic wheel loads and number of repeated loads should be determined separately. Afterwards, Equations (11) and (12) of the companion paper (i.e., Part I: Development) can be employed to determine the total number of equivalent repeated load applications of the wheel load on the ballast layer. The design criterion for preventing the progressive shear failure (i.e., allowable plastic strain at the subgrade surface, $\left.\varepsilon_{\left(p_{-} s\right) a}\right)$ is thus substituted by enforcing the allowable total plastic deformation of the track substructure layers, $\rho_{t a}$.

Step 2: This step is to determine the deformation of granular ballast layer, as follows:

- Assume a granular layer thickness, $H_{b}$, equal to the granular layer thickness obtained from the design procedure used earlier for preventing the progressive shear failure.

- Select a suitable chart from Appendix $B$ for estimating the distribution of the dimensionless strain influence factor, $I_{\varepsilon_{-} b}$, with depth for the granular the ballast layer (e.g., Fig. 4) that best corresponds to the elastic modulus of the ballast and subgrade, and the granular layer thickness.

- Determine the deformation of the granular ballast layer, $\rho_{b}$, using the following equation developed in the companion paper (i.e., Part I: Development): 


$$
\rho_{b}=\frac{x\left[1+\ln \left(N_{b}\right)\right]^{z}}{100}\left(\frac{P_{d}}{A \sigma_{s_{-} b}}\right)^{y} \int_{0}^{H_{b}}\left(I_{\varepsilon_{-} b}\right)^{y} d h
$$

179

190

$$
I_{\left(\rho_{-} s\right) a}=\frac{\rho_{t a}-\rho_{b}}{\frac{a L N_{s}^{b}}{100}\left(\frac{P_{d}}{A \sigma_{s_{-} s}}\right)^{m}}
$$

where, $P_{d}$ is the design dynamic wheel load; $\sigma_{s_{-} b}$ is the static strength of ballast; $N_{b}$ is the total number of equivalent repeated load applications of the wheel load for the ballast layer; $x, y$ and $z$ are material parameters for a particular ballast type (see Table 1 of the companion paper, i.e., Part I: Development); $H_{b}$ is the granular ballast thickness; $I_{\varepsilon_{-} b}$ is the distribution of strain influence factor with ballast depth; and $A$ is the area coefficient $\left(=1 \mathrm{~m}^{2}\right)$. All corresponding information are obtained from Step 1.

Step 3: This step is to determine the allowable subgrade deformation influence factor, $I_{\left(\rho_{-} s\right) a}$, using the information obtained from Steps 1 and 2 and applying the following equation developed in the companion paper (i.e., Part I: Development):

where, $\rho_{t a}$ is the allowable track deformation; $\rho_{b}$ is the contribution to track deformation by the ballast layer; $N_{s}$ is the total equivalent number of load repetitions in the subgrade for the 194 design traffic tonnage; $P_{d}$ is the design dynamic wheel load; $\sigma_{s_{-} s}$ is the unconfined compressive strength of the soil; $a, b$ and $m$ are material parameters dependent on the soil type (see Table 2 of the companion paper, i.e., Part I: Development); $A$ is the area coefficient $197\left(=1 \mathrm{~m}^{2}\right)$; and $L$ is the length coefficient $(=1 \mathrm{~m})$. 
198 Step 4: Finally, determine the required granular layer thickness, $H_{b}$, needed to prevent the 199 excessive plastic deformation of the track, as follows:

200

201

- Select a suitable design chart from Appendix $C$ (e.g., Fig. 5) that best corresponds to the ballast modulus, existing subgrade soil type, and modulus.

- Calculate the granular layer thickness, $H_{b}$, corresponding to the allowable deformation influence factor of subgrade and thickness of deformable subgrade layer using the selected design charts.

- Compare the design thickness obtained in this step with the thickness assumed in the calculation of the granular layer deformation in Step 2. If the obtained thickness from Step 4 is not equal to the assumed thickness, then repeat Steps 2-4 until the assumed $H_{b}$ converges with the design thickness obtained in Step 4. In each iteration, the calculated thickness can be assumed for the next iteration to achieve faster convergence.

\section{Design applications}

To validate the proposed design method, it is applied to four well-documented case studies found in the literature and the results obtained are compared with field measurements. These two case studies are for test tracks reported by Li and Selig (1998b), including the Association of American Railroads (AAR) low track modulus (LTM) and trial low track modulus (TLTM). Another two case studies of real track sites at the Northeast Corridor (NC) between Baltimore and Philadelphia are also considered for additional validation of the proposed design method, and results obtained are again compared with field measurements and found to be in good agreement. 


\section{LTM and TLTM tracks}

221 In 1991, a 183 m long low track modulus (LTM) test track was built on a fat clay type 222 subgrade at the Association of American Railroads (AAR) Heavy Tonnage Loop (HTL) in 223 Pueblo, Colorado. The information needed for design of these ballasted tracks are given in 224 Table 1. Prior to the construction of the LTM, a $30 \mathrm{~m}$ long trial low track modulus (TLTM) 225 test track was constructed to examine the practicality of building a longer LTM track. The 226 key objective of constructing the LTM test track was to investigate the impact of soft 227 subgrade on track performance under repeated heavy axle train (HAT) moving loads (Li and 228 Selig 1996). The subgrade soil at the Pueblo test track site was originally silty sand, which 229 does not represent a soft subgrade soil. To construct a track on soft subgrade soil, a $3.66 \mathrm{~m}$ 230 wide and $1.5 \mathrm{~m}$ deep trench was dug in the natural subgrade and filled with the Mississippi 231 buckshot clay of liquid limit $(L L=60 \sim 70)$ and plasticity index $(P I=40 \sim 45)$. To achieve a 232 subgrade of low stiffness, the filled material within the trench was compacted with the water 233 content $(30 \%)$ and dry density at $90 \%$ of its maximum dry density, which according to the 234 ASTM D698 was found to be $14.91 \mathrm{kN} / \mathrm{m}^{3}$. Although the water content for both the LTM and 235 TLTM subgrades was targeted to be $30 \%$, the average water contents in the LTM and TLTM 236 subgrades were actually $33 \%$ and $29 \%$, respectively ( $\mathrm{Li}$ and Selig 1996). Hence, the 237 corresponding unconfined compressive strength of subgrade soil was about $90 \mathrm{kPa}$ for the 238 LTM track and $166 \mathrm{kPa}$ for the TLTM track. The relevant soil modulus of the LTM track 239 subgrade varied from $14 \mathrm{MPa}$ to $21 \mathrm{MPa}$, while it was in the range of $41 \mathrm{MPa}$ to $55 \mathrm{MPa}$ for 240 the TLTM track. The difference between these two track sites was in their subgrade modulus 241 and unconfined compressive strength (see Table 1). Accordingly, the design thickness for 242 each track is expected to be different. 
244 Step 1: At first, the information needed for design of ballasted railway track foundations 245 (i.e., loading condition, design criteria, ballast and subgrade material characteristics) are 246 specified and listed in Table 1. For train geometry, the value of wheel spacing factor (WSF) 247 corresponding to a wheel spacing of $1.8 \mathrm{~m}$ is found to be 1.38 (obtained from Fig. $12 \mathrm{~b}$ of the 248 companion paper, i.e., Part I: Development). Also, for this particular track-ground condition, 249 the value of dynamic amplification factor (DAF) corresponding to the train speed is obtained 250 to be 1.04, using Fig. 13 of the companion paper (i.e., Part I: Development). Afterwards, the 251 design dynamic wheel load, $P_{d}$, is calculated to be $250 \mathrm{kN}$ using Equation (7) of the 252 companion paper (i.e., Part I: Development). The equivalent number of load repetitions in the 253 subgrade layer is determined using Equation (9) of the companion paper (i.e., Part I: 254 Development) to be $N_{s}=386,000$.

255 Step 2: Considering the appropriate respective design parameters and number of load 256 repetitions, $N_{s}$, obtained in Step 1, the allowable deviatoric stress at the subgrade surface, $257 \sigma_{\left(d_{-} s\right) a}$, is calculated using Equation (1) to be $41 \mathrm{kPa}$ and $76 \mathrm{kPa}$ for the LTM and TLTM 258 tracks, respectively.

259 Step 3: The allowable strain influence factors corresponding to the allowable deviatoric 260 stresses, $\sigma_{\left(d_{-} s\right) a}$, and design dynamic wheel load, $P_{d}$, are determined using Equation (2) to be $261 I_{\left(\varepsilon_{-}\right) a}=0.16$ for the LTM track and 0.31 for the TLTM track.

262 Step 4: The design chart A2 of Appendix $A$ is selected as it corresponds to ballast modulus $E_{b}$ $263=270 \mathrm{MPa}$, for both the LTM and TLTM tracks (see Fig. 2). The required granular layer 264 thickness for the LTM track needed to prevent the progressive shear failure is determined for $265 I_{\varepsilon_{-} s}=0.16$ and $E_{s}=15 \mathrm{MPa}$, and is found to be $H_{b}=0.53 \mathrm{~m}$. Similarly, using the same design 
266 chart, the required granular layer thickness for the TLTM track is found to be $H_{b}=0.40 \mathrm{~m}$ 267 considering $I_{\varepsilon_{-} s}=0.31, E_{s}=41 \mathrm{MPa}$ and $E_{b}=270 \mathrm{MPa}$.

Step 1: This step is similar to Step 1 in the design procedure for preventing the progressive shear failure. Therefore, the design dynamic wheel load is obtained to be $P_{d}=250 \mathrm{kN}$ and the equivalent number of load repetitions in the subgrade to be $N_{s}=386,000$. Moreover, the number of load repetitions in the ballast layer is determined using Equation (8) of the companion paper (i.e., Part I: Development) to be $N_{b}=772000$.

Step 2: At first, the granular layer thickness is assumed to be equal to the thickness obtained from the design procedure for preventing the progressive shear failure (i.e., $H_{b}=0.53 \mathrm{~m}$ for the LTM track and $H_{b}=0.40 \mathrm{~m}$ for the TLTM track). For the LTM track with $E_{b}=270 \mathrm{MPa}$, $H_{b}=0.53 \mathrm{~m}$ and $E_{s}=15 \mathrm{MPa}$, the distribution of the dimensionless strain influence factor, $I_{\varepsilon_{-} b}$, with the ballast depth is obtained from Appendix B (Charts B7 and B8). Afterwards, for the granite ballast (assumed), the deformation of the ballast layer, $\rho_{b}$, is determined using Equation (3) to be $0.011 \mathrm{~m}$, considering $\sigma_{s_{-} b}=307 \mathrm{kPa}, P_{d}=250 \mathrm{kN}$ and $N_{b}=772,000$. Similarly, for the TLTM track with $E_{b}=270 \mathrm{MPa}, H_{b}=0.40 \mathrm{~m}$ and $E_{s}=41 \mathrm{MPa}$, the distribution of dimensionless strain influence factor, $I_{\varepsilon_{-} b}$, with ballast depth is obtained from Appendix B (Charts B6 and B7). Afterwards, the deformation of the ballast layer is determined using Equation (3) to be $0.006 \mathrm{~m}$.

Step 3: For the LTM track loading and subgrade conditions (i.e., $P_{d}=250 \mathrm{kN}, N_{s}=386000$,

$\mathrm{CH}$ type subgrade and $\sigma_{s_{s} s}=90 \mathrm{kPa}$ ) and the design criterion of $\rho_{t a}=0.025 \mathrm{~m}$, the 
288 Equation (4). Likewise, for the TLTM track, the allowable subgrade deformation influence 289 factor is obtained using Equation (4) to be $I_{\left(\rho_{-} s\right) a}=0.06$ for $P_{d}=250 \mathrm{kN}, N_{s}=386000, \mathrm{CH}$ 290 type subgrade, and $\sigma_{s_{-} s}=165 \mathrm{kPa}$.

291 Step 4: To determine the design thickness, chart C21 from Appendix $C$ [see Fig. 5(a)] is 292 selected which best corresponds to the LTM track substructure conditions (i.e., $E_{b}=270$ $293 \mathrm{MPa}, E_{s}=15 \mathrm{MPa}$, and $\mathrm{CH}$ soil). From this chart, the required granular layer thickness 294 corresponding to the deformable subgrade layer (i.e., $H_{s}=1.5 \mathrm{~m}$ and $I_{\left(\rho_{-} s\right) a}=0.01$ obtained 295 in Step 3), is found to be $H_{b}=0.66 \mathrm{~m}$. As the obtained thickness is not equal to assumed 296 thickness (i.e. obtained $H_{b} \neq H_{b}$ of Step 1), Step 2 (i.e., calculation of granular ballast 297 deformation, $\rho_{b}$ ) is repeated considering the granular ballast thickness obtained in Step 4 298 (i.e., $H_{b}=0.66 \mathrm{~m}$ ). After several repetitions of Steps $2-4$, the granular layer thickness for the LTM track is obtained to be $H_{b}=0.70 \mathrm{~m}$. Similarly, for the TLTM track with $E_{b}=270 \mathrm{MPa}$, 300 $E_{s}=41 \mathrm{MPa}$, and $\mathrm{CH}$ soil, Fig. 5(b) is selected from Appendix C. Employing the selected design chart, the required granular layer thickness is determined corresponding to the deformable subgrade layer (i.e., $H_{s}=1.5 \mathrm{~m}$ and $I_{\left(\rho_{-} s\right) a}=0.06$ ) to be $H_{b}=0.25 \mathrm{~m}$. Again, as the obtained $H_{b} \neq H_{b}$ of Step 1, Steps 2-4 are repeated. Finally, the required granular layer thickness needed to prevent the excessive plastic deformation is calculated to be $H_{b}=0.30 \mathrm{~m}$.

Design thickness

As presented above, the granular layer thickness required to prevent the excessive plastic deformation (i.e., $H_{b}=0.70 \mathrm{~m}$ ) for the LTM track is higher than that needed to prevent the progressive shear failure (i.e., $H_{b}=0.53 \mathrm{~m}$ ). Thus, the design thickness is the maximum of the two obtained results (i.e., $H_{b}=0.70 \mathrm{~m}$ ). On the other hand, for the TLTM track, the granular layer thickness required to prevent the excessive plastic deformation (i.e., $H_{b}=0.30$ 
$311 \mathrm{~m}$ ) is less than that needed to prevent the progressive shear failure (i.e., $H_{b}=0.40 \mathrm{~m}$ ). Hence,

312 the design thickness to be used is $H_{b}=0.40 \mathrm{~m}$.

313

314

\section{Comparisons between proposed design method and field measurements}

Based on the design criteria for preventing the progressive shear failure (i.e., $\varepsilon_{\left(p_{-} s\right) a} \leq 2 \%$ ) and for preventing the excessive plastic deformation (i.e., $\rho_{t a} \leq 0.025 \mathrm{~m}$ ), the required granular layer thickness for the LTM and TLTM tracks are determined to be $H_{b}=0.70 \mathrm{~m}$ and $0.40 \mathrm{~m}$, respectively, as calculated in the earlier section. In reality, during the construction of both the LTM and TLTM tracks, a granular layer of $0.45 \mathrm{~m}$ thickness $(0.30 \mathrm{~m}$ ballast and $0.15 \mathrm{~m}$ sub-ballast) was adopted based on an assumption of $30 \%$ water content in the subgrade soil and minimum density of $90 \%$ of the standard maximum dry density. Afterwards, the track response in these sites was measured and the subgrade conditions were evaluated experimentally, which provide an excellent opportunity to assess the proposed design method. From the field measurements, it was found that the LTM track with the adopted granular layer thickness of $0.45 \mathrm{~m}$ was unable to bear the HAL for design traffic of $60 \mathrm{MGT}$, and thus had difficulty in sustaining the required track surface geometry. The LTM track subgrade suffered rapid progressive shear failure and excessive plastic deformation. Therefore, the test track needed frequent rail lifting by ballast tamping. Fig. 6 shows the cumulative track settlement with the traffic loading for the LTM track (Li 1994). It can be seen that the track actually required frequent ballast tamping and surfacing (rail lift up) following 12.4 MGT, and finally, the traffic along the track had to be stopped after approximately 62.3 MGT and the test track was then rebuilt. On the other hand, the TLTM track with the same granular layer thickness of $0.45 \mathrm{~m}$ was able to carry the HAL for design traffic of 60 MGT without any track failure. Consequently, no major track maintenance was invoked during the design life of this track. 
335 A comparison between the originally adopted $H_{b}$ and that obtained from design (see Table 2)

336 indicates that the adopted thickness for the LTM track of $0.45 \mathrm{~m}$ was much less than the 337 required thickness of $0.70 \mathrm{~m}$, but the adopted thickness for the TLTM track of $0.45 \mathrm{~m}$ was 338 higher than the required thickness of $0.40 \mathrm{~m}$. Therefore, the LTM track was unable to 339 maintain the track geometry and invoked maintenance, whereas the TLTM track was able to 340 sustain the required track geometry without any maintenance. In other words, the proposed 341 design method was successful in predicting the failure of the LTM track and the proper 342 thickness of the TLTM track. These results are extremely encouraging for the proposed 343 design method.

344 As an additional validation tool, the actual LTM track-subgrade condition with the adopted $3450.45 \mathrm{~m}$ granular layer thickness is simulated using the 3D FE modelling and the distribution 346 of the strain influence factor with depth in the ballast and subgrade layers is obtained. Then, 347 the cumulative vertical track deflections for the ballast and subgrade layers at different traffic 348 loads are computed using the results obtained from the $3 \mathrm{D}$ FE modelling as well as the 349 following equation developed in the companion paper (i.e., Part I: Development): 350

351

$$
\begin{aligned}
\rho_{t}= & \frac{x\left[1+\ln \left(N_{b}\right)\right]^{z}}{100}\left(\frac{P_{d}}{A \sigma_{s_{-} b}}\right)^{y} \int_{0}^{H_{b}}\left(I_{\varepsilon_{-} b}\right)^{y} d h+ \\
& \frac{a L N_{s}^{b}}{100}\left(\frac{P_{d}}{A \sigma_{s_{-} s}}\right)^{m} \int_{0}^{H_{s}}\left(I_{\varepsilon_{-} s}\right)^{m} \frac{d h}{L}
\end{aligned}
$$

353 The cumulative track deflections are then plotted against the traffic load in MGT and 354 compared with the field measurements available in the literature (Li 1994), as shown in Fig. 355 7. It can be clearly seen that good agreement exists between the FE predictions and field 356 measurements, which confirms that the validity of the FE modelling process and improved 
357

empirical models for predicting the cumulative plastic deformation of ballast and subgrade adopted in this study. This indicates that the design method developed in this study based on the combined FE modelling and improved empirical models is reliable and can be used with confidence to predict the railway track behavior.

\section{Northeast Corridor track}

In this section, two more case studies of real track sites at the Northeast Corridor (NC) between Baltimore and Philadelphia are used for further validation of the proposed method. One of the two sites is located at Edgewood, Maryland, and the other site is located at Aberdeen, Maryland, some $16 \mathrm{~km}$ apart from the Edgewood site. The track in Edgewood site suffered frequent bouts of differential settlements over a distance of approximately $10 \mathrm{~km}$. This track site needed frequent maintenance by ballast tamping at least twice a year. Moreover, remedy measures such as application of geotextiles and lime slurry injection were taken since 1984; however, such remedies were not fruitful. For the other site at Aberdeen, only a small portion of the track (about $60 \mathrm{~m}$ long) suffered a problem of mud pumping; however, the geometry deterioration was not a concern (Li and Selig 1998b).

To investigate the key reasons for track failures at both sites, the loading characteristics and material properties were studied by Li and Selig (1994). Based on the information available in the literature, the minimum required granular layer thickness for both sites are determined using the current proposed design method. At the Edgewood site, the subgrade soil was lean clay (LC) with unconfined compressive strength of approximately $48-83 \mathrm{kPa}$. On the other hand, the subgrade soil at the Aberdeen site was also lean clay but its unconfined compressive strength was in the range of $97-290 \mathrm{kPa}$. The subgrade soil properties and other information required for design of tracks at both sites are given in Table 3. As both sites were parts of the $\mathrm{NC}$ and not far away from each other, the traffic was the same. The traffic along 
the NC track was mixed (50\% passenger trains and 50\% freight trains). Table 4 gives the loading characteristics used for design of these two tracks. As the traffic was mixed, the number of equivalent load applications in the ballast and subgrade layers is determined using Equations (7-13) of the companion paper (i.e., Part I: Development).

Based on the design criteria of preventing the progressive shear failure (i.e. $\varepsilon_{p a} \leq 2 \%$ ) and for preventing the excessive plastic deformation (i.e. $\rho_{t a} \leq 0.025 \mathrm{~m}$ ), the required granular layer thicknesses, $H_{b}$, for the Edgewood site are determined to be $1.08 \mathrm{~m}$ and $1.16 \mathrm{~m}$, respectively. Consequently, the design thickness for this site should be taken as $1.20 \mathrm{~m}$. However, the actual granular layer thickness at the Edgewood site was varied from 0.30 to $0.50 \mathrm{~m}$ (from the cone penetration tests and cross trench measurements of the track site), as reported by Li and Selig (1994). This thickness is significantly less than the obtained design thickness of $1.20 \mathrm{~m}$ required to reduce the dynamic train induced stresses transmitted to the subgrade to prevent the progressive shear failure and excessive plastic deformation. As a result, it is not surprising that the track of this site has suffered a significant progressive shear failure at the subgrade surface, and deep ballast pockets have also occurred. Moreover, the non-uniform compressive strength of the subgrade ( $48 \mathrm{kPa}$ to $83 \mathrm{kPa}$ ) caused excessive differential track settlement.

For the Aberdeen site, the required granular layer thickness calculated from the proposed design method is $H_{b}=0.66 \mathrm{~m}$ for preventing the progressive shear failure and $H_{b}=0.60 \mathrm{~m}$ for preventing the excessive plastic deformation. Therefore, the design thickness of this site should be $H_{b} \approx 0.70 \mathrm{~m}$. From the field measurements reported by Li and Selig (1994), the actual granular layer thickness at this site was varied between 0.70 and $1.0 \mathrm{~m}$, which is equal or larger than the required design thickness. As the dynamic train induced stresses in the subgrade were lower than the allowable value, this track was able to carry the design load without any geometry deterioration. Comparison of the design thickness obtained from the 
405 proposed design method and actual thickness at both the Edgewood and Aberdeen sites is 406 summarized in Table 5, which also includes the track conditions for both sites. Evidently, the 407 results of the proposed design method are consistent with the field measurements.

\section{Summary and conclusions}

409 In this paper, step-by-step design procedures were presented for a new design method of 410 ballasted railway track foundations. The new proposed method has substantial benefits over 411 the existing methods in the way at which the railway traffic was characterized and stress was 412 analyzed. In addition, the new method has taken into account the deformation of both the 413 ballast and subgrade layers. The main parameters considered in design include the train 414 speed, track-ground condition, geometry and magnitude of train wheel loads, number of load 415 repetition, as well as modulus, thickness and type of ballast and subgrade. All these 416 parameters considerably affect a safe design for preventing track failures. Design predictions 417 obtained from the developed design method were examined against field measurements for 418 four different case studies and the results were found to be in good agreement. Consequently, 419 the proposed design method can be used with confidence and it is expected to provide a 420 significant contribution to the current railway track code of practice. To facilitate the use of 421 the new design method by practitioners, a user friendly software will be developed in the near 422 future and will be made available upon request. 


\section{References}

423

424

425

426

427

428

Li, D. 1994. Railway track granular layer thickness design based on subgrade performance under repeated loading. PhD Thesis, Department of Civil and Environmental Engineering. University of Massachusetts, Amherst, Massachusetts, USA.

Li, D., Hyslip, J., Sussmann, T., and Chrismer, S. 2016. Railway Geotechnics. CRC Press, Tailor \& Francis Group, Broken Sound Parkway NW, USA.

Li, D., and Selig, E.T. 1994. Investigation of AMTRAK track foundation problems in Edgewood and Aberdeen, MD. Internal Rep. to the Assoc. of Am. Railroads and Amtrak.

Li, D., and Selig, E.T. 1996. Cumulative plastic deformation for fine-grained subgrade soils. Journal of Geotechnical Engineering 122(12): 1006-1013.

Li, D., and Selig, E.T. 1998a. Method for railroad track foundation design. I: Development. Journal of Geotechnical and Geoenvironmental Engineering 124(4): 316.

Li, D., and Selig, E.T. 1998b. Method for railroad track foundation design. II: Applications. Journal of Geotechnical and Geoenvironmental Engineering 124(4): 323.

Li, D., Sussmann, T.R., and Selig, E.T. 1996. Procedure for railway track granular layer thickness determination. Association of American Railroads, Transportation Technology Center. Report No. R-898.

Sayeed, M.A., and Shahin, M.A. 2016. Three-dimensional numerical modelling of ballasted railway track foundations for high-speed trains with special reference to critical speed. $\begin{array}{lllll}\text { Transportation } & \text { Geotechnics } & 6 & \text { 6: } & \text { 55-65. }\end{array}$ http://dx.doi.org/10.1016/j.trgeo.2016.01.003.

Sayeed, M.A., and Shahin, M.A. 2017. Design of ballasted railway track foundations using numerical modelling: Part I-Development. Canadian Geotechnical Journal, doi: 10.1139/cgj-2016-0633. 
447 Stewart, H.E. 1982. The prediction of track performance under dynamic traffic loading. In

448 Department of Civil Engineering. University of Massachusetts, Amherst, 449 Massachusetts, USA. 


\section{List of symbols}

a material parameter pertinent to the subgrade soil type

$b \quad$ material parameter pertinent to the subgrade soil type

$m$ material parameter pertinent to the subgrade soil type

$x \quad$ material parameter dependent on ballast type

$y \quad$ material parameter dependent on ballast type

$z \quad$ material parameter dependent on ballast type

A area coefficient

$E_{b} \quad$ ballast modulus

$E_{s} \quad$ subgrade soil modulus

$H_{b} \quad$ granular layer thickness

$H_{s} \quad$ subgrade thicknesses

$L \quad$ length coefficient

$L_{a} \quad$ wheel spacing

$N_{b} \quad$ number of load applications in the ballast layer

$N_{S} \quad$ number of load applications in the subgrade layer

$P_{d} \quad$ design dynamic wheel load

$P_{s} \quad$ maximum static wheel load

$\varepsilon_{\left(p_{-} s\right) a}$ allowable subgrade surface cumulative plastic strain

$\sigma_{\left(d_{-} s\right) a}$ allowable deviatoric stress at the subgrade surface

$\sigma_{s_{-} b}$ compressive strength of ballast at $50 \mathrm{kPa}$ confining pressure

$\sigma_{s_{-} s} \quad$ unconfined compressive strength of the soil

$\rho_{b} \quad$ deformation of granular ballast layer

$\rho_{t a} \quad$ allowable total plastic deformation of the track

$I_{\varepsilon_{-} b} \quad$ strain influence factor in the granular layer

$I_{\left(\varepsilon_{-} s\right) a}$ allowable subgrade surface strain influence factor

$I_{\left(\rho_{-} s\right) a}$ allowable subgrade deformation influence factor 


\section{Figure captions}

Fig. 1. Flowchart of design of railway track foundations for preventing the progressive shear failure of track subgrade.

Fig. 2. Typical example of design chart to calculate the granular layer thickness for preventing the progressive shear failure of track subgrade (obtained from Appendix A, Chart A2).

Fig. 3. Flowchart of design of railway track foundations for preventing the excessive track deformation.

Fig. 4. Distribution of strain influence factor with depth for the ballast layer.

Fig. 5. Typical examples of design charts to calculate the granular layer thickness for preventing the excessive track deformation (obtained from Appendix C, Charts C21 and C25).

Fig. 6. Field measurements of average settlement and lift-up of rail with traffic load for the LTM test track (redrawn from Li 1994).

Fig. 7. Comparison between new design method and field measurements. 


\section{Table captions}

Table 1. Design parameters for the LTM and TLTM test tracks (adapted from Li et al. 1996).

Table 2. Design results and track conditions for the LTM and TLTM test tracks.

Table 3. Design parameters for tracks at Edgewood and Aberdeen sites (adapted from Li and Selig 1998b).

Table 4. Traffic characteristics at the Northeast Corridor between Baltimore and Philadelphia (adapted from Li and Selig 1998b).

Table 5. Comparison of results between new design method and site conditions for tracks at Edgewood and Aberdeen sites. 


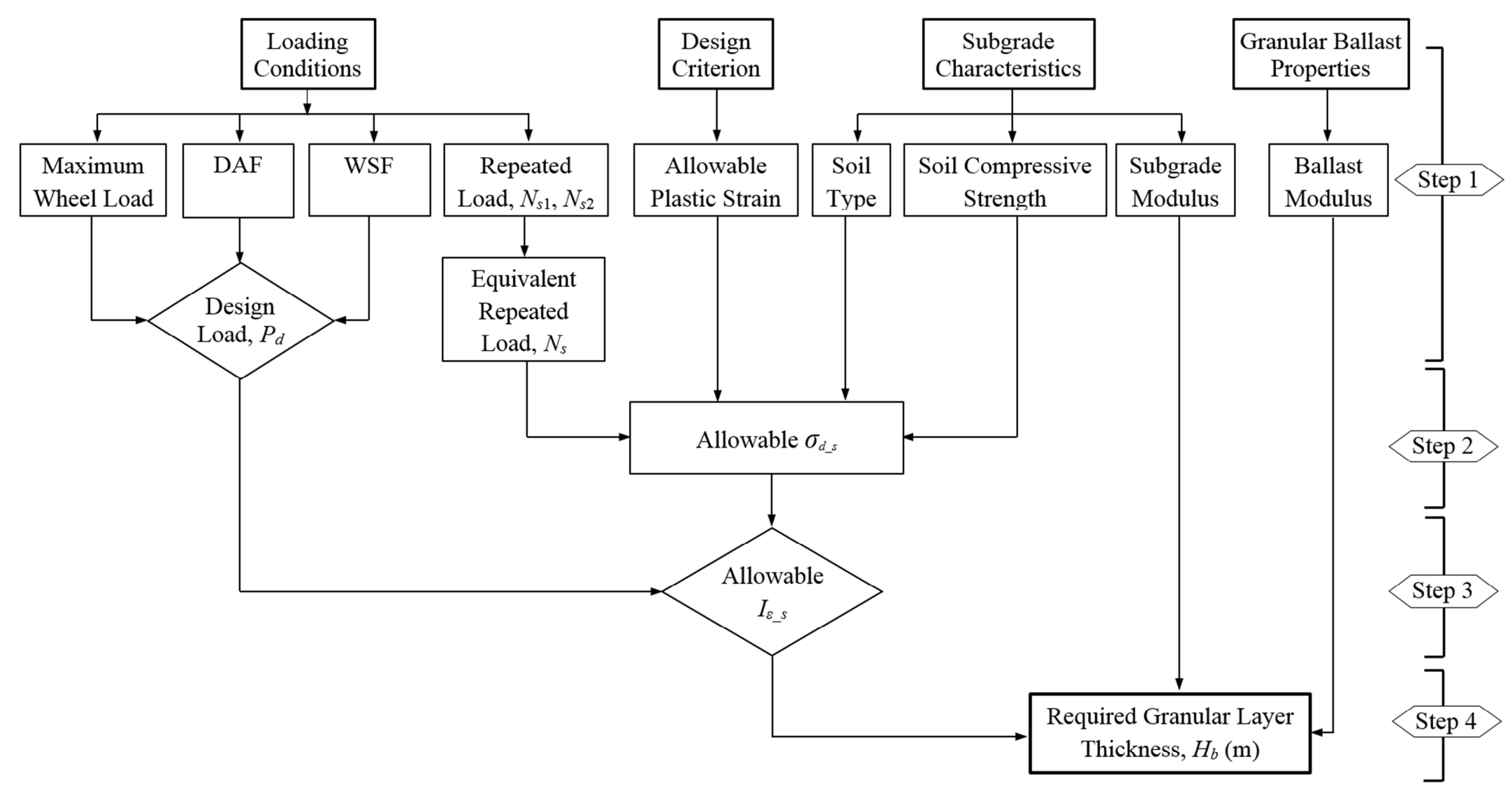

Fig. 1. Flowchart of design of railway track foundations for preventing the progressive shear failure of track subgrade. 


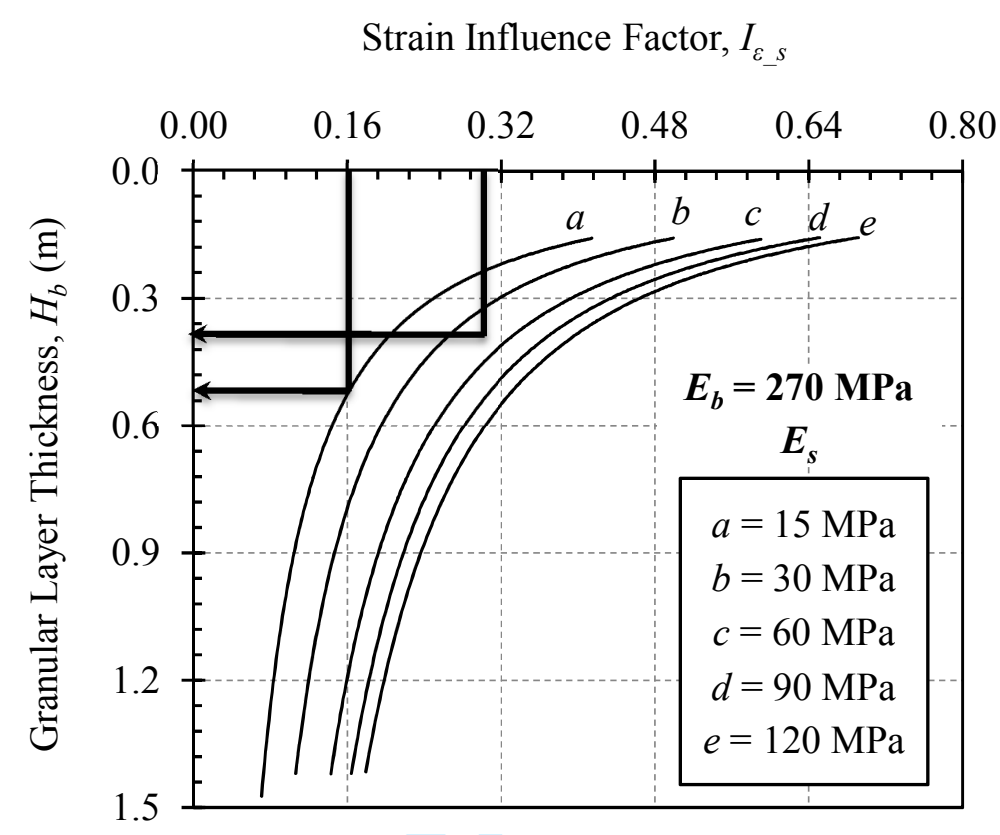

Fig. 2. Typical example of design chart to calculate the granular layer thickness for preventing the progressive shear failure of track subgrade (obtained from Appendix A, Chart A2). 


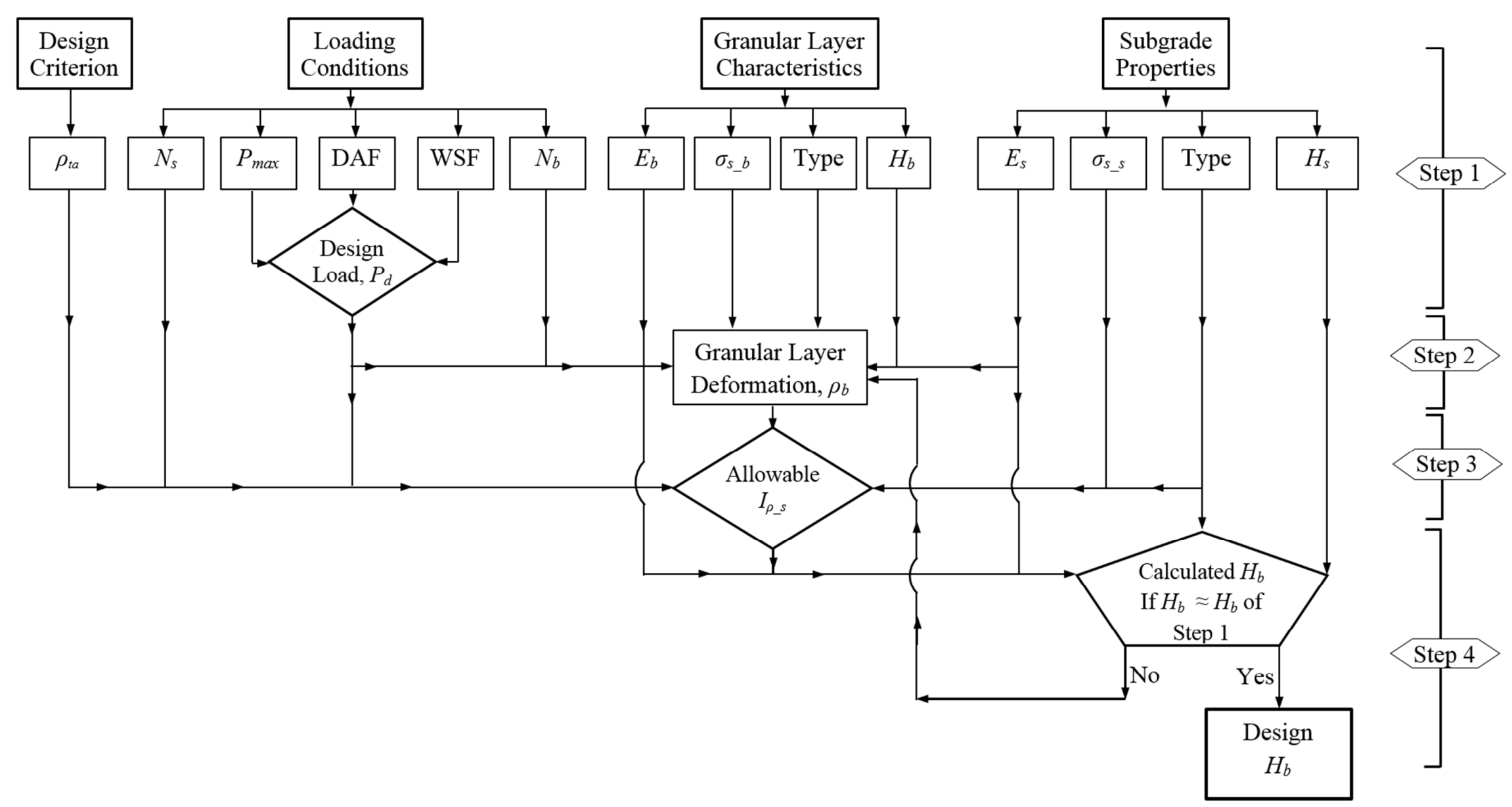

Fig. 3. Flowchart of design of railway track foundations for preventing the excessive track deformation. 


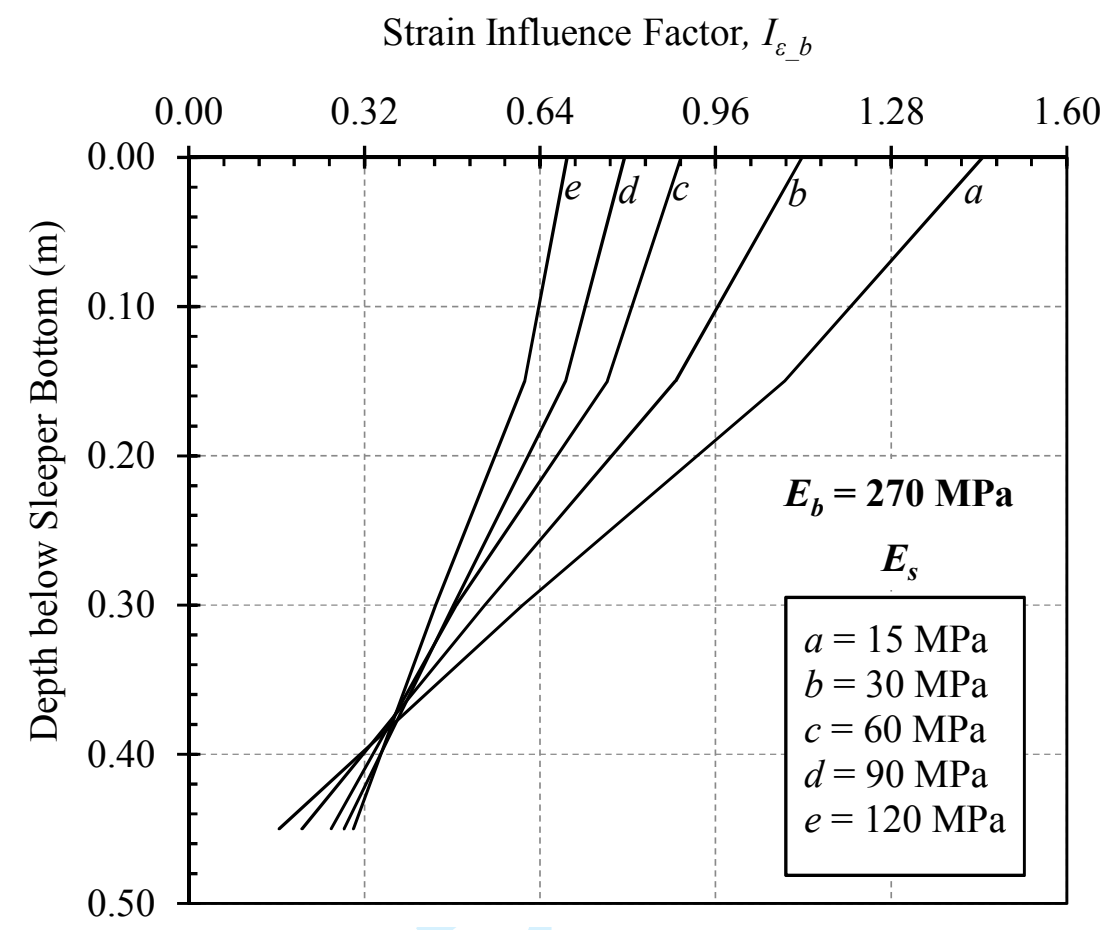

Fig. 4. Distribution of strain influence factor with depth for the ballast layer. 
Deformation Influence Factor, $I_{\rho_{-} s}$

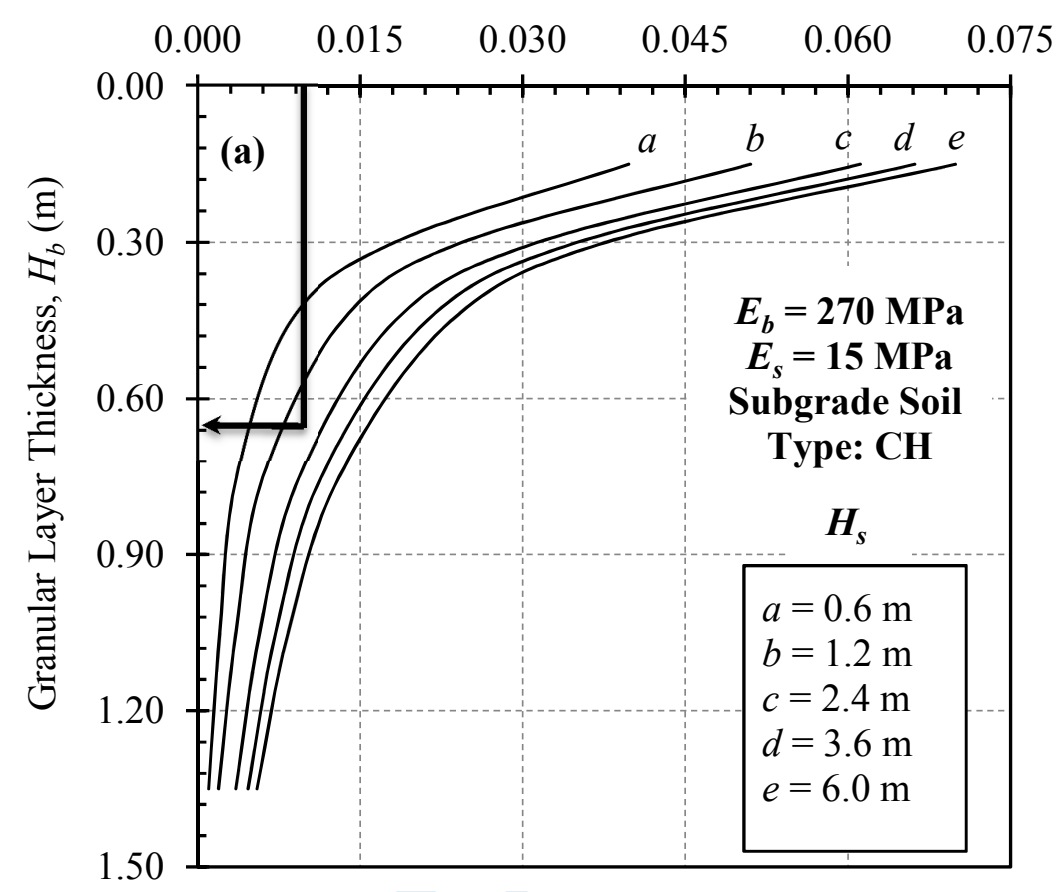

Deformation Influence Factor, $I_{\rho_{-} s}$

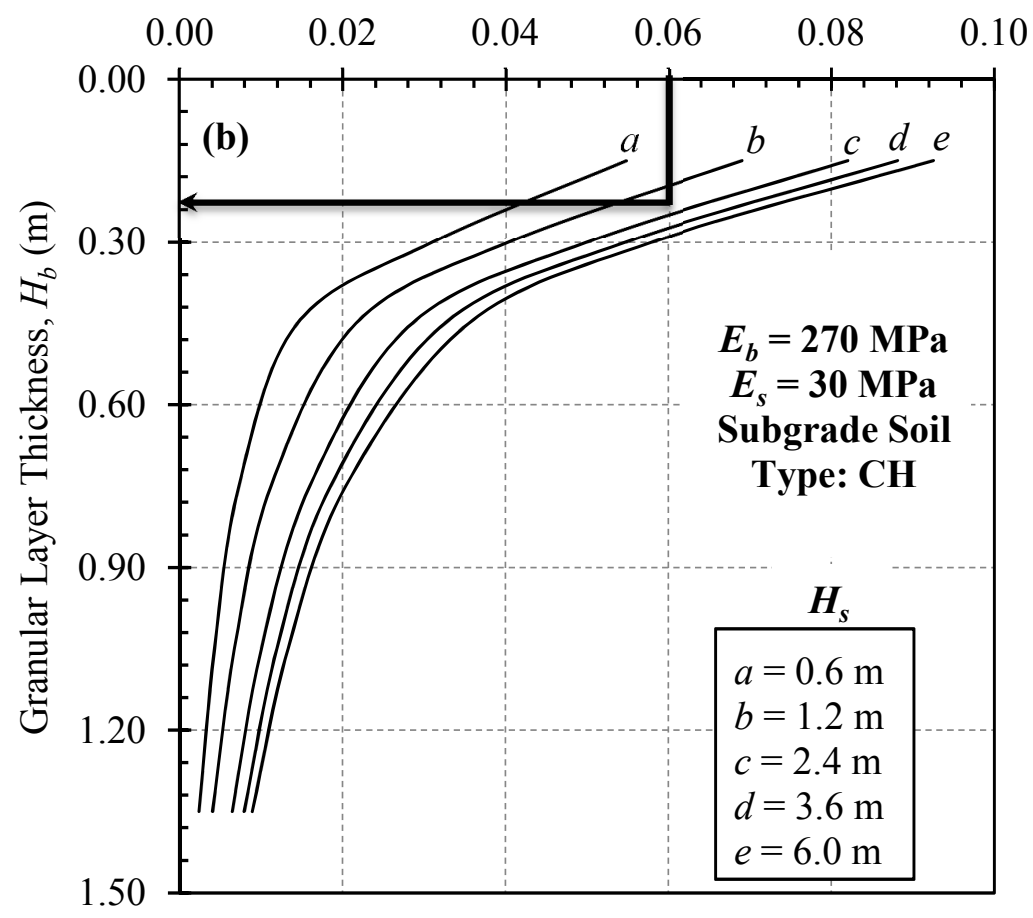

Fig. 5. Typical examples of design charts to calculate the granular layer thickness for preventing the excessive track deformation (obtained from Appendix C, Charts C21 and C25). 


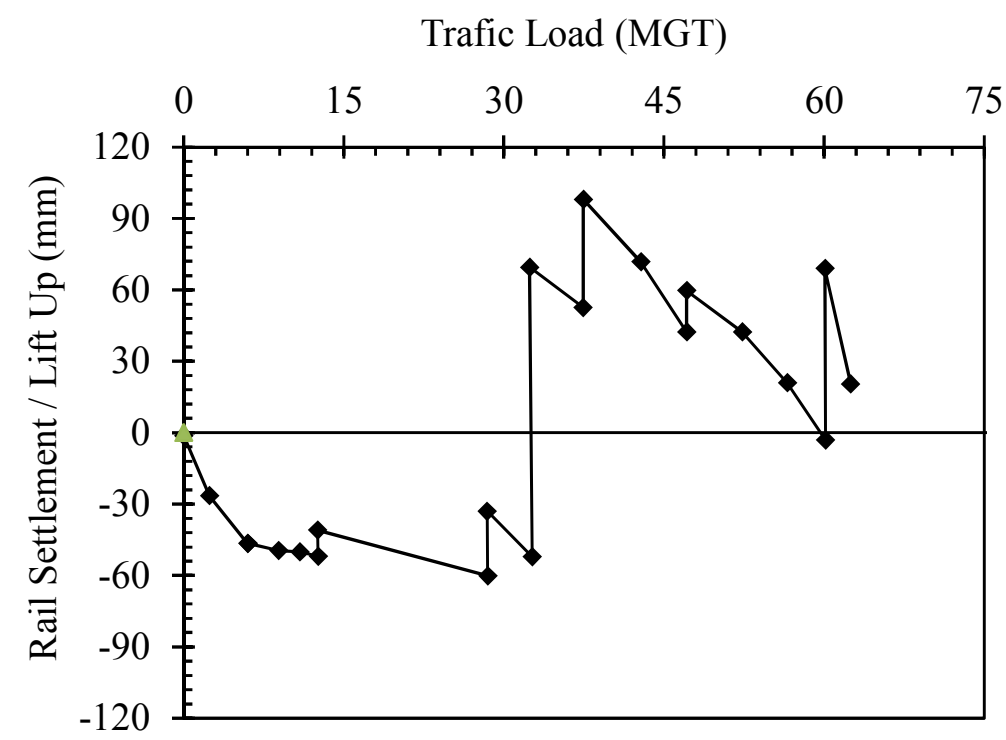

Fig. 6. Field measurements of average settlement and lift-up of rail with traffic load for the LTM test track (redrawn from Li 1994). 


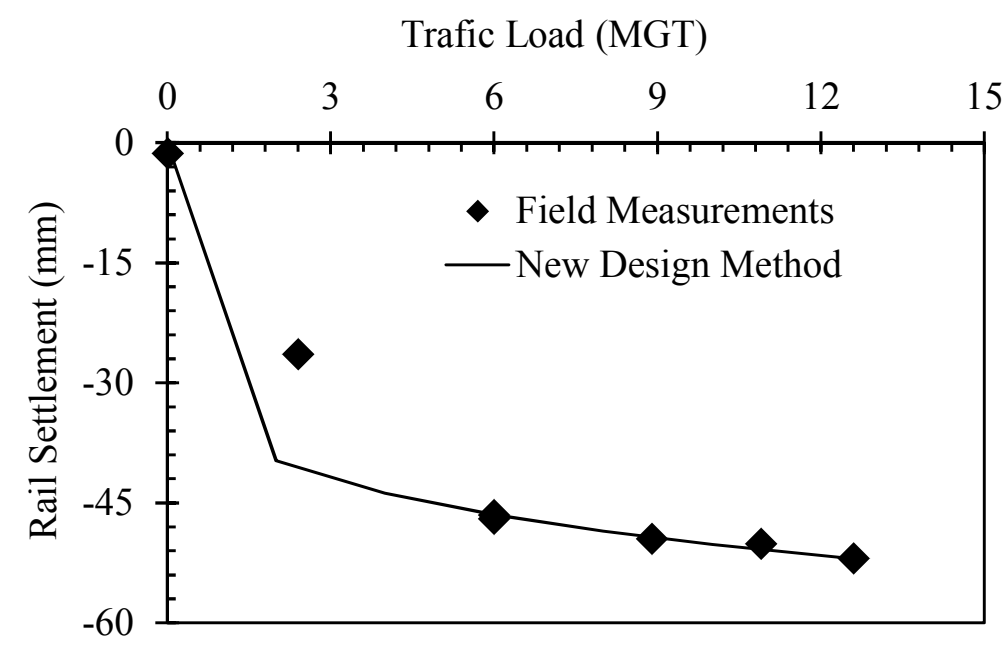

Fig. 7. Comparison between new design method and field measurements. 
Table 1. Design parameters for the LTM and TLTM test tracks (adapted from Li et al. 1996).

\begin{tabular}{lll}
\hline Design parameters & LTM & TLTM \\
\hline Loading condition & & \\
Static wheel load, $P_{s}(\mathrm{kN})$ & 173 & 173 \\
Wheel spacing, $L_{a}(\mathrm{~m})$ & 1.8 & 1.8 \\
Train speed, $(\mathrm{m} / \mathrm{s})$ & 18 & 18 \\
Design tonnage $(\mathrm{MGT})$ & 60 & 60 \\
\hline Design criteria & & \\
Cumulative plastic strain, $\varepsilon_{\left(p_{-} s\right) a}(\%)$ & $2 \%$ & $2 \%$ \\
Cumulative plastic deformation, $\rho_{t a}(\mathrm{~mm})$ & 25 & 25 \\
\hline Subgrade characteristics & & \\
Soil type & Fat clay $(\mathrm{CH})$ & Fat clay $(\mathrm{CH})$ \\
Thickness, $H_{s}(\mathrm{~m})$ & 1.50 & 1.50 \\
Subgrade modulus, $E_{s}(\mathrm{MPa})$ & 15 & 41 \\
Unconfined compressive strength, $\sigma_{s_{-} s}(\mathrm{kPa})$ & 90 & 165 \\
\hline Ballast characteristics & & \\
Ballast type $($ assumed $)$ & Granite $(\mathrm{G})$ & Granite $(\mathrm{G})$ \\
Ballast modulus, $E_{b}(\mathrm{MPa})$ & 270 & 270 \\
Compressive strength, $\sigma_{s_{-} b}(\mathrm{kPa})$ & 307 & 307 \\
\hline
\end{tabular}


Table 2. Design results and track conditions for the LTM and TLTM test tracks.

\begin{tabular}{lll}
\hline Comparison parameters & LTM & TLTM \\
\hline Unconfined compressive strength, $\sigma_{s_{-} s}(\mathrm{kPa})$ & 90 & 165 \\
Subgrade modulus, $E_{s}(\mathrm{MPa})$ & 14 & 41 \\
Adopted granular layer thickness, $H_{b}(\mathrm{~m})$ & 0.45 & 0.45 \\
Required granular layer thickness, $H_{b}(\mathrm{~m})$ & 0.70 & 0.40 \\
$\begin{array}{l}\text { Track condition with the adopted granular } \\
\text { layer thickness }\end{array}$ & $\begin{array}{l}\text { Track excessive } \\
\text { plastic deformation } \\
\text { and progressive } \\
\text { shear failure }\end{array}$ & No track \\
& failures \\
\hline
\end{tabular}


Table 3. Design parameters for tracks at Edgewood and Aberdeen sites (adapted from Li and Selig 1998b).

\begin{tabular}{lll}
\hline Design parameters & Edgewood site & Aberdeen site \\
\hline Subgrade characteristics & & \\
Soil type & Lean clay $(\mathrm{CL})$ & Lean clay $(\mathrm{CL})$ \\
Thickness, $H_{s}(\mathrm{~m})$ & 1.5 & 1.5 \\
Subgrade modulus, $E_{s}(\mathrm{MPa})$ & 15 & 30 \\
Unconfined compressive strength, $\sigma_{s_{-} s}(\mathrm{kPa})$ & $48-83$ & $97-290$ \\
\hline Ballast characteristics & & \\
Ballast type (assumed) & $\mathrm{Granite}(\mathrm{G})$ & $\mathrm{Granite}(\mathrm{G})$ \\
Ballast modulus, $E_{b}(\mathrm{MPa})$ & 270 & 270 \\
Compressive strength, $\sigma_{s_{-} b}(\mathrm{kPa})$ & 307 & 307 \\
\hline Design criteria (for 10 years $)$ & & $2 \%$ \\
Cumulative plastic strain, $\varepsilon_{\left(p_{-} s\right) a}(\%)$ & $2 \%$ & 25 \\
\hline Cumulative plastic deformation, $\rho_{t a}(\mathrm{~mm})$ & 25 & \\
\hline
\end{tabular}


Table 4. Traffic characteristics at the Northeast Corridor between Baltimore and Philadelphia (adapted from Li and Selig 1998b).

\begin{tabular}{lllll}
\hline $\begin{array}{l}\text { Loading } \\
\text { condition }\end{array}$ & $\begin{array}{l}\text { Annual traffic } \\
\text { tonnage }(\mathrm{MGT})\end{array}$ & $\begin{array}{l}\text { Static wheel } \\
\text { load }(\mathrm{kN})\end{array}$ & $\begin{array}{l}\text { Speed } \\
(\mathrm{km} / \mathrm{h})\end{array}$ & $\begin{array}{l}\text { Wheel } \\
\text { spacing }(\mathrm{m})\end{array}$ \\
\hline Freight train & & 156 & 60 & 2.2 \\
Wheel 1 & 15 & 44 & 60 & 2.2 \\
Wheel 2 & 22 & & & \\
\hline Passenger train & & 70 & 190 & 2.9 \\
Wheel 1 & 15 & & & \\
\hline
\end{tabular}


Table 5. Comparison of results between new design method and site conditions for tracks at Edgewood and Aberdeen sites.

\begin{tabular}{lll}
\hline Comparison parameters & Edgewood site & Aberdeen site \\
\hline Design thickness, $H_{b}(\mathrm{~m})$ & 1.20 & 0.70 \\
Existing thickness, $H_{b}(\mathrm{~m})$ & $0.3-0.5$ & $0.70-1.0$ \\
Remark & $\begin{array}{l}\text { Existing thickness is } \\
\text { less than design } \\
\text { thickness. }\end{array}$ & $\begin{array}{l}\text { Existing thickness is } \\
\text { more than design } \\
\text { thickness. }\end{array}$ \\
$\begin{array}{l}\text { Track failure condition for } \\
\text { the adopted thickness }\end{array}$ & $\begin{array}{l}\text { Subgrade progressive } \\
\text { shear failure, deep } \\
\text { ballast pocket and } \\
\text { differential settlement }\end{array}$ & No track failures \\
& & \\
\hline
\end{tabular}


Appendix A: Design Charts to Calculate the Granular Layer Thickness for Preventing the Progressive Shear Failure.

Strain Influence Factor, $I_{\varepsilon_{-} s}$

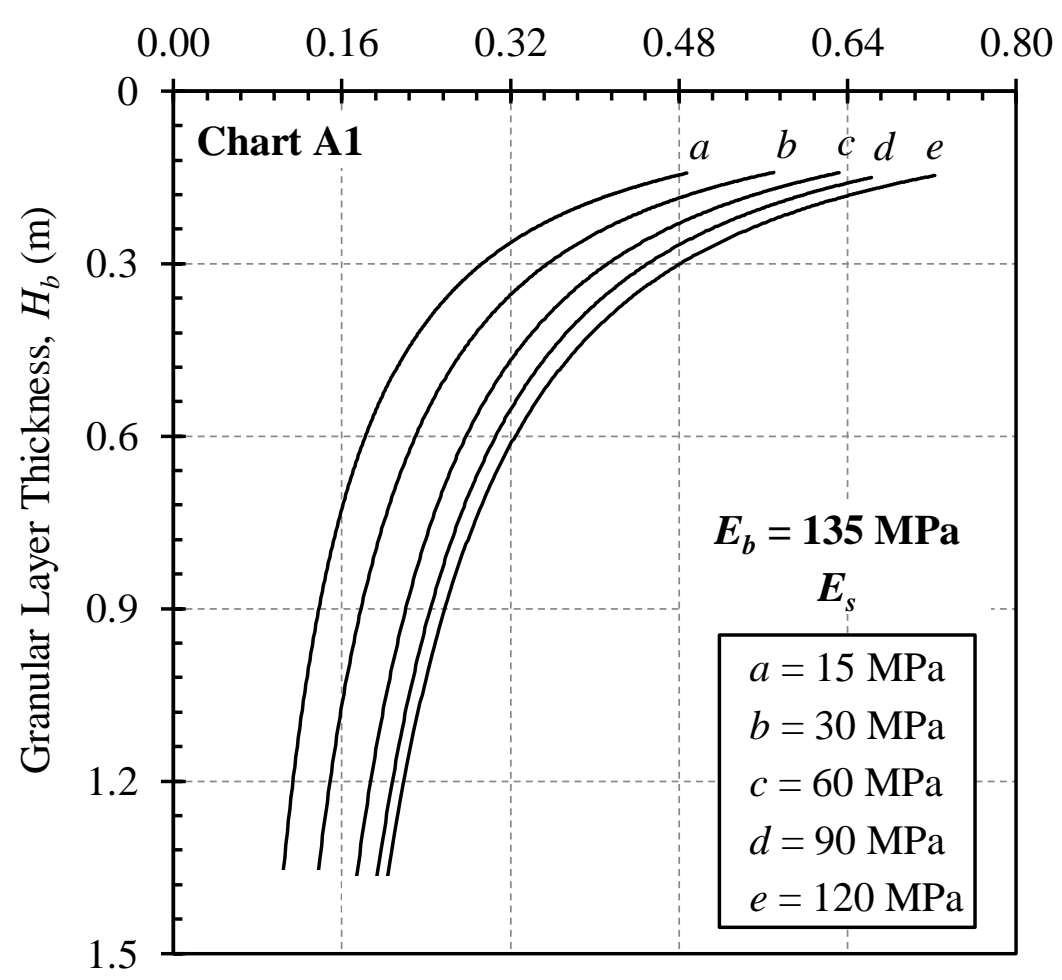

Strain Influence Factor, $I_{\varepsilon_{-} s}$

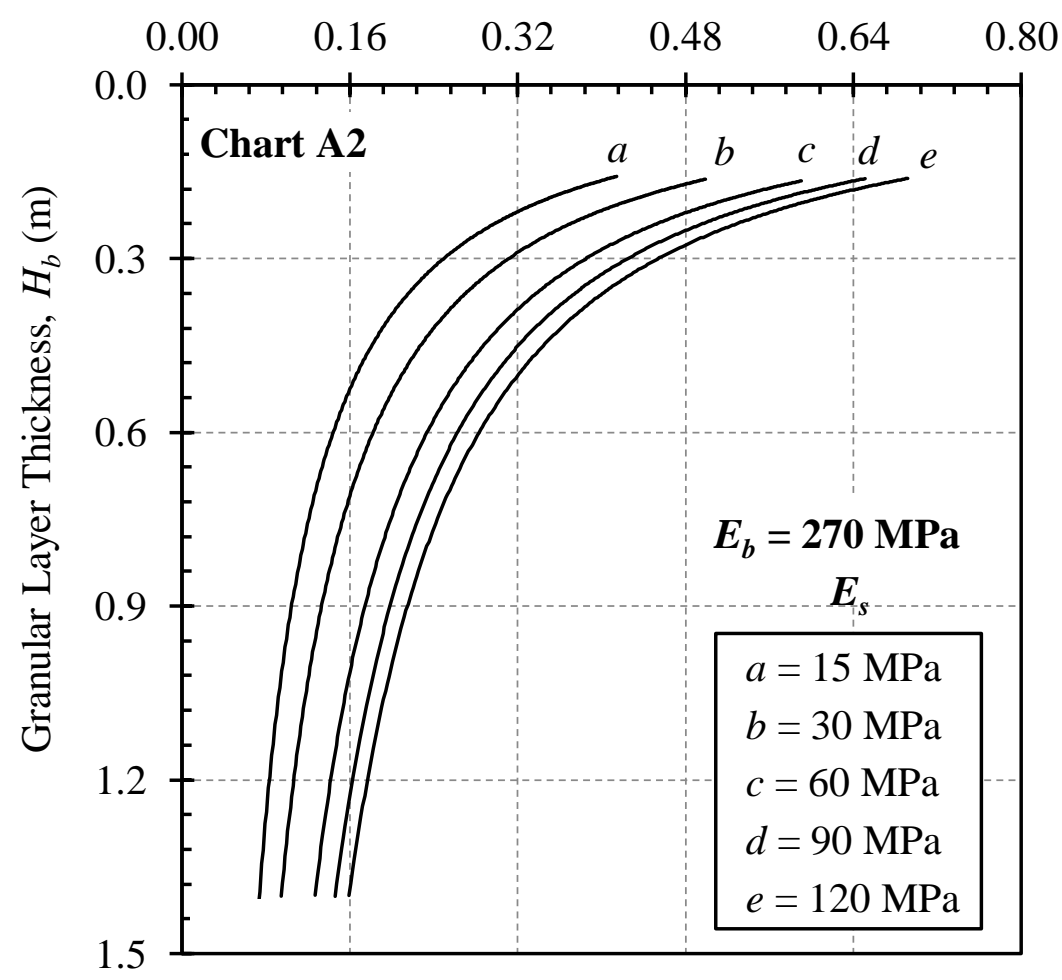


Strain Influence Factor, $I_{\varepsilon_{-} s}$

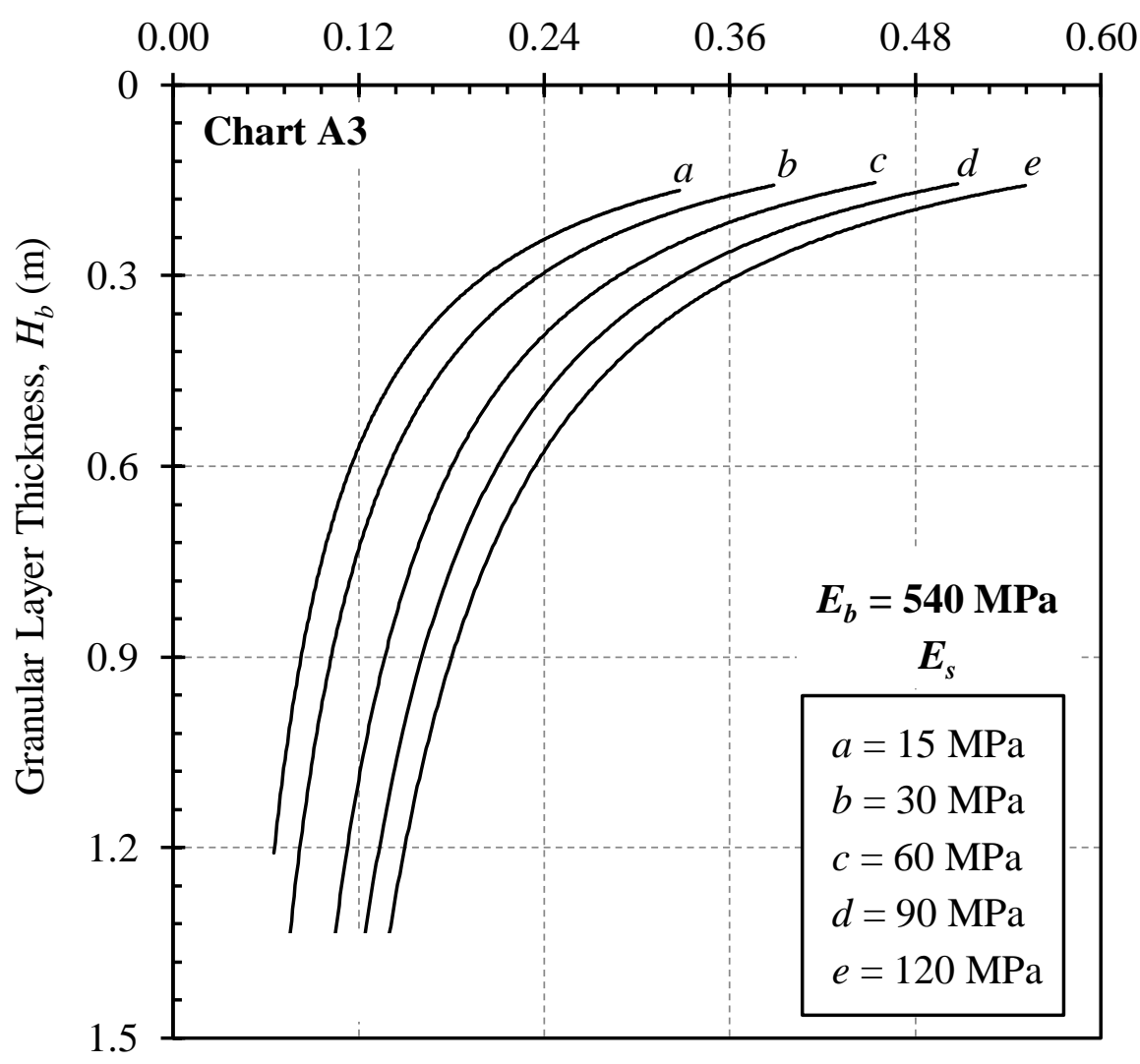



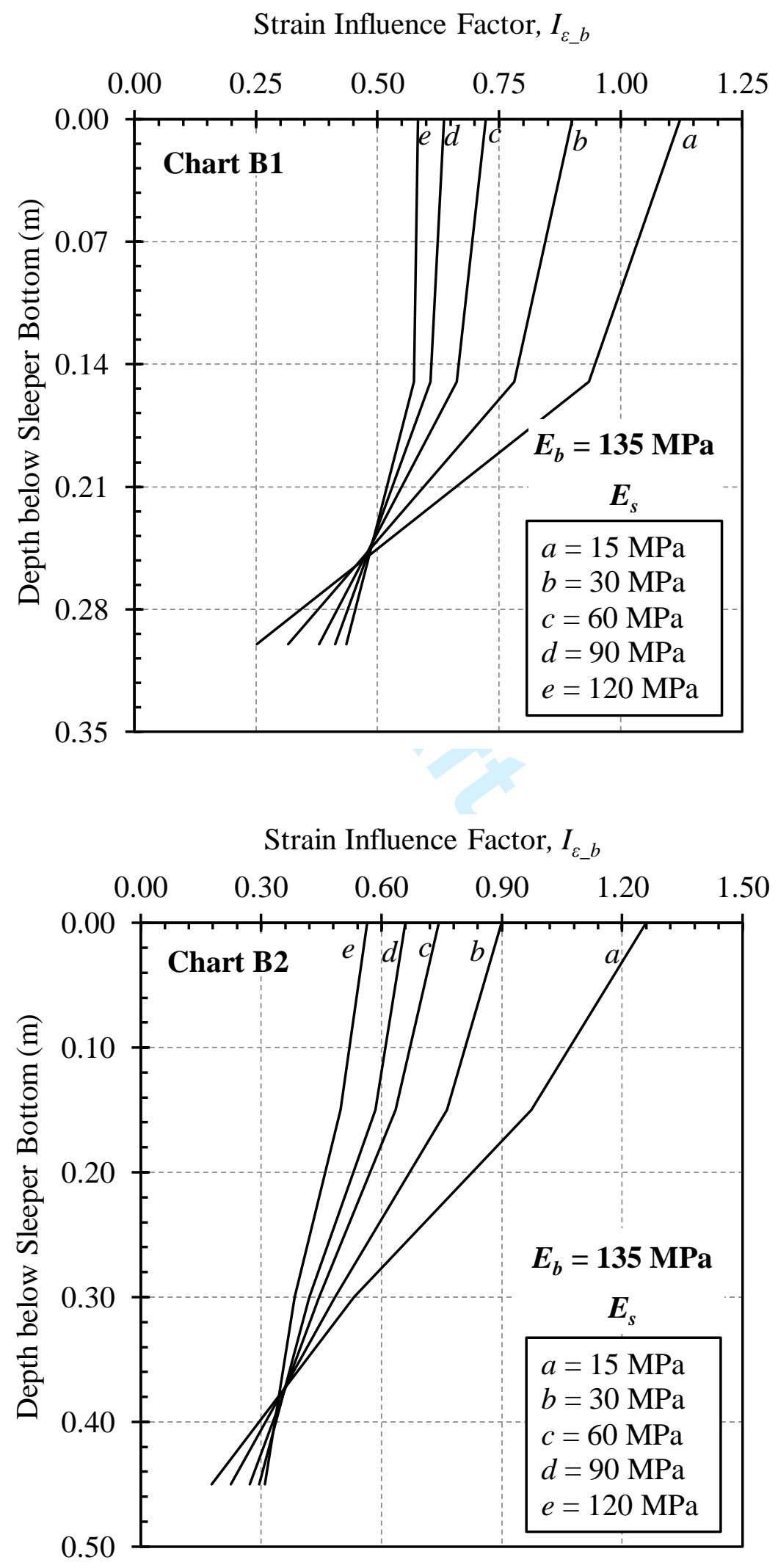
Strain Influence Factor, $I_{\varepsilon_{-} b}$

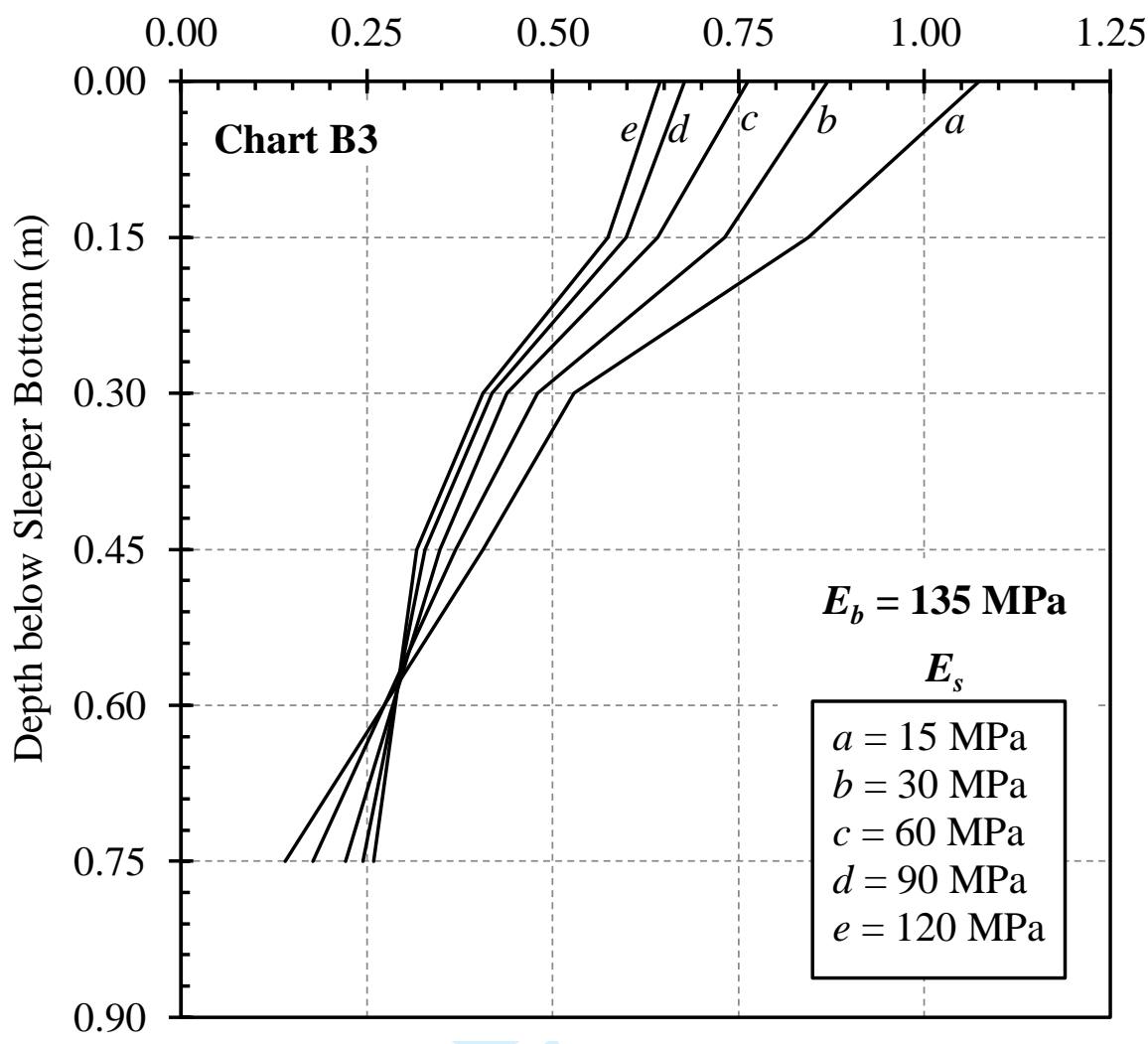

Strain Influence Factor, $I_{\varepsilon_{-} b}$

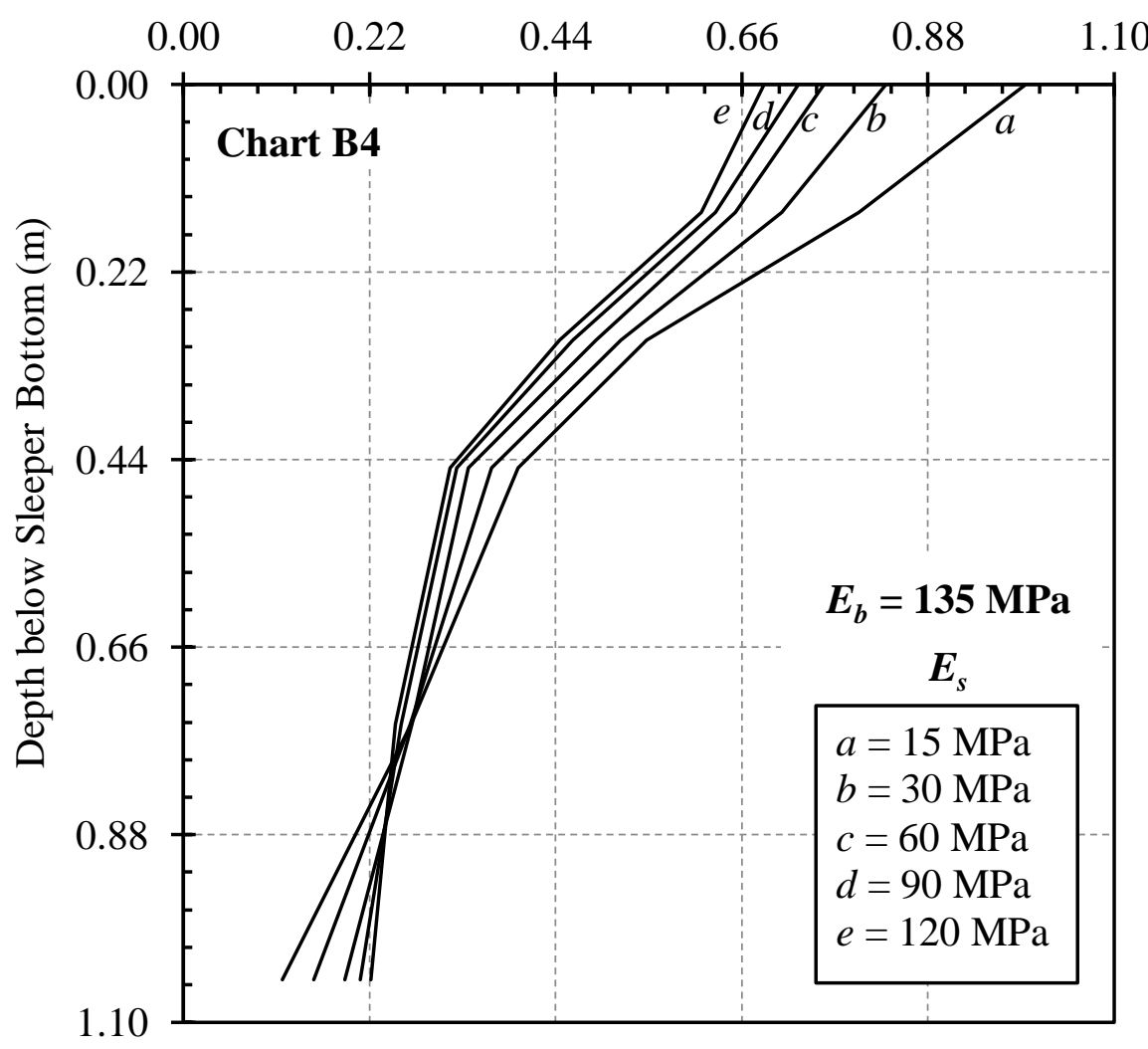


Strain Influence Factor, $I_{\varepsilon_{-}} b$

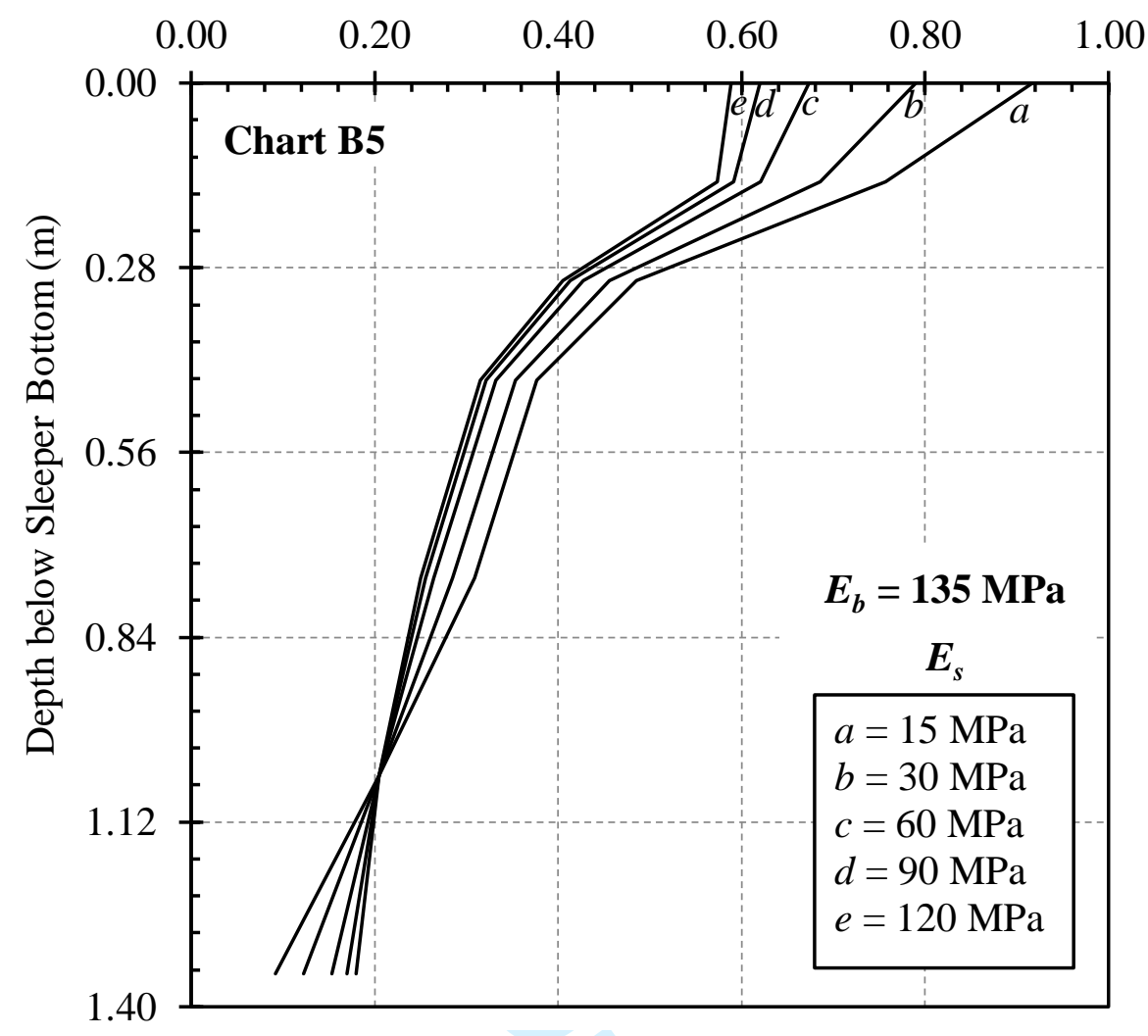

Strain Influence Factor, $I_{\varepsilon_{-} b}$

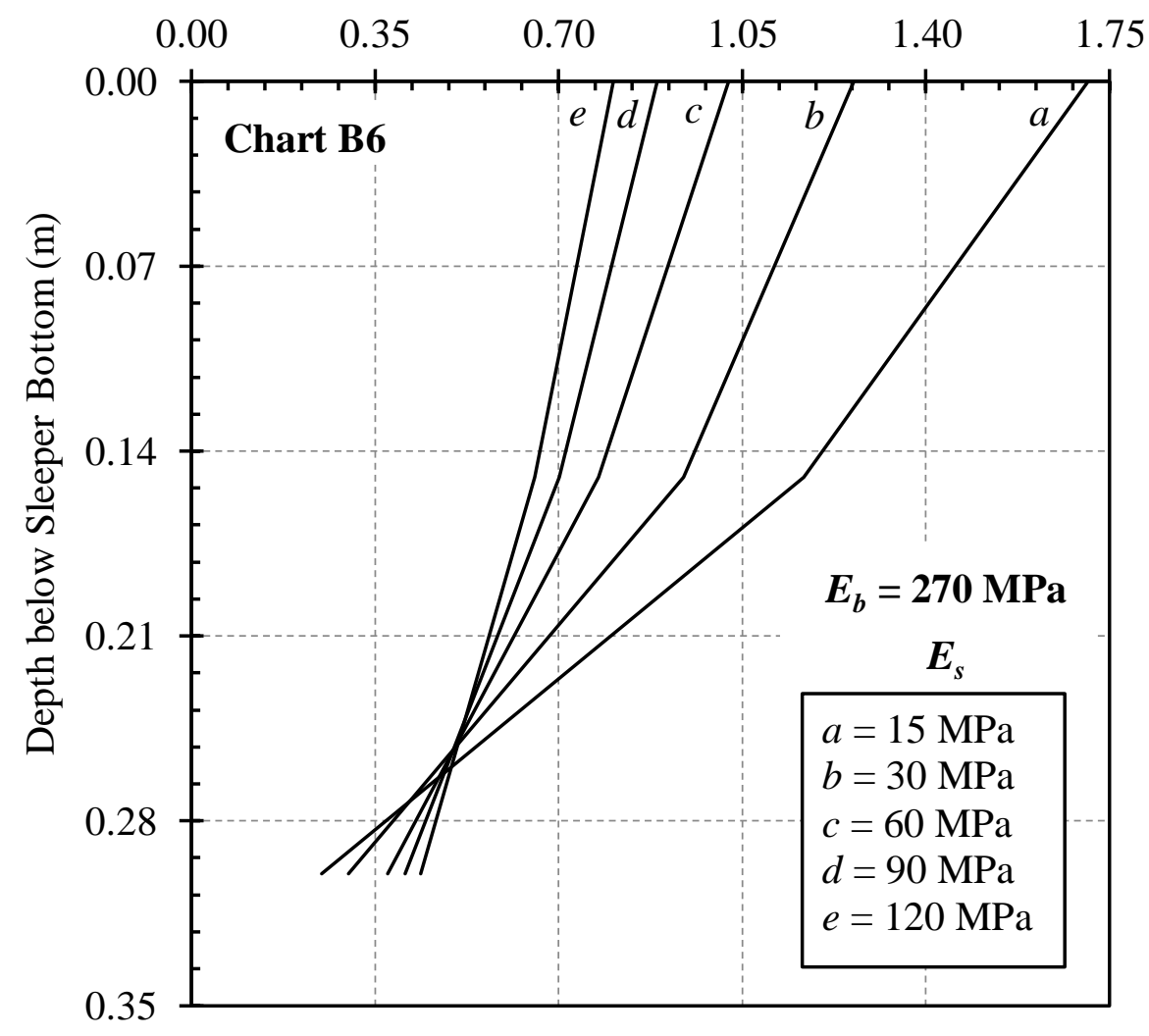


Strain Influence Factor, $I_{\varepsilon_{-} b}$

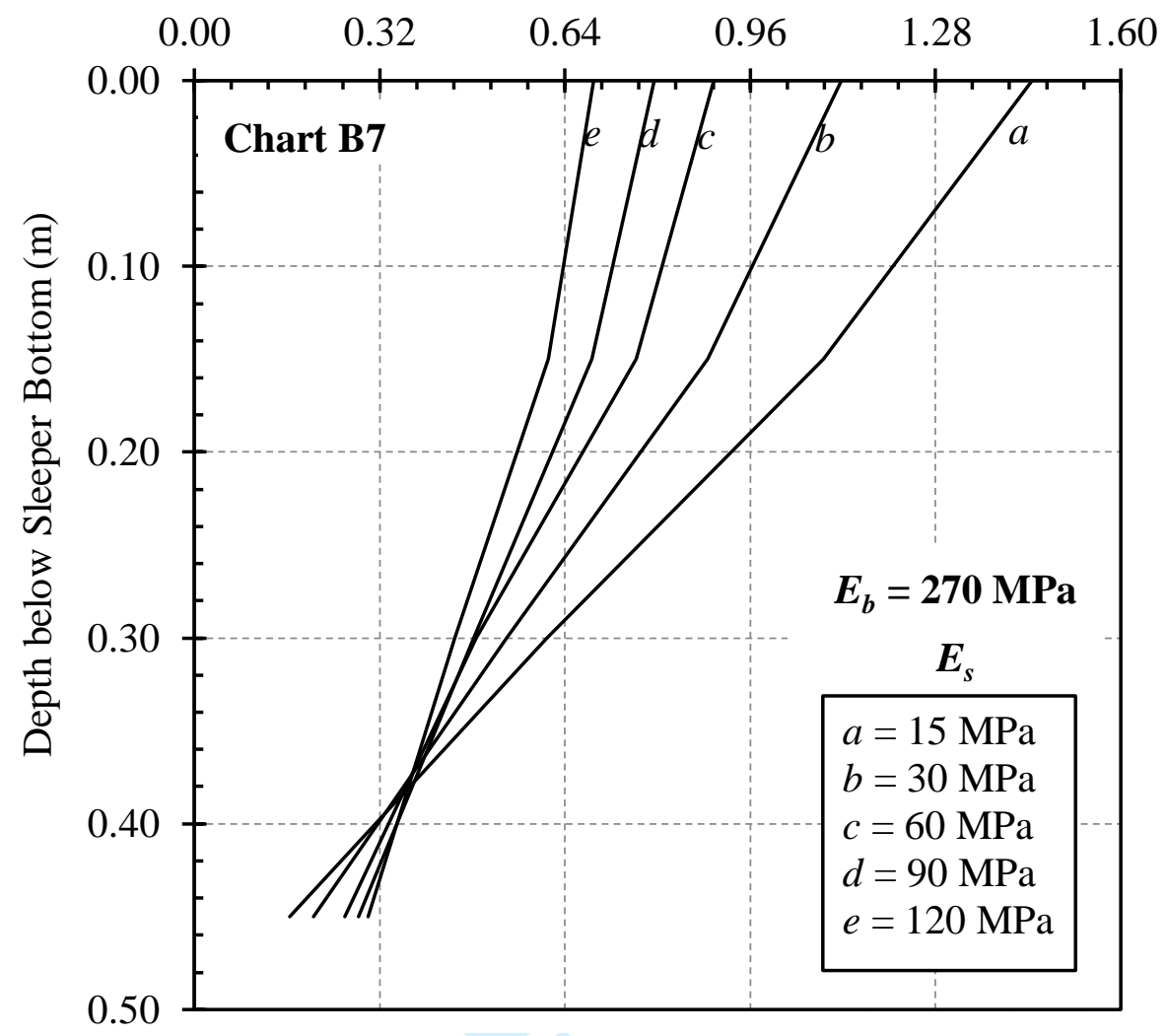

Strain Influence Factor, $I_{\varepsilon_{-} b}$

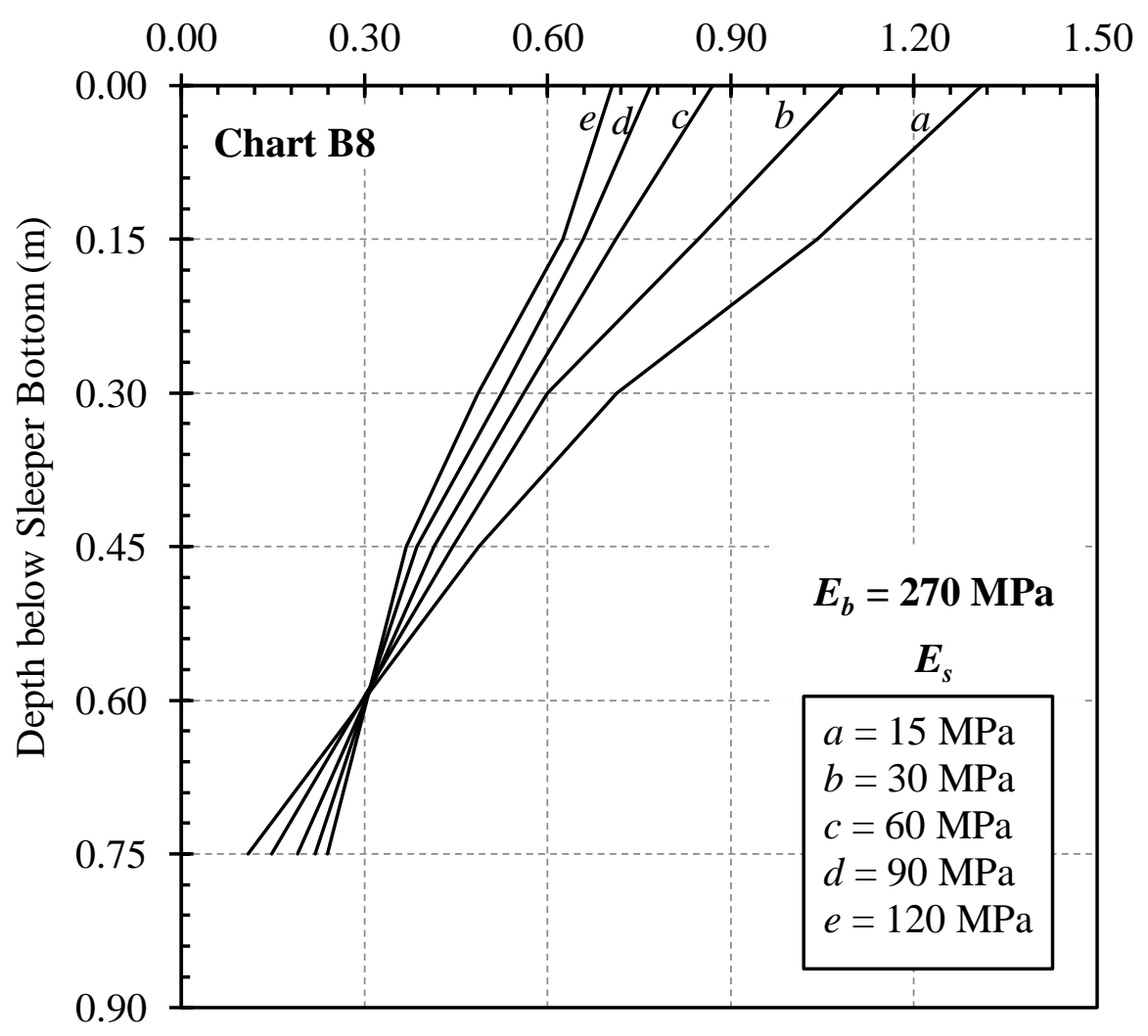




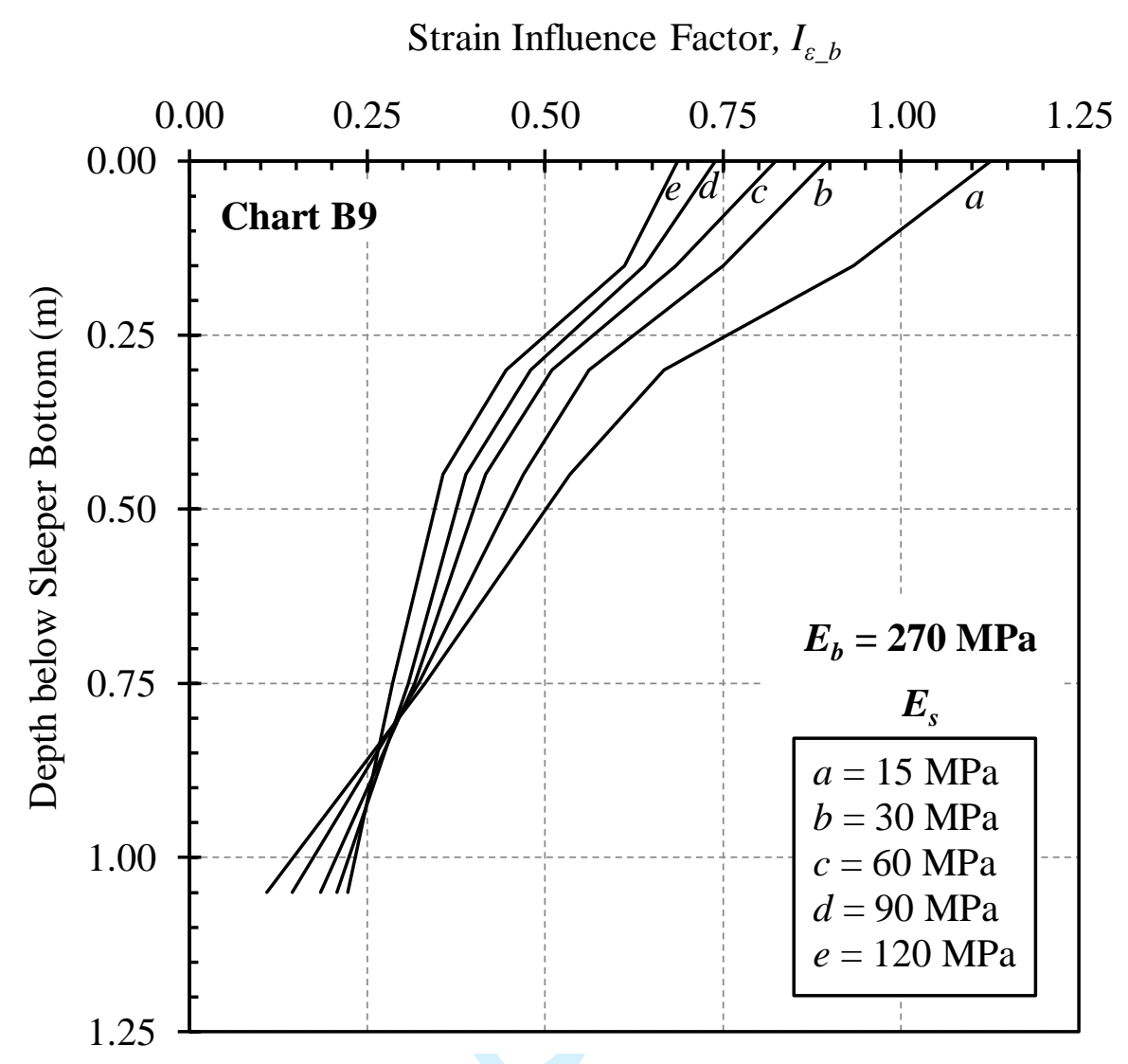

Strain Influence Factor, $I_{\varepsilon_{-}} b$

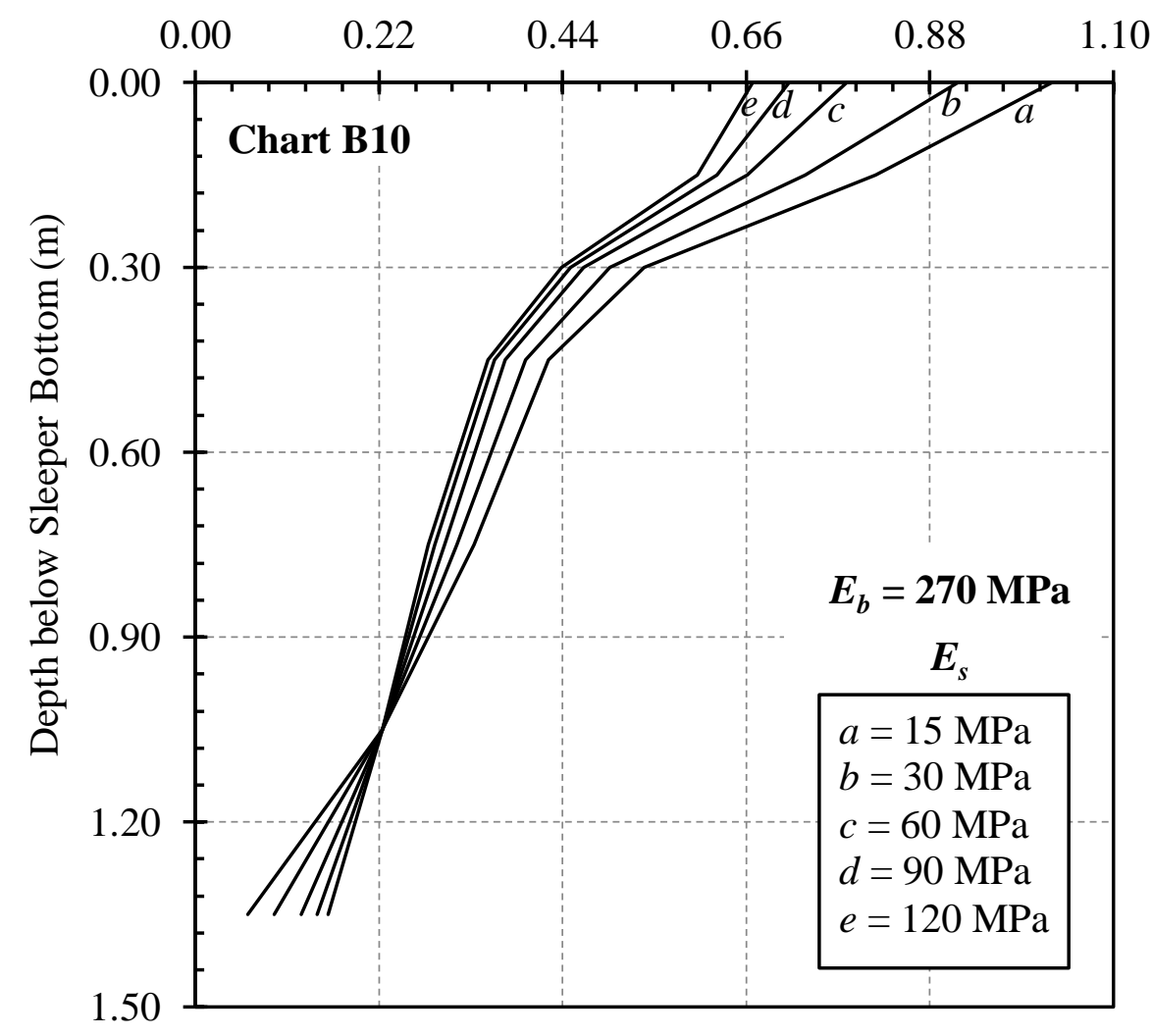


Strain Influence Factor, $I_{\varepsilon_{-} b}$

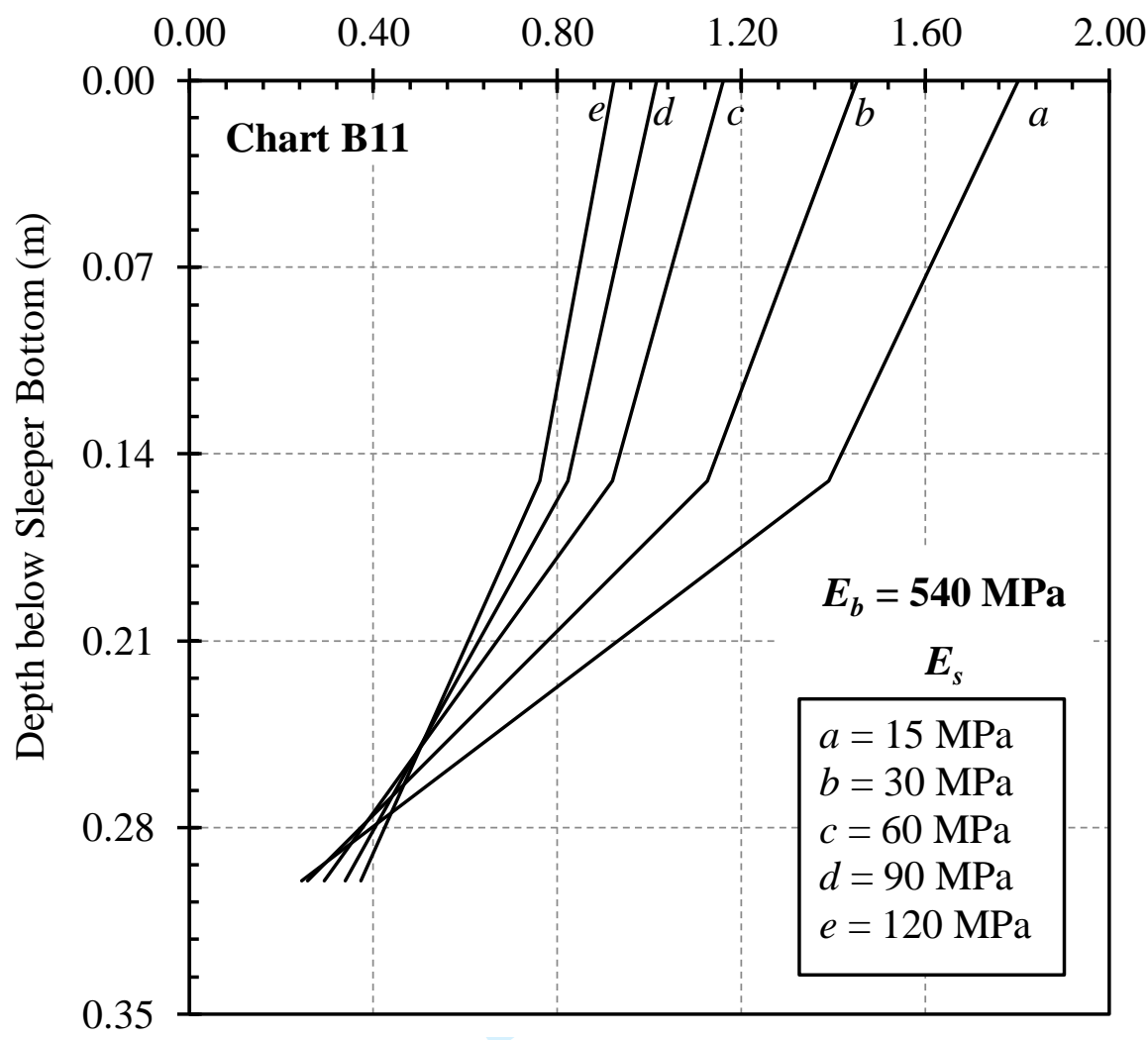

Strain Influence Factor, $I_{\varepsilon_{-} b}$

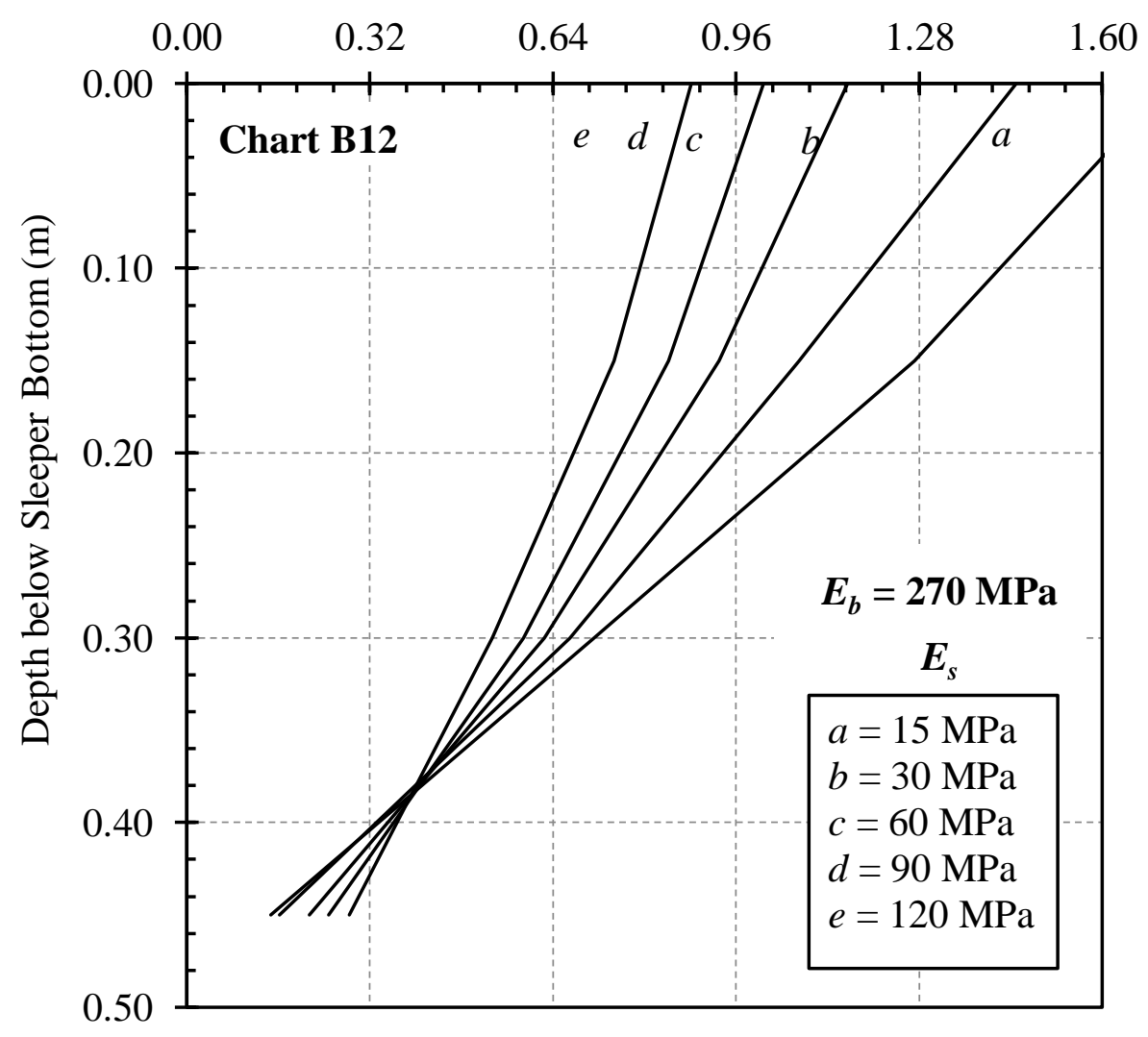


Strain Influence Factor, $I_{\varepsilon_{-} b}$

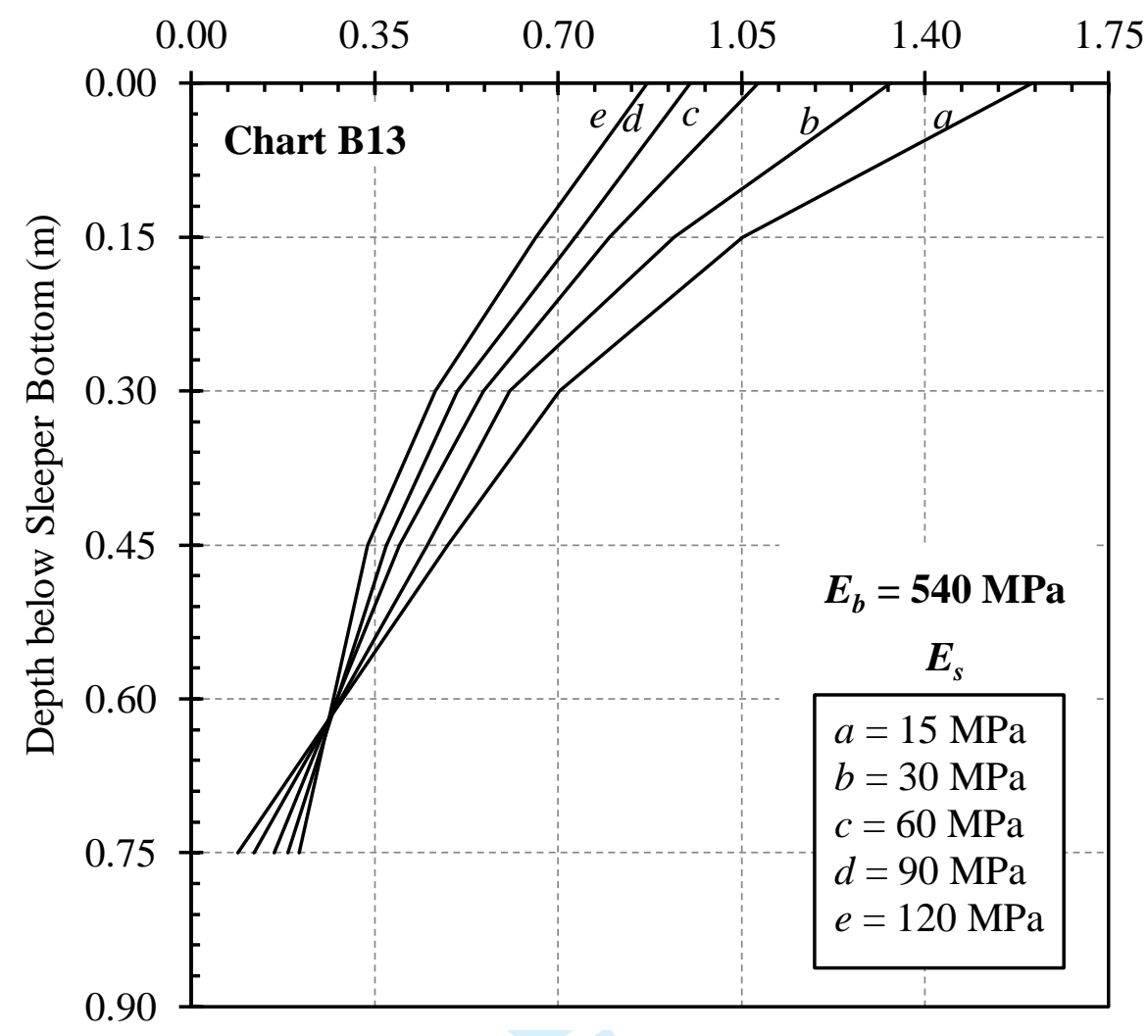

Strain Influence Factor, $I_{\varepsilon_{-}} b$

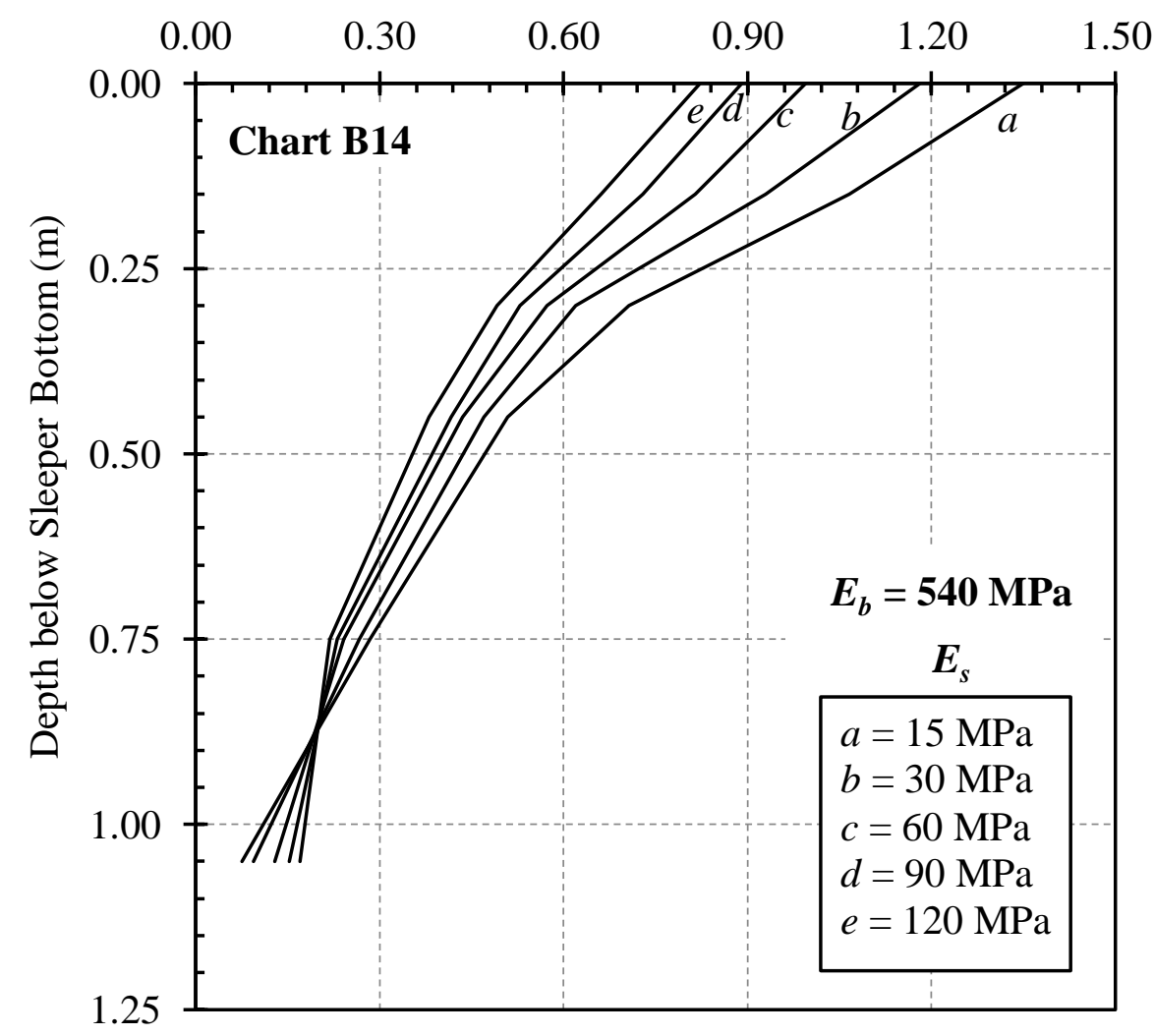




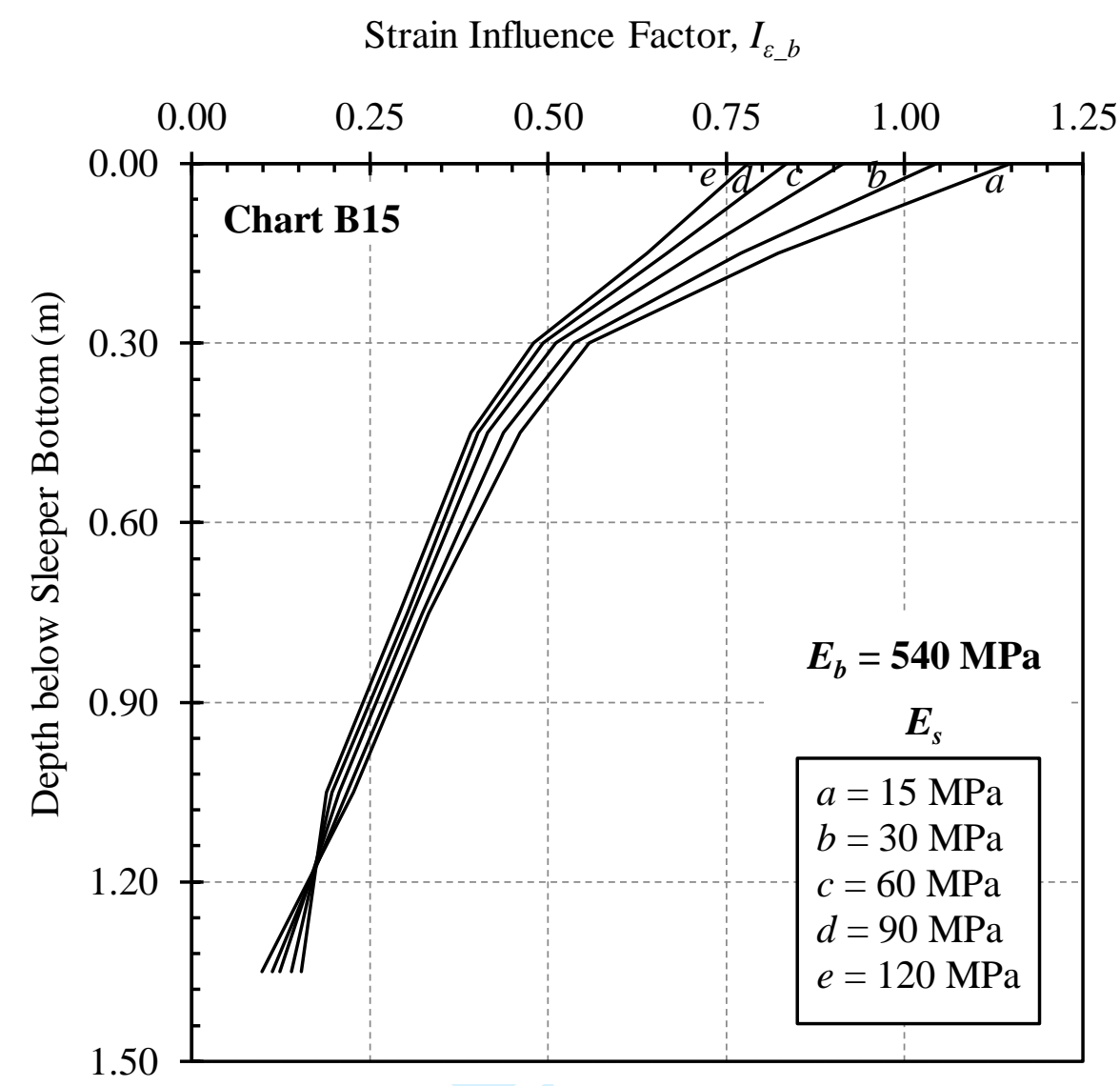


Appendix C: Design Charts to Calculate the Granular Layer Thickness for Preventing the Excessive Plastic Deformation.

Deformation Influence Factor, $I_{\rho_{-} s}$

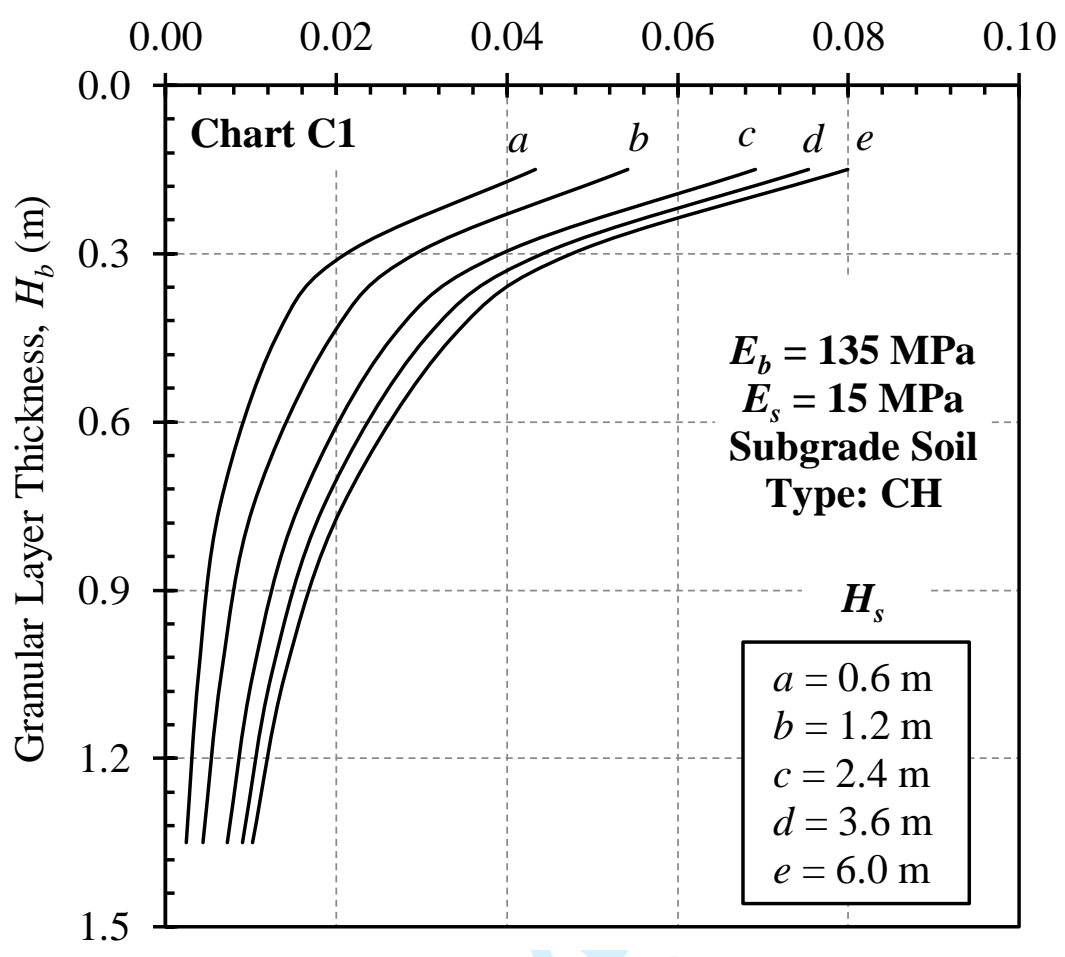

Deformation Influence Factor, $I_{\rho_{-} s}$

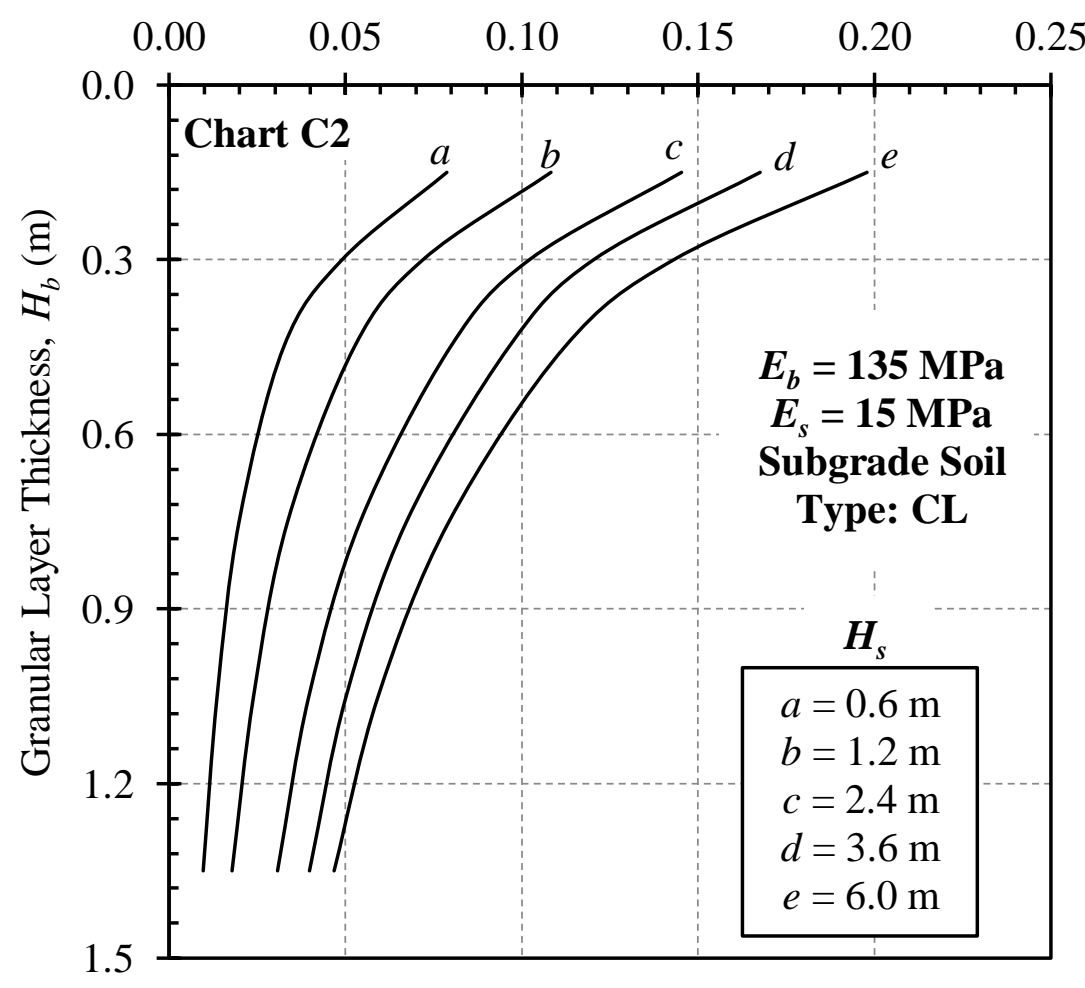


Deformation Influence Factor, $I_{\rho_{-} s}$

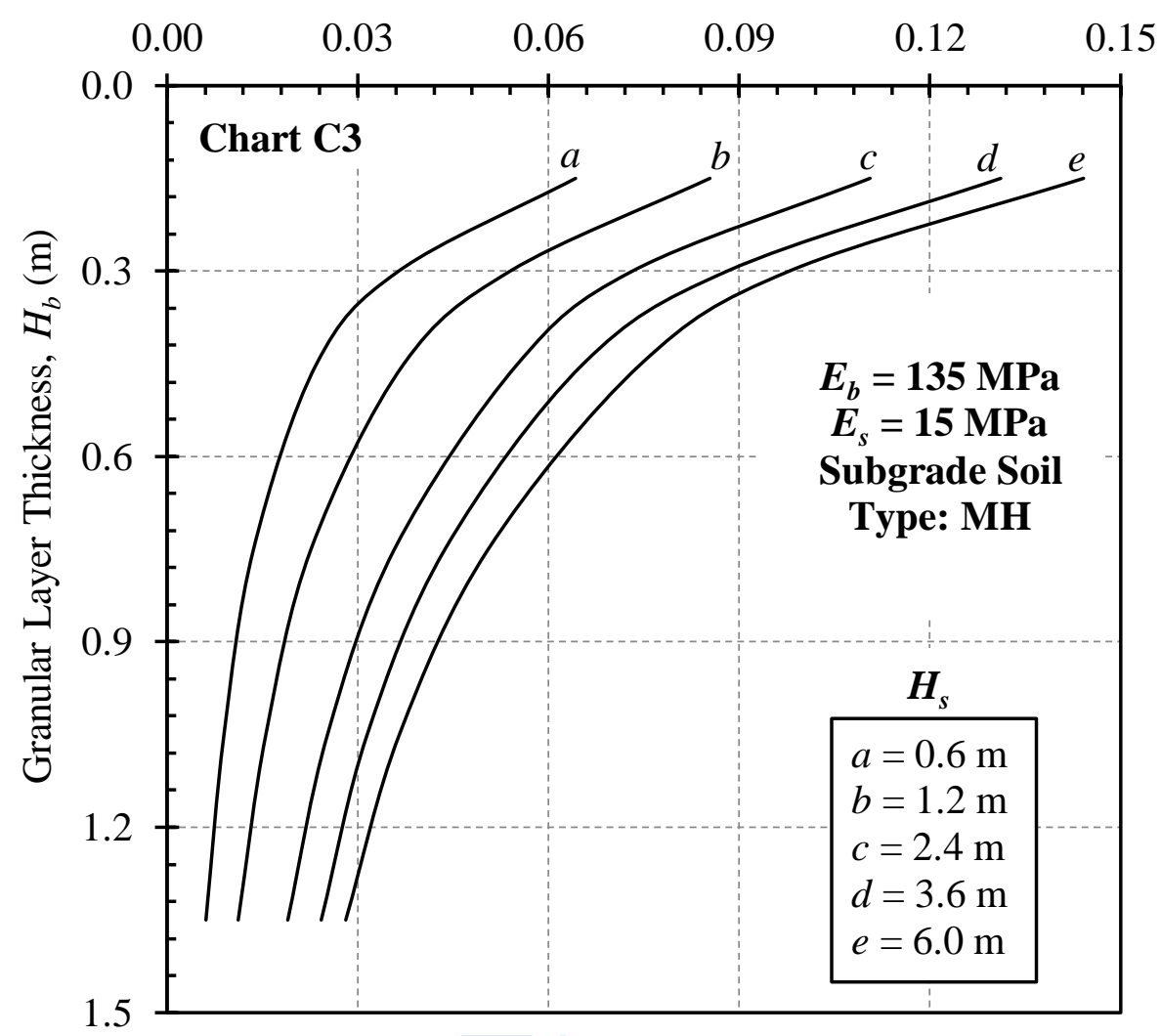

Deformation Influence Factor, $I_{\rho_{-} s}$

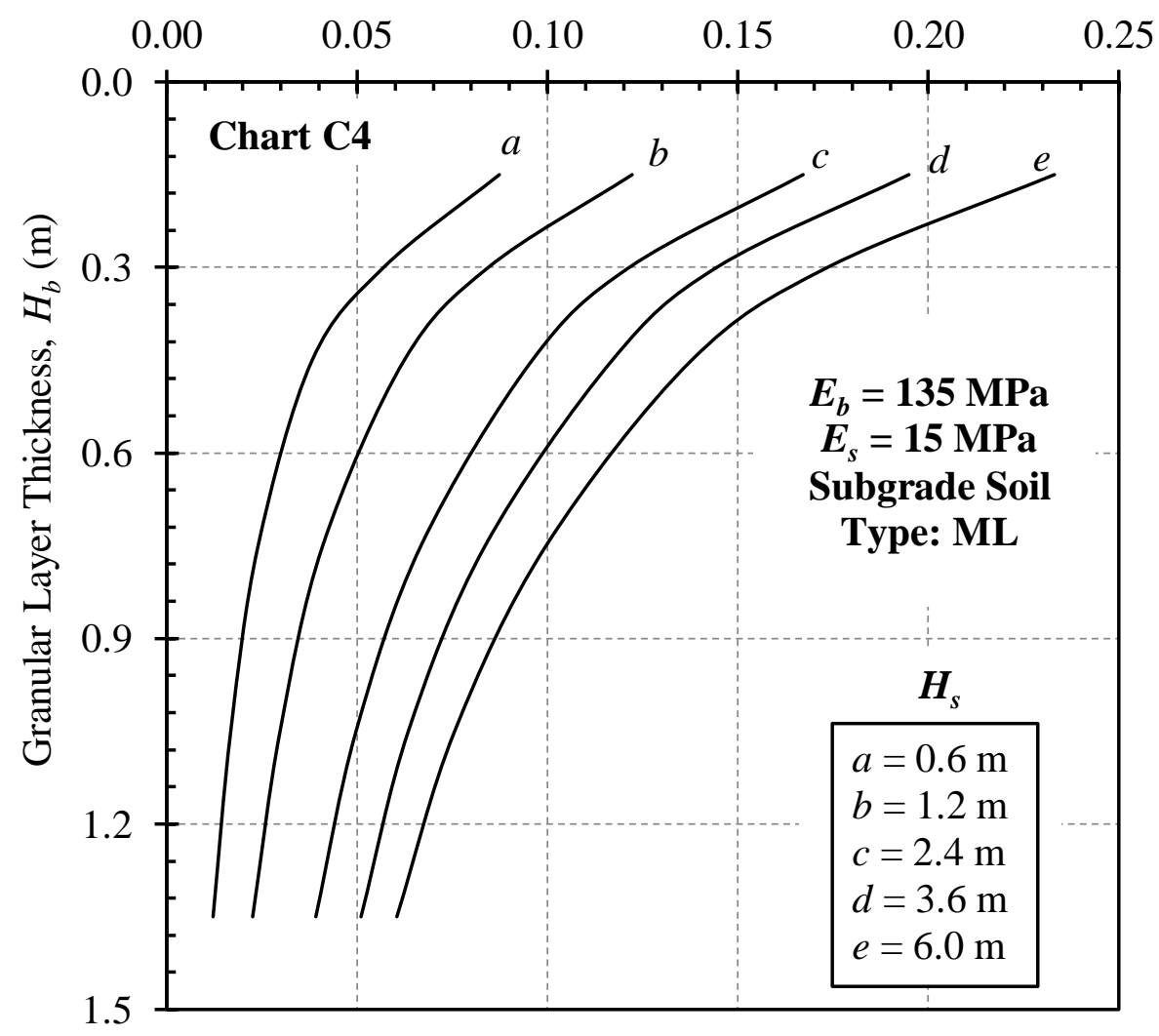


Deformation Influence Factor, $I_{\rho_{-} s}$

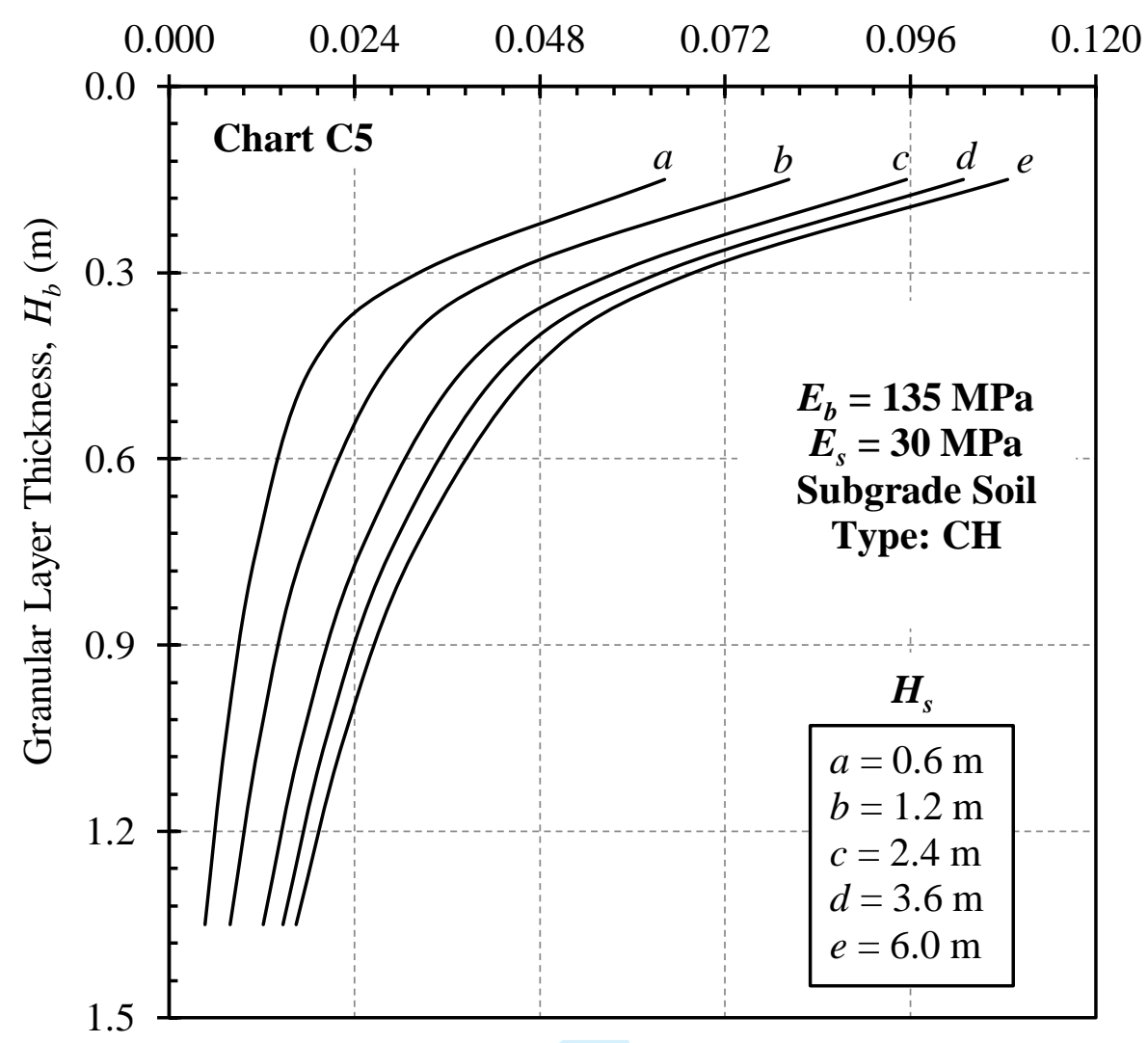

Deformation Influence Factor, $I_{\rho_{-} s}$

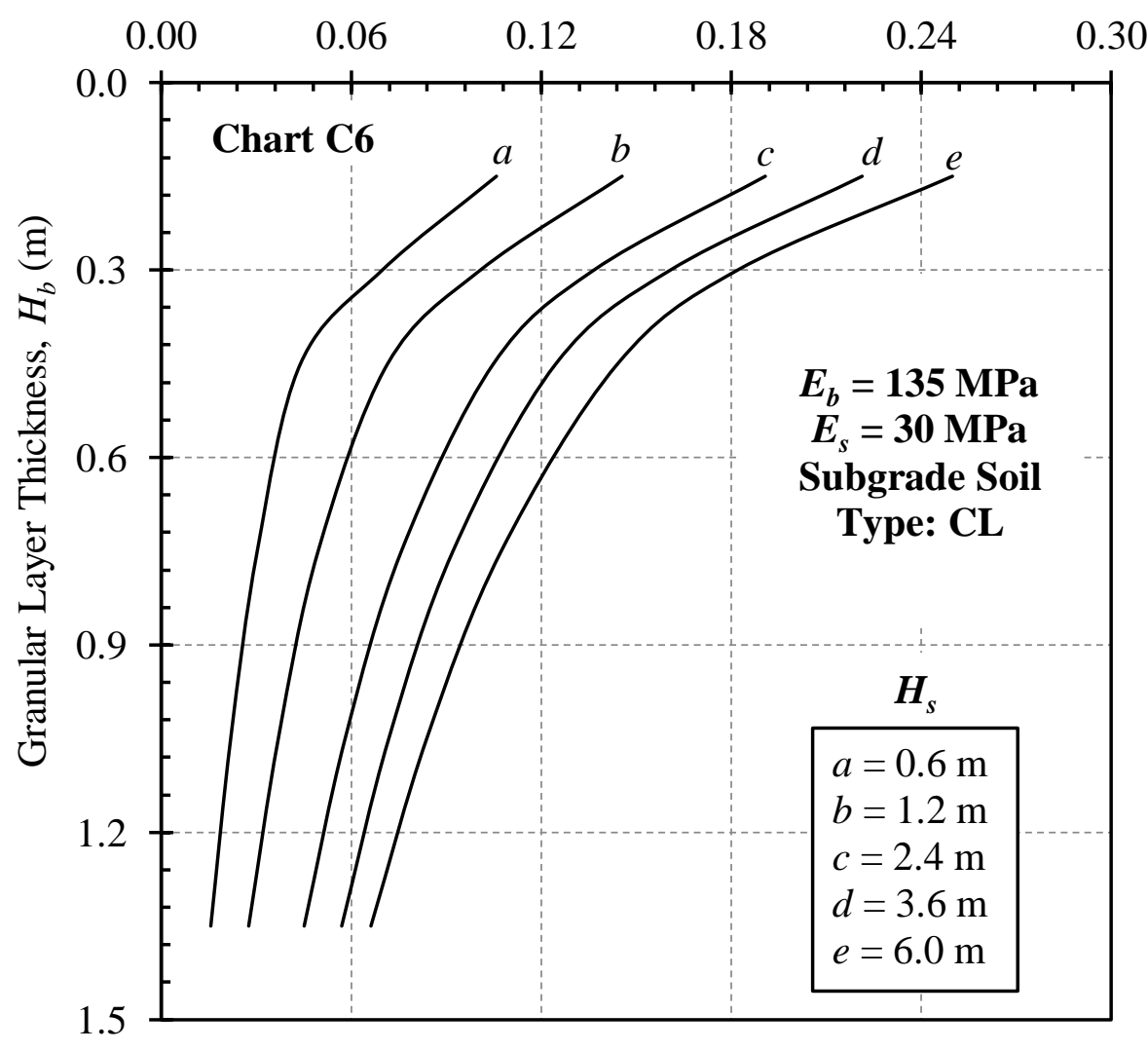


Deformation Influence Factor, $I_{\rho_{-} s}$

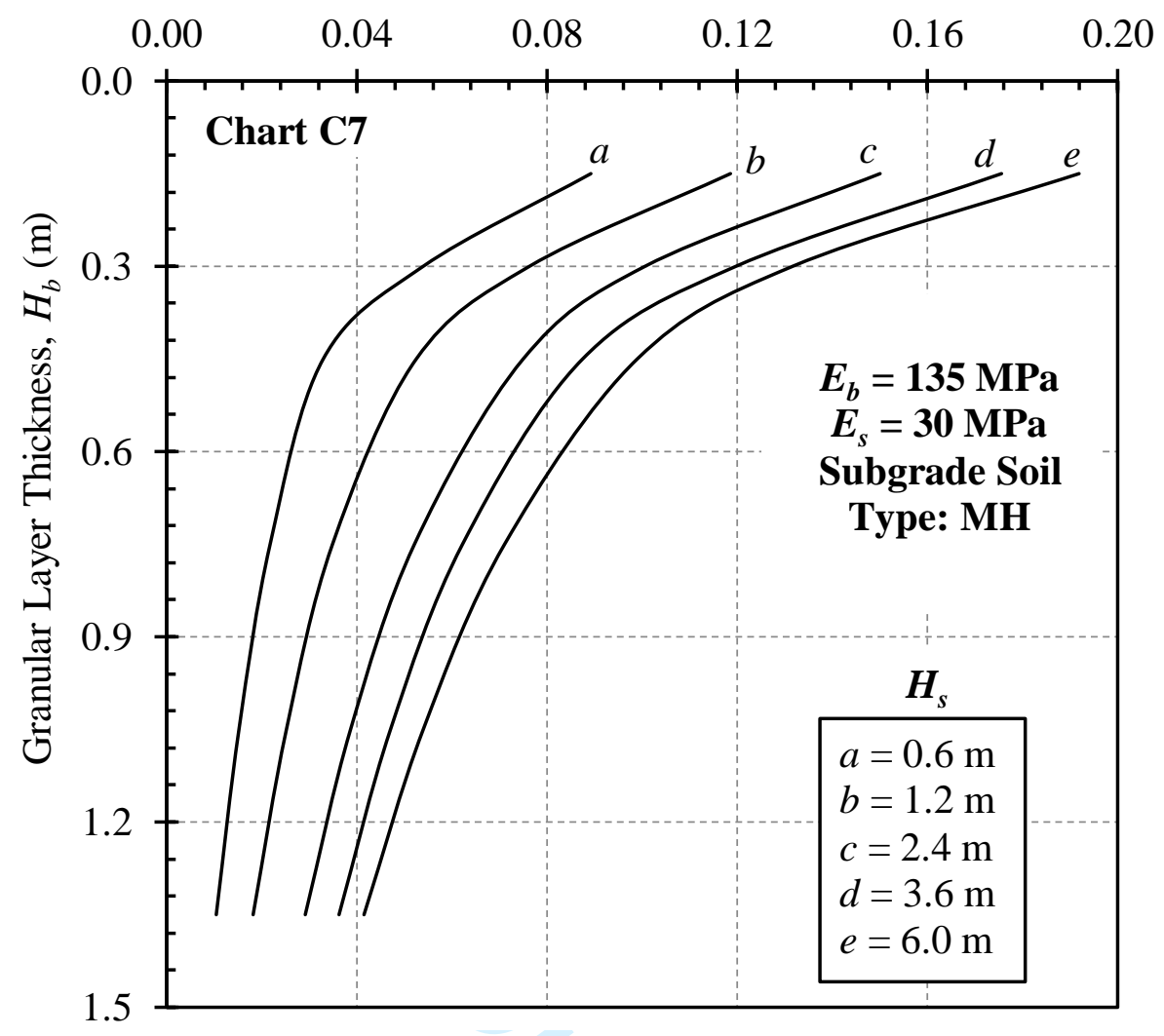

Deformation Influence Factor, $I_{\rho_{-} s}$

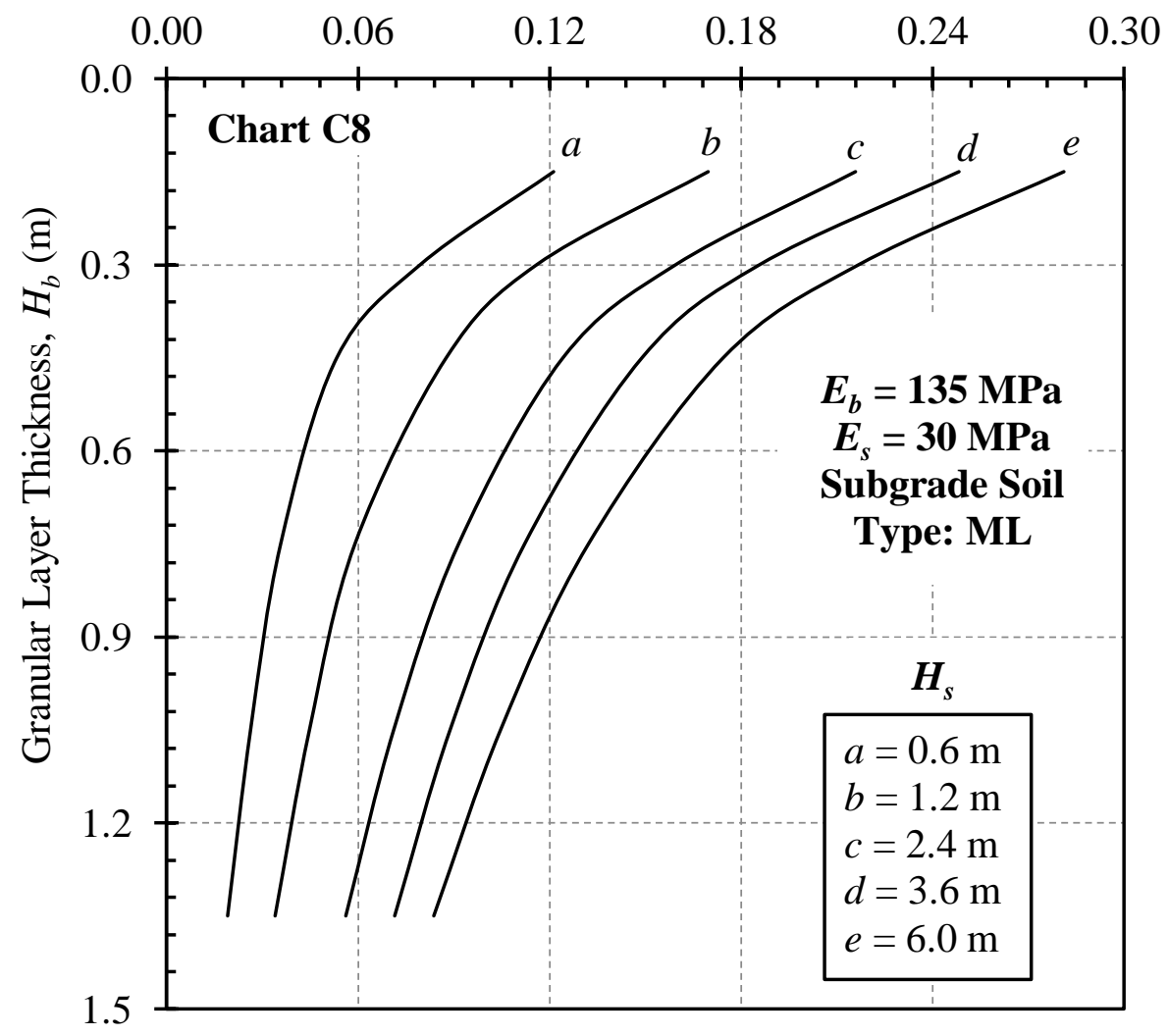


Deformation Influence Factor, $I_{\rho_{-} s}$

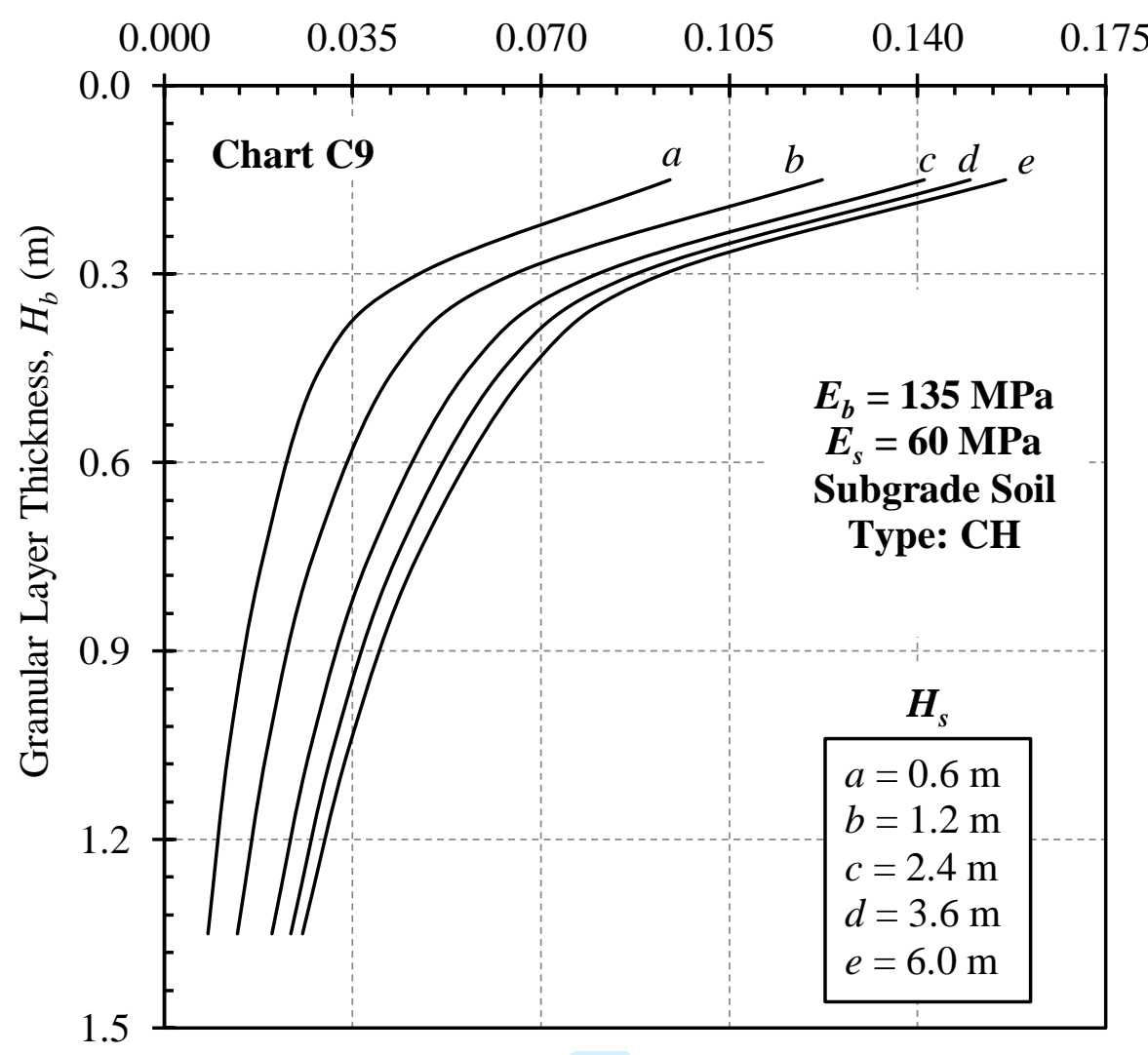

Deformation Influence Factor, $I_{\rho_{-} s}$

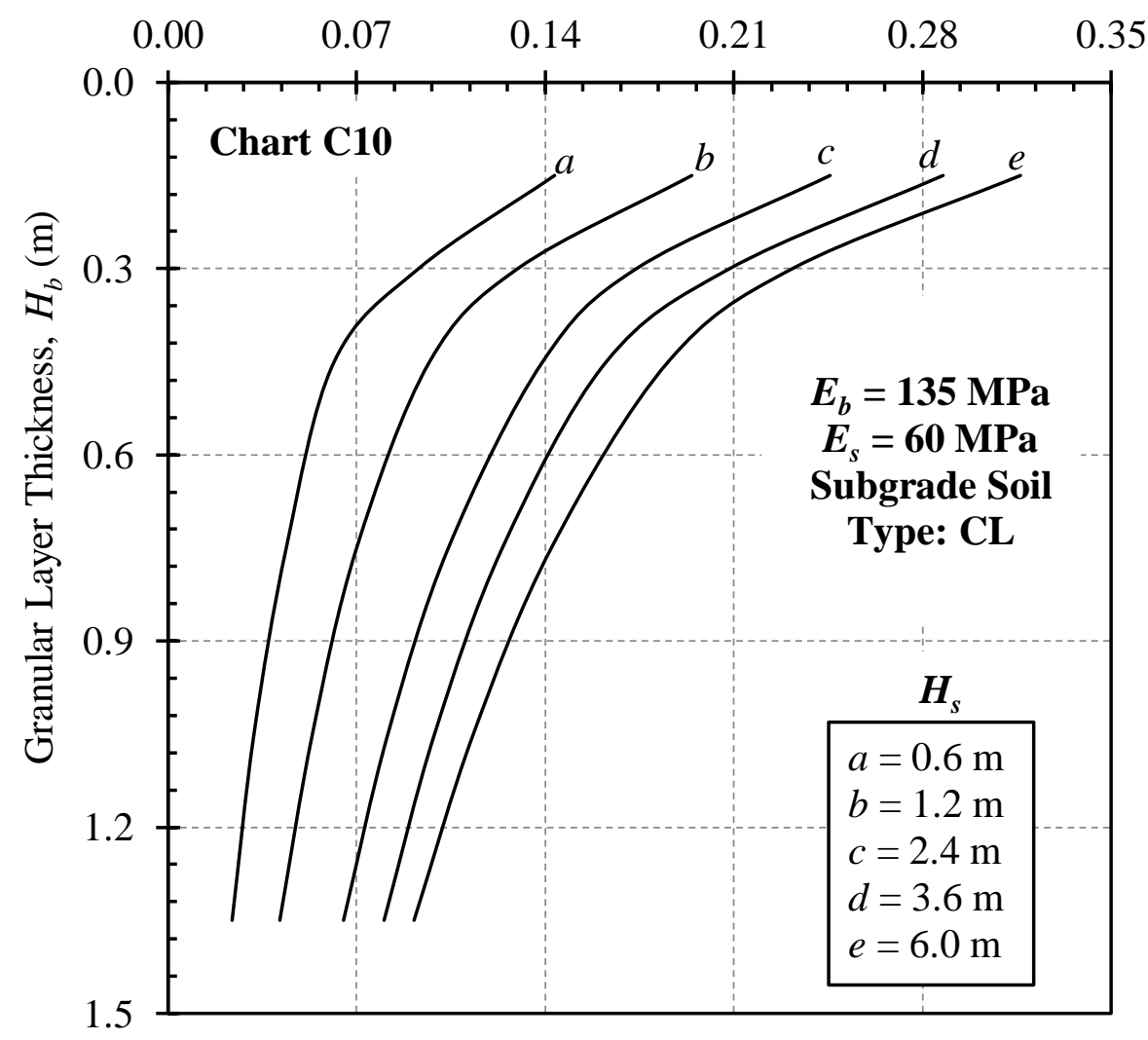


Deformation Influence Factor, $I_{\rho_{-} s}$

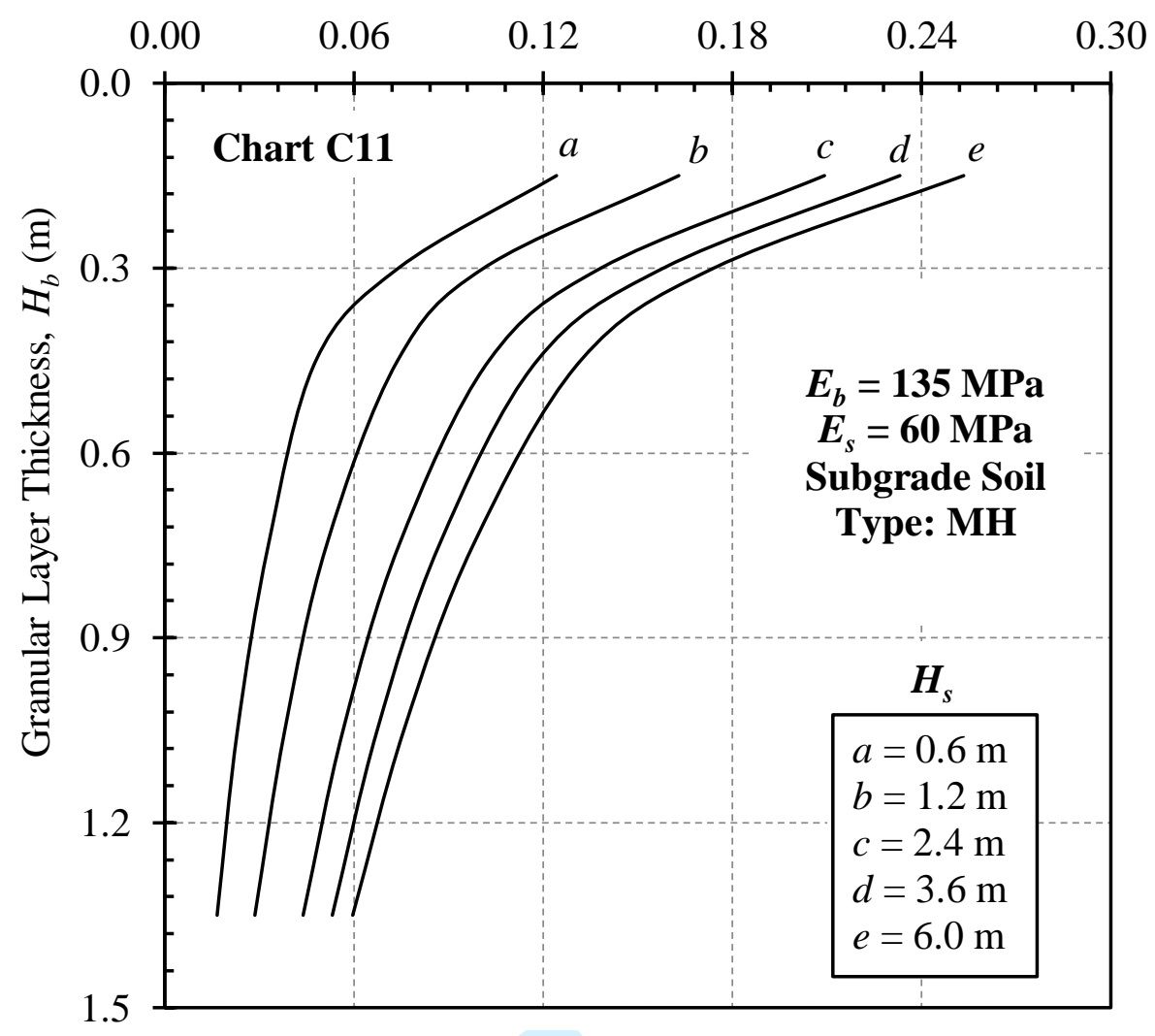

Deformation Influence Factor, $I_{\rho_{-} s}$

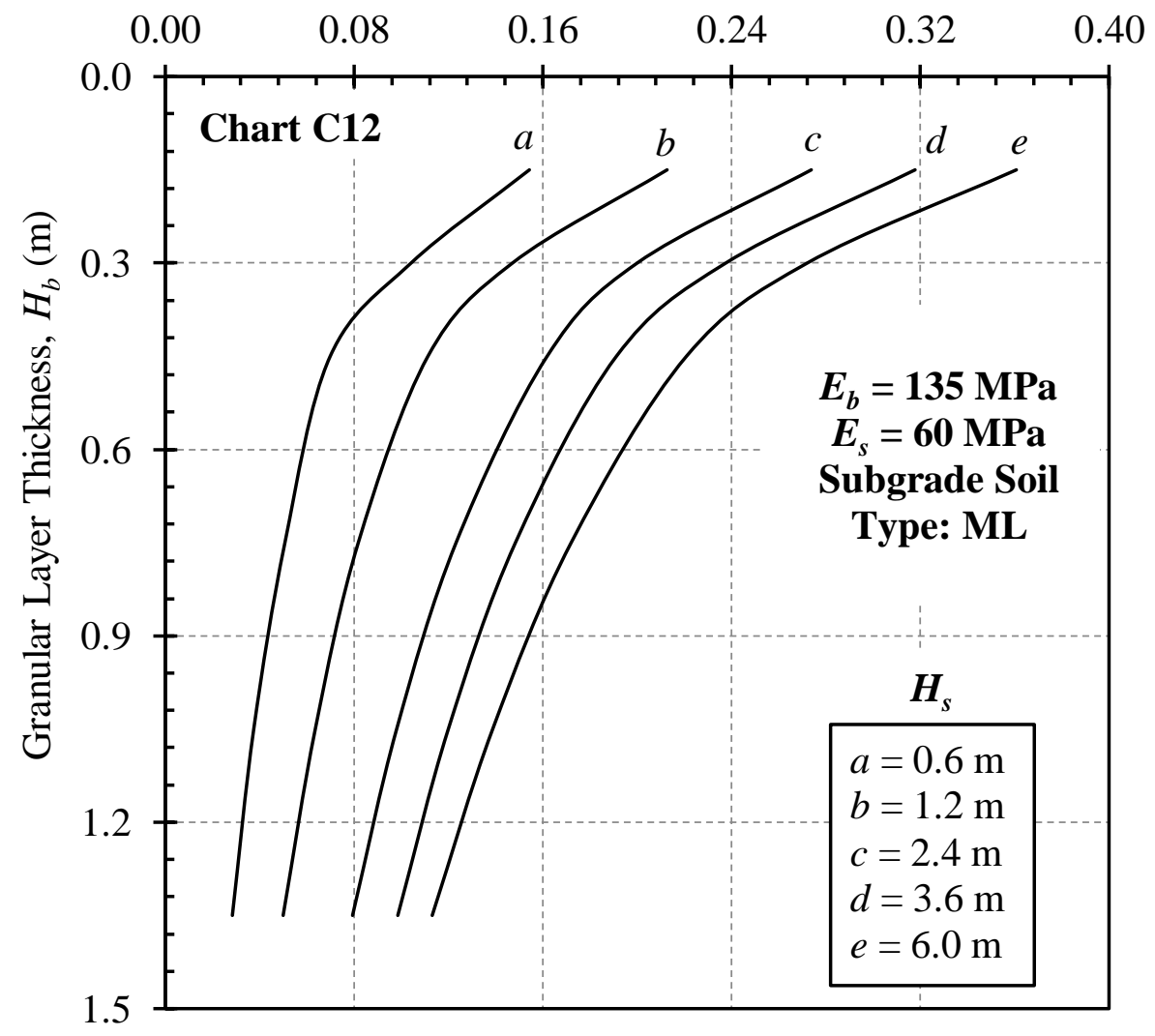


Deformation Influence Factor, $I_{\rho_{-} s}$

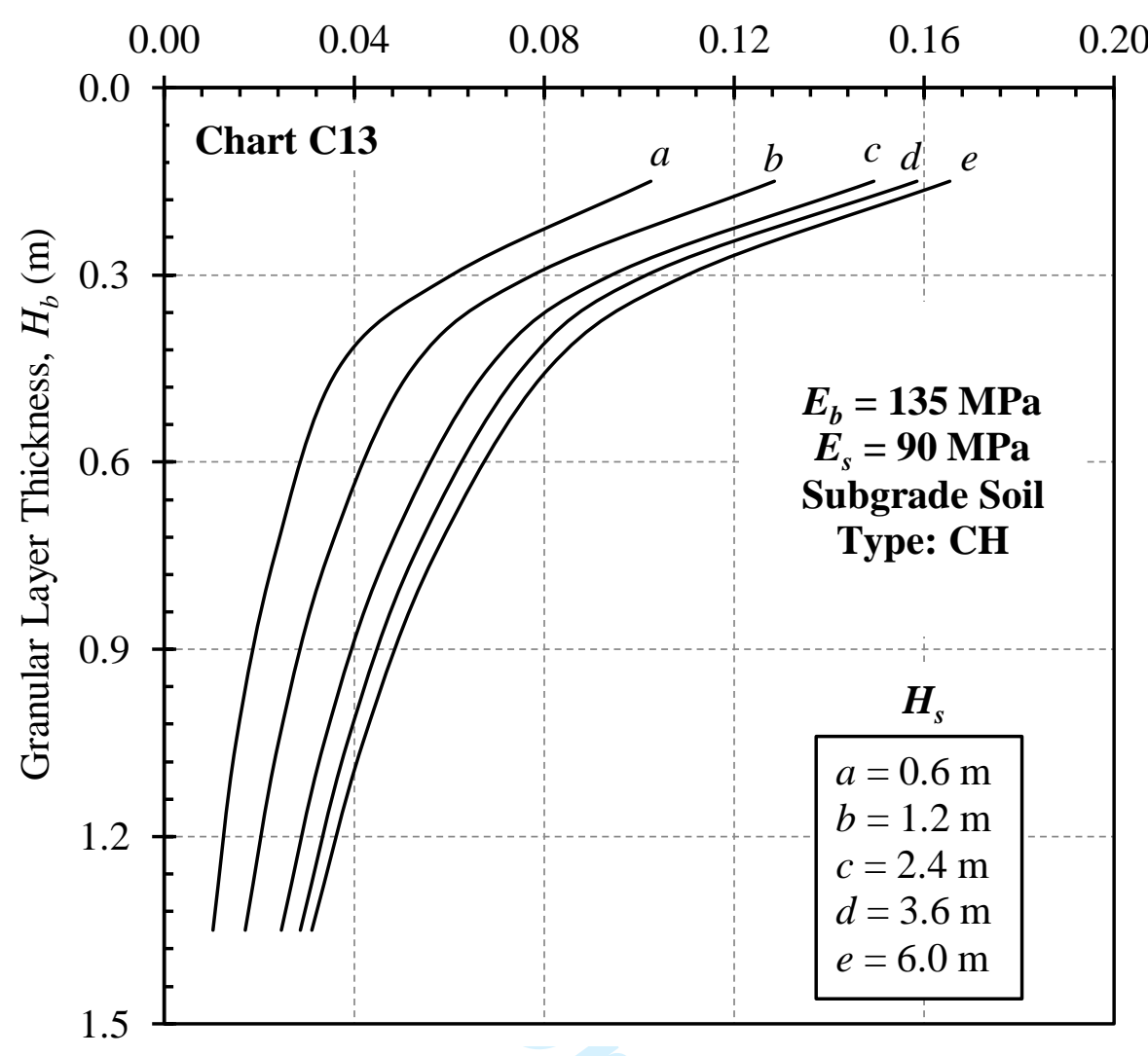

Deformation Influence Factor, $I_{\rho_{-} s}$

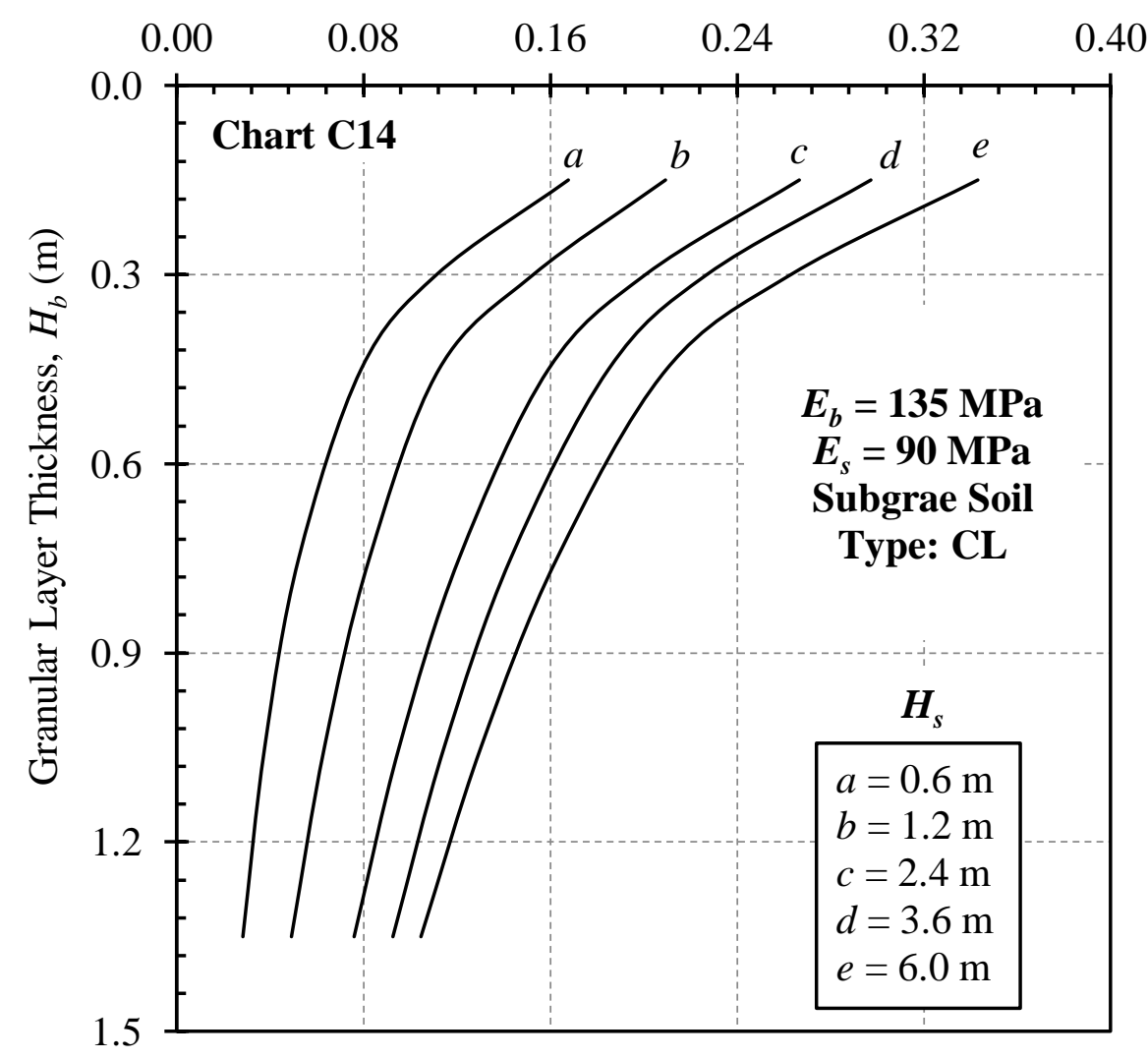


Deformation Influence Factor, $I_{\rho_{-} s}$

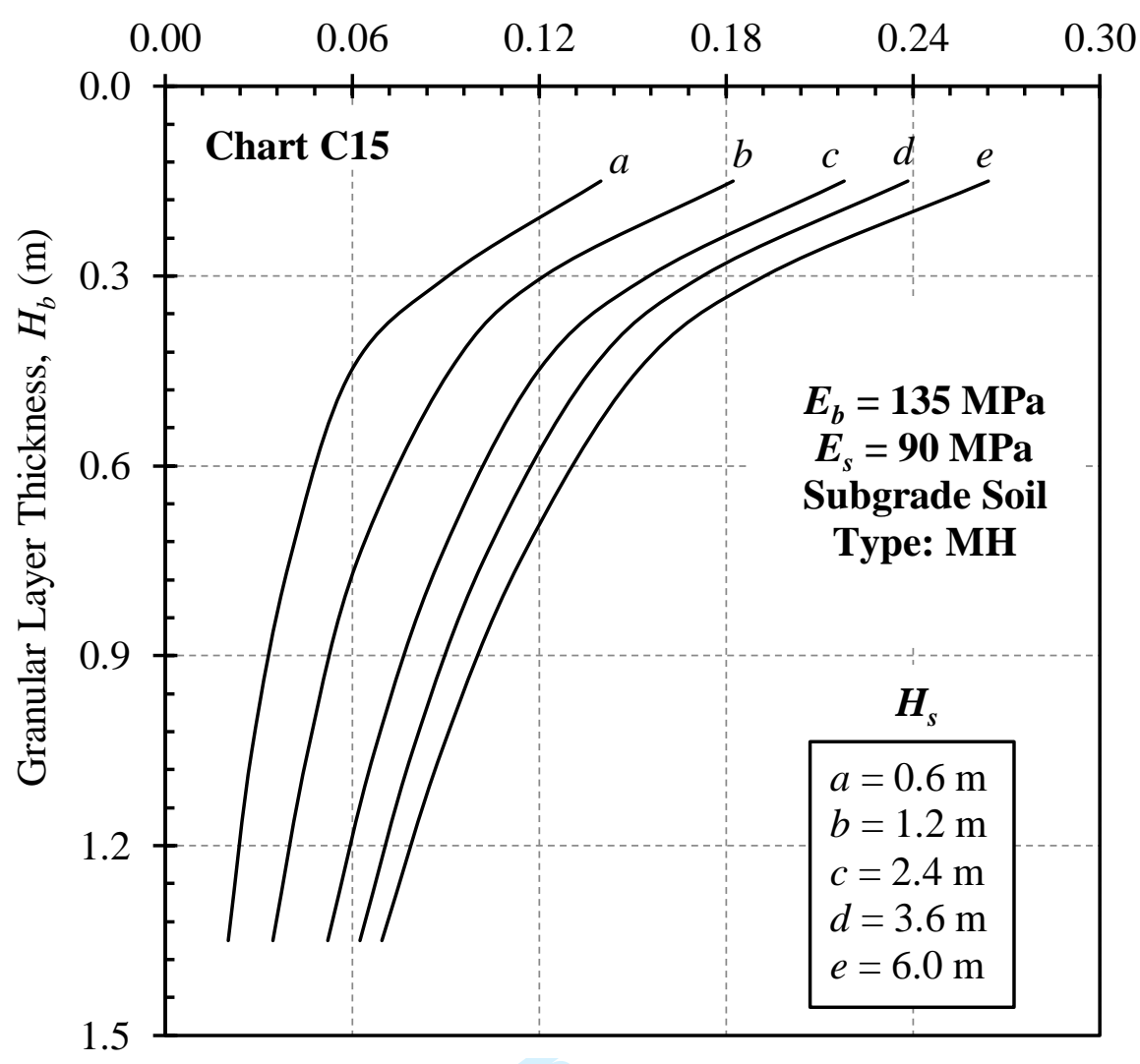

Deformation Influence Factor, $I_{\rho_{-} s}$

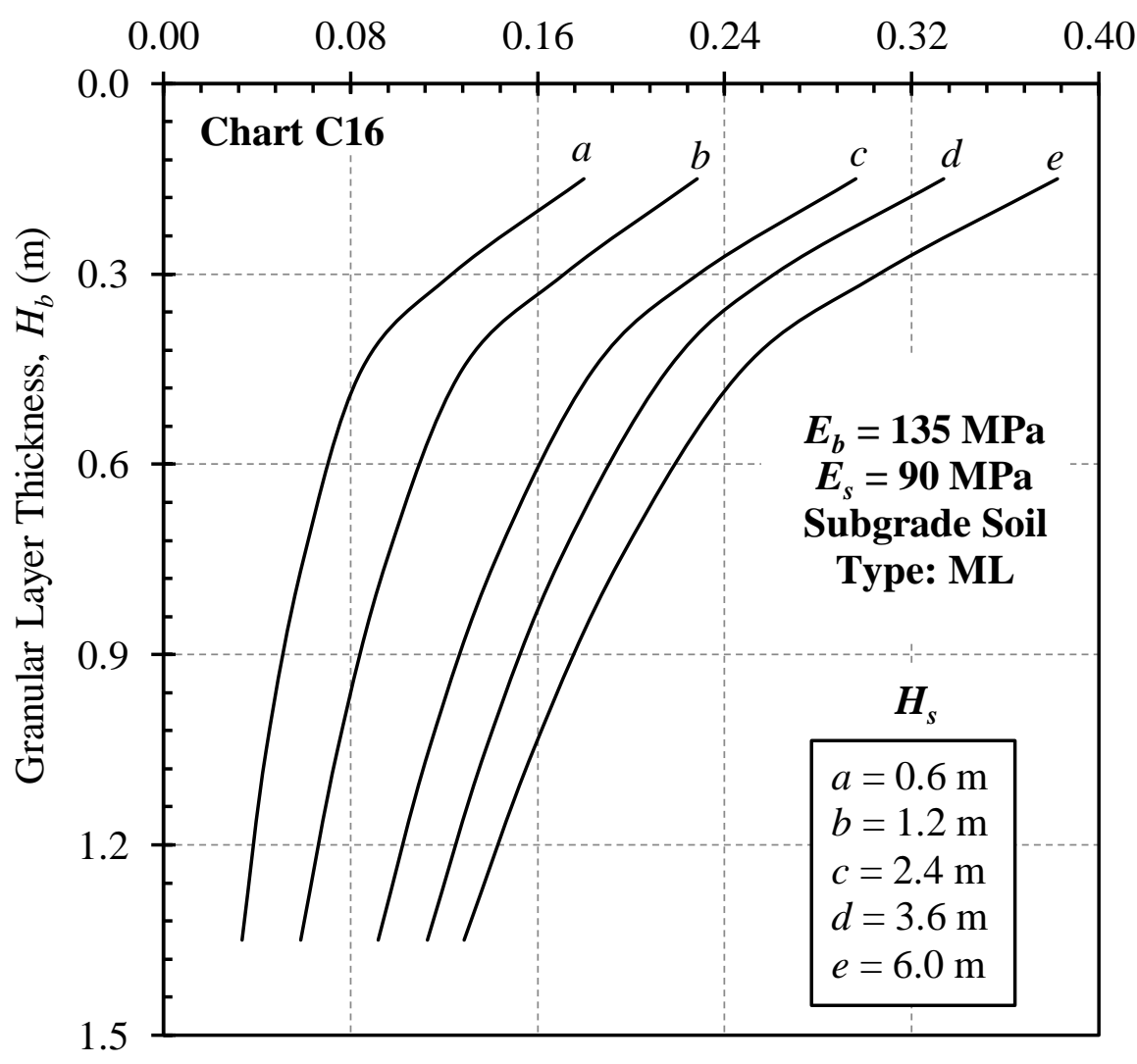


Deformation Influence Factor, $I_{\rho_{-} s}$

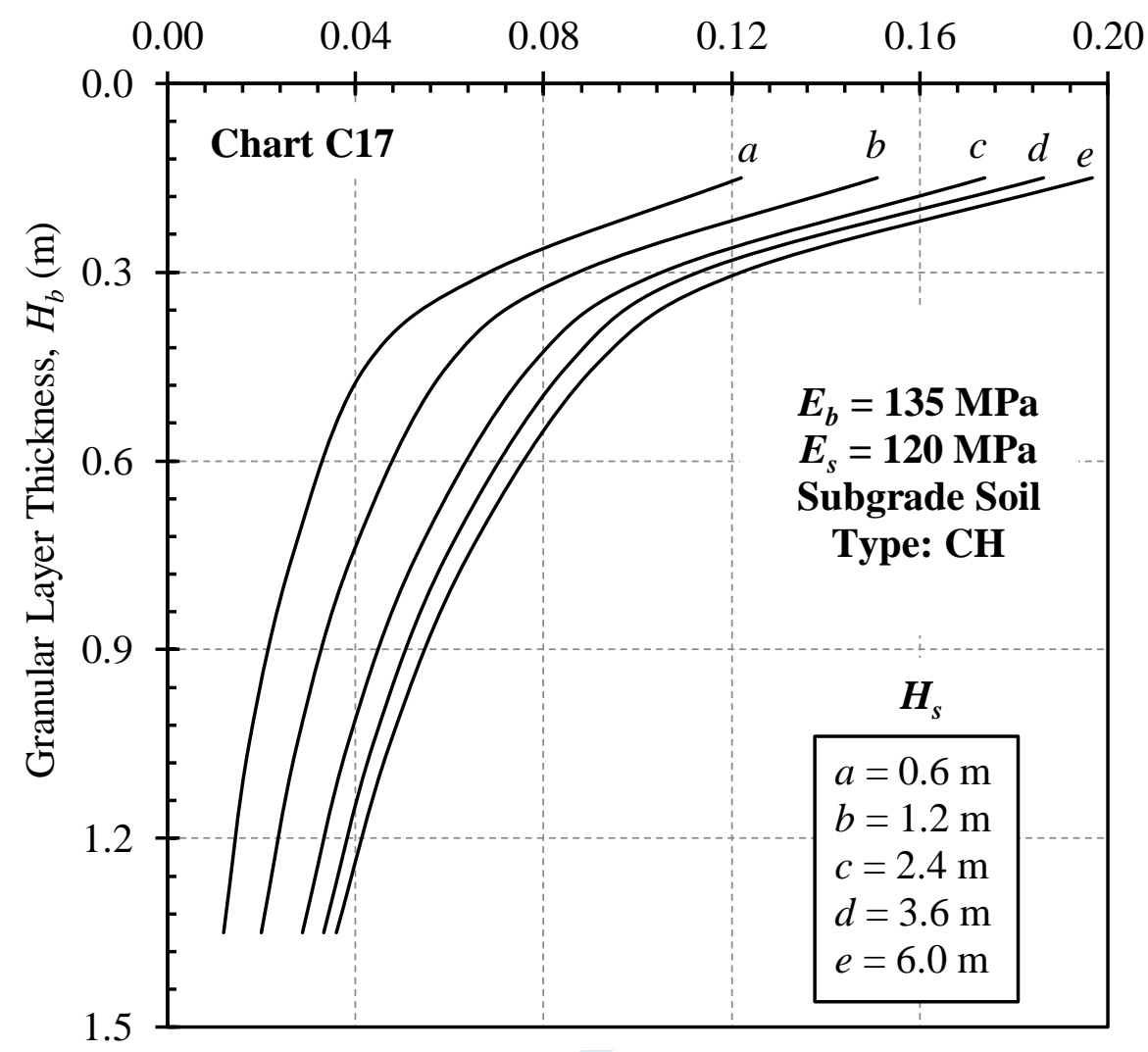

Deformation Influence Factor, $I_{\rho_{-} s}$

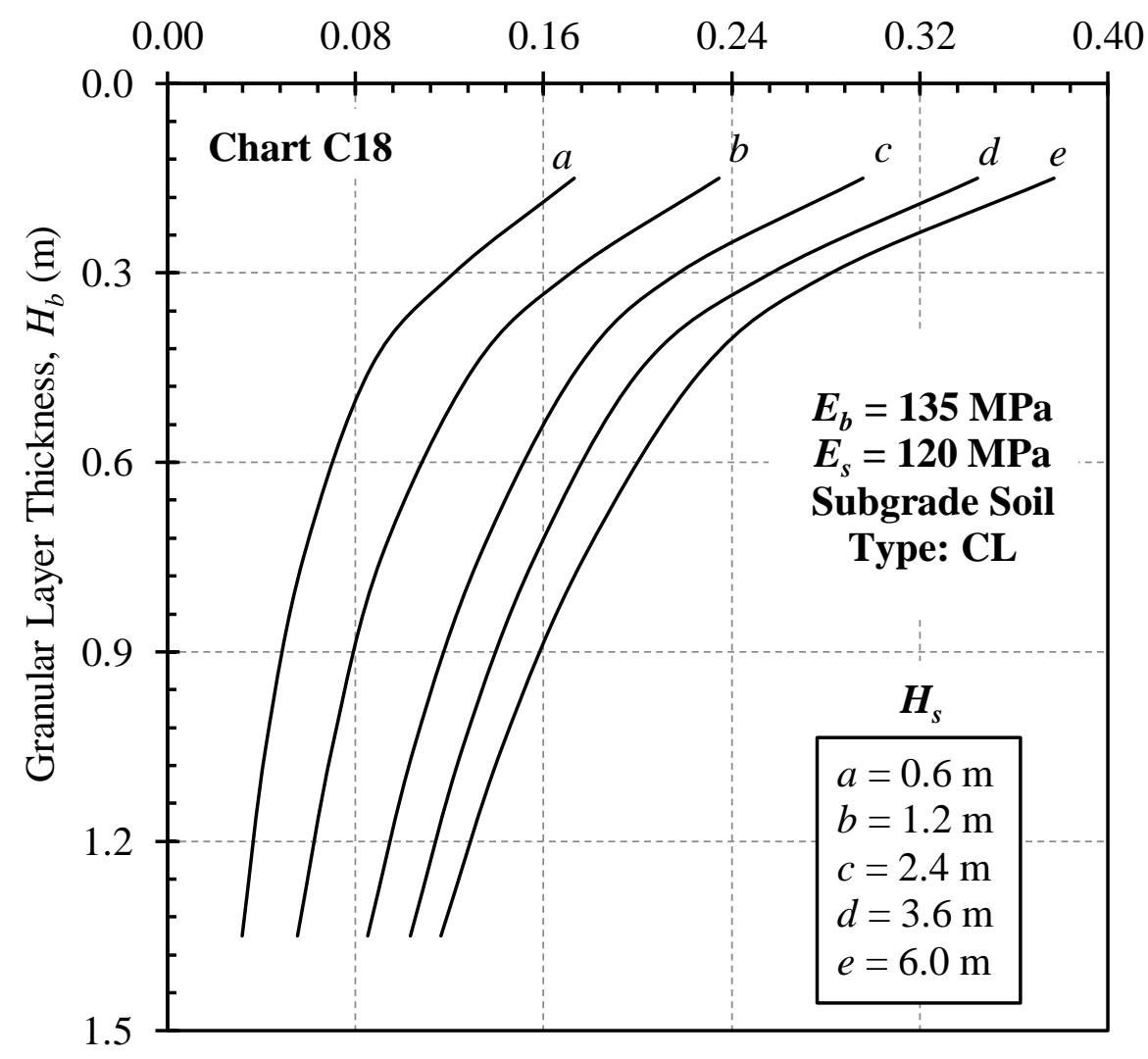


Deformation Influence Factor, $I_{\rho_{-} s}$

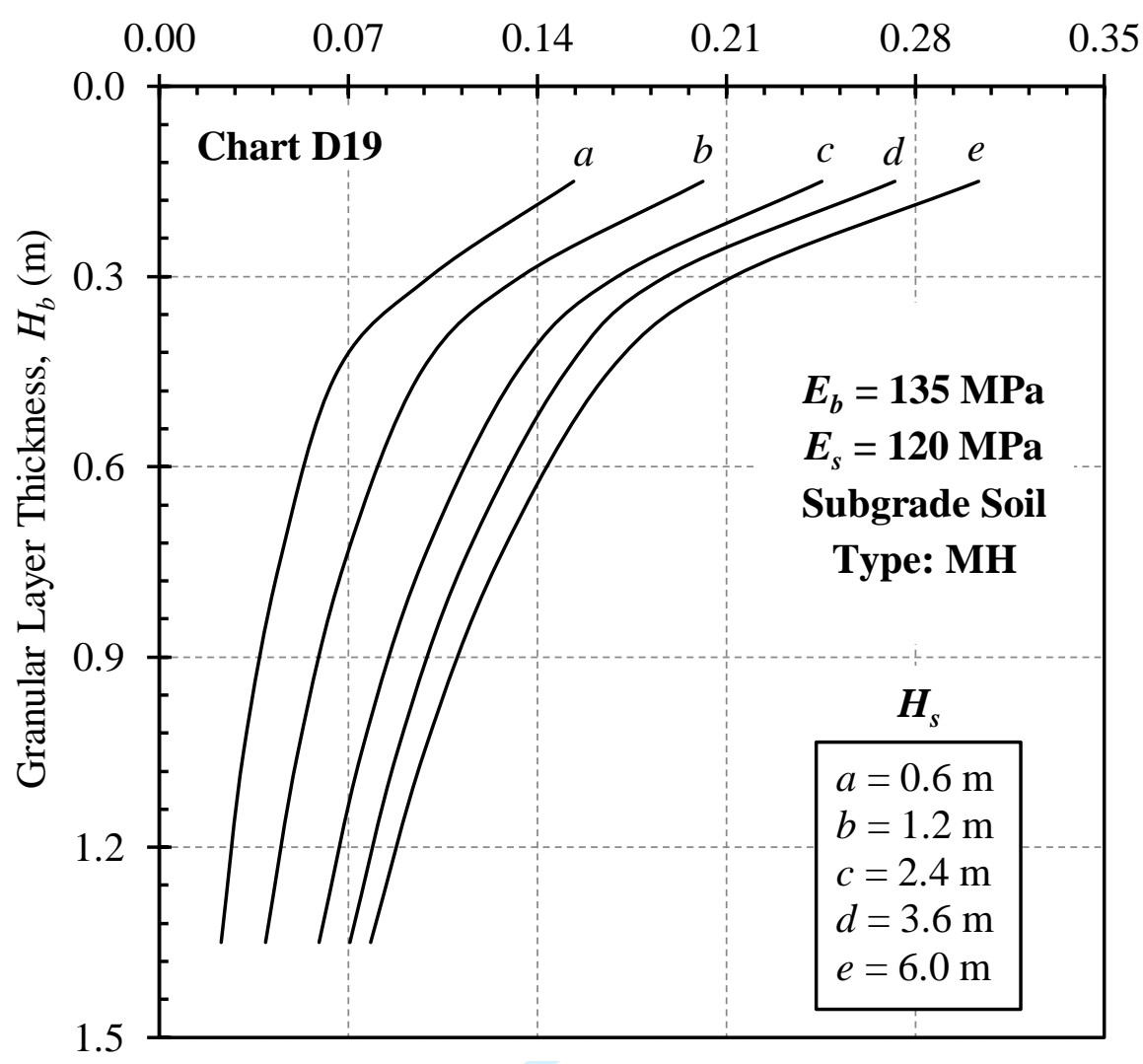

Deformation Influence Factor, $I_{\rho_{-} s}$

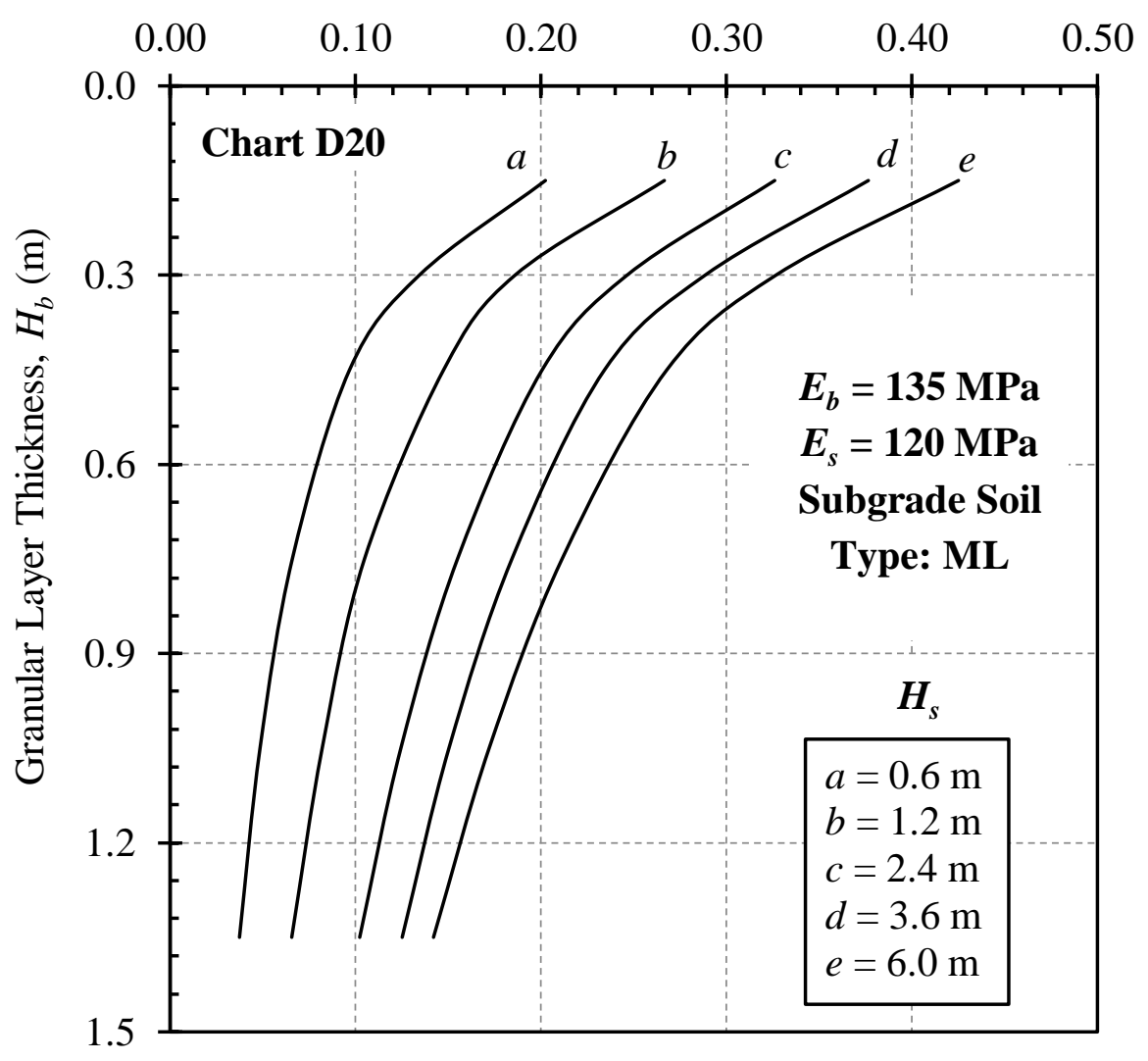


Deformation Influence Factor, $I_{\rho_{-} s}$

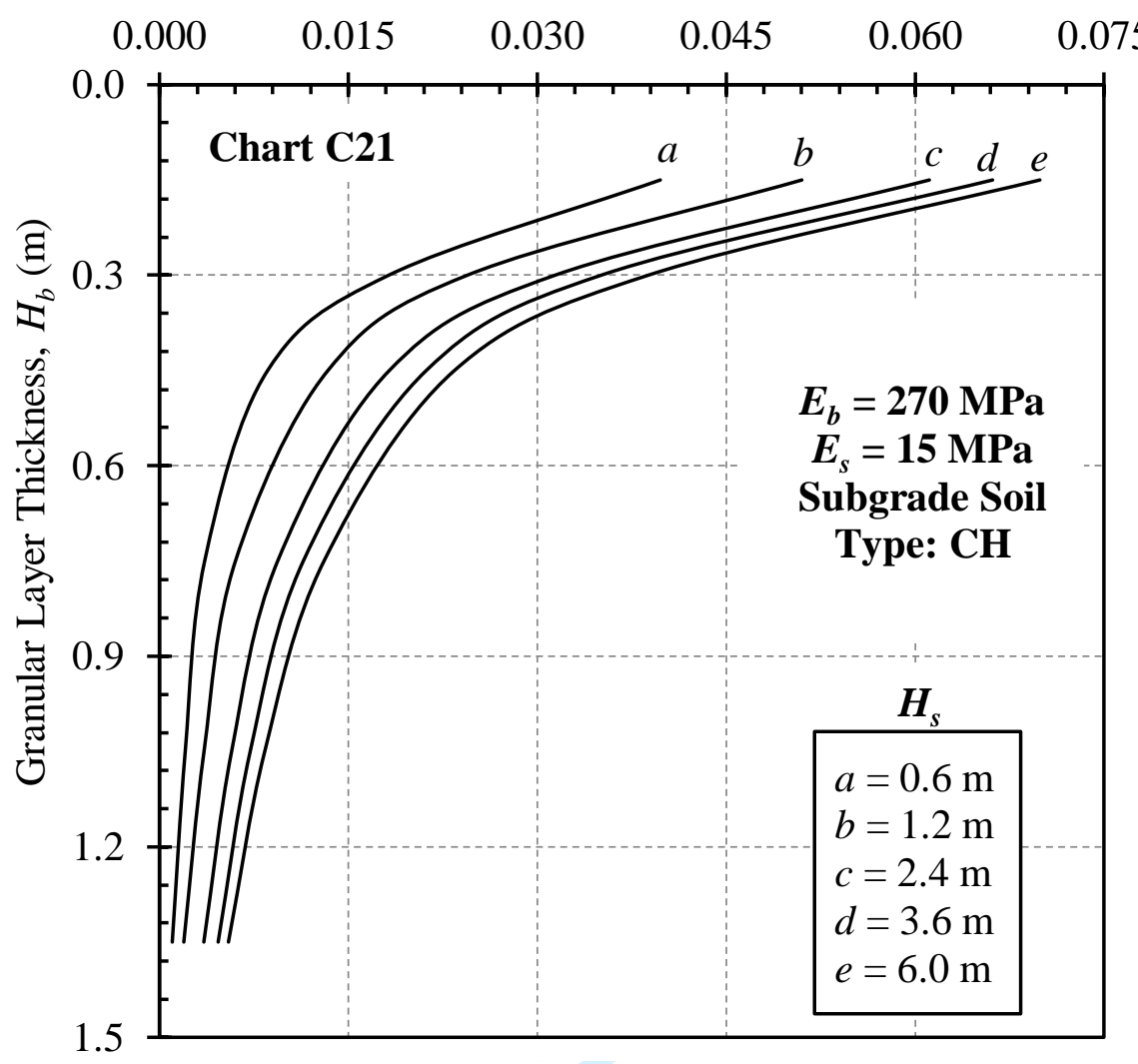

Deformation Influence Factor, $I_{\rho_{-} s}$

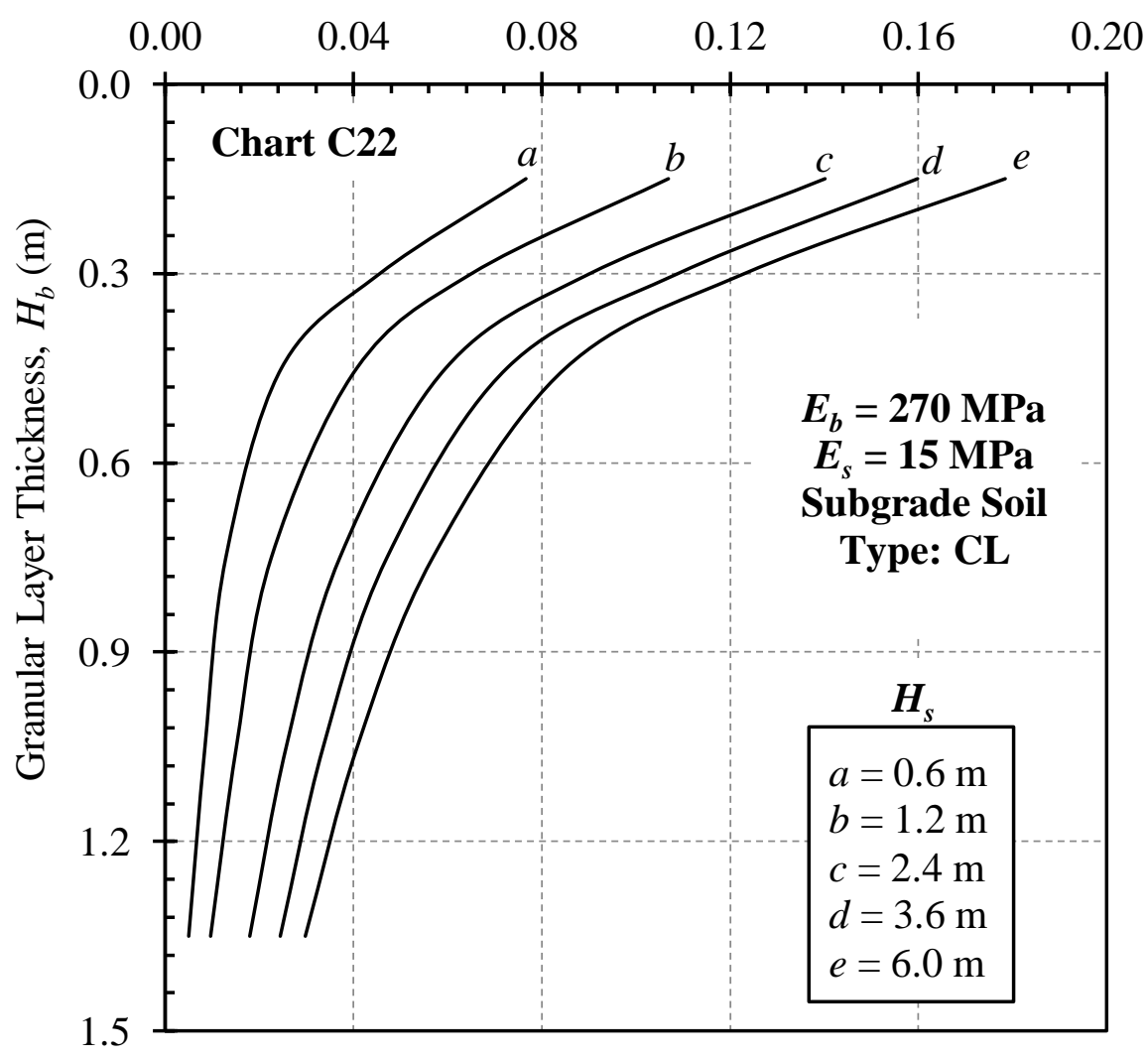


Deformation Influence Factor, $I_{\rho_{-} s}$

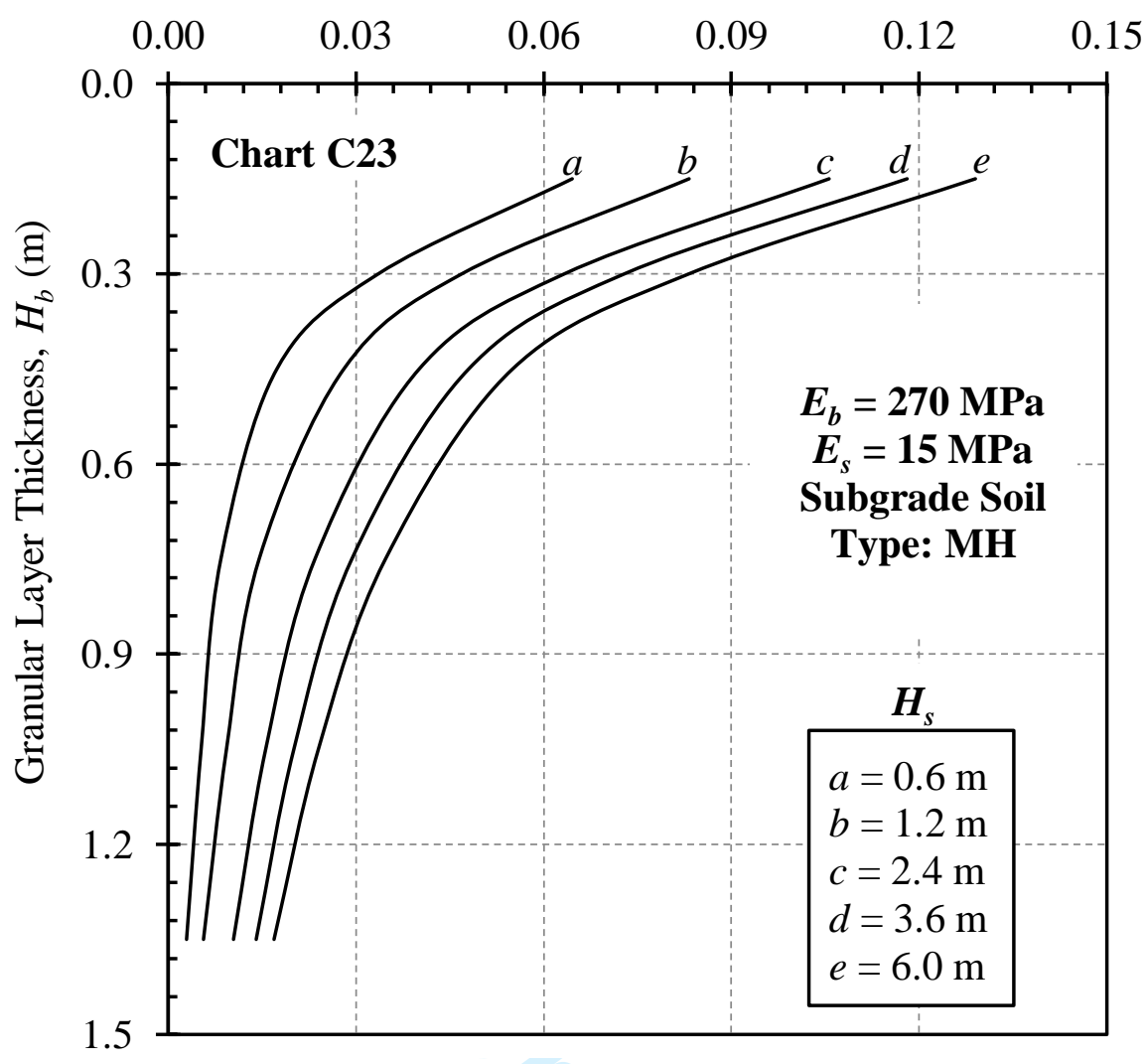

Deformation Influence Factor, $I_{\rho_{-} s}$

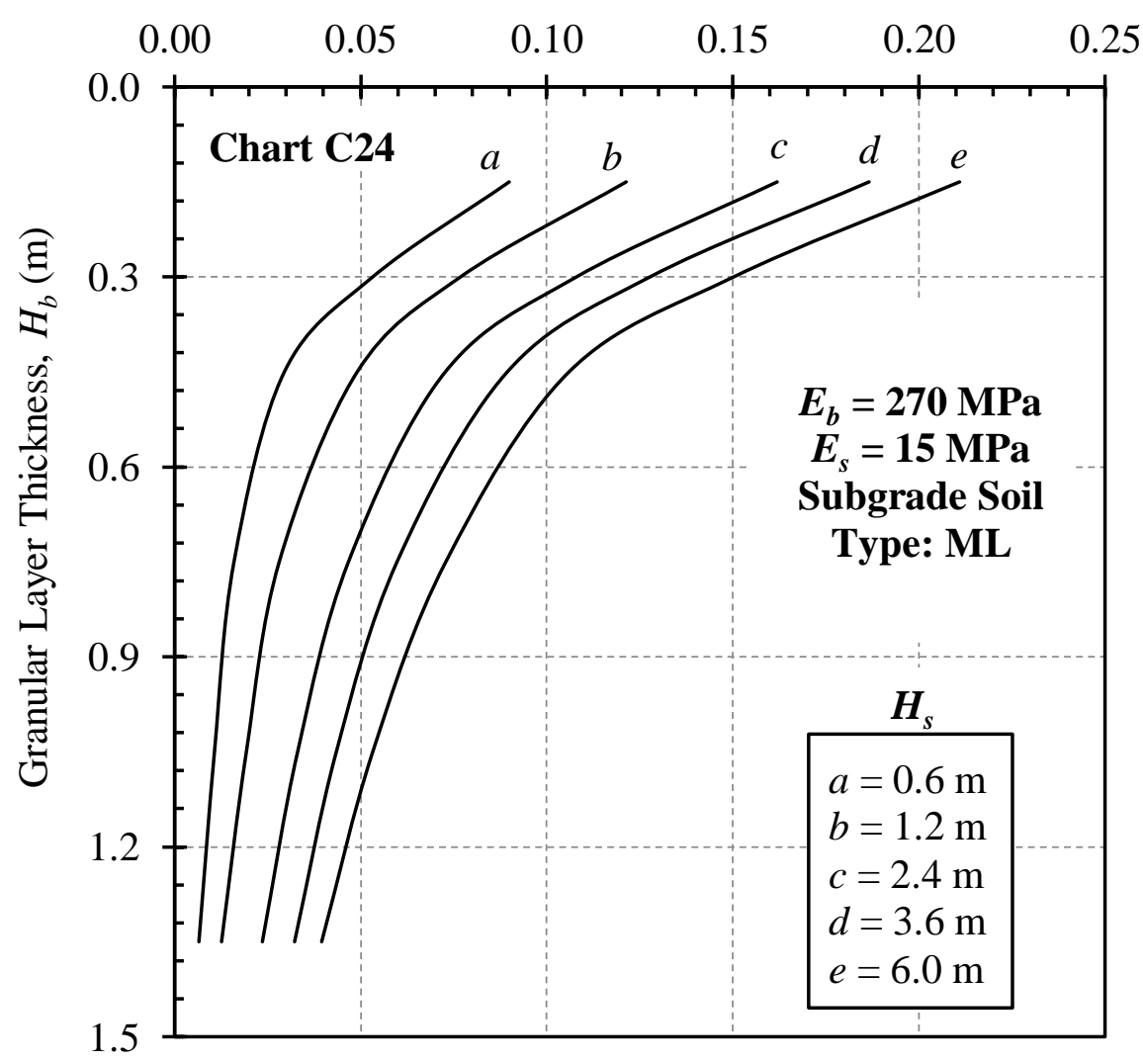


Deformation Influence Factor, $I_{\rho_{-} s}$

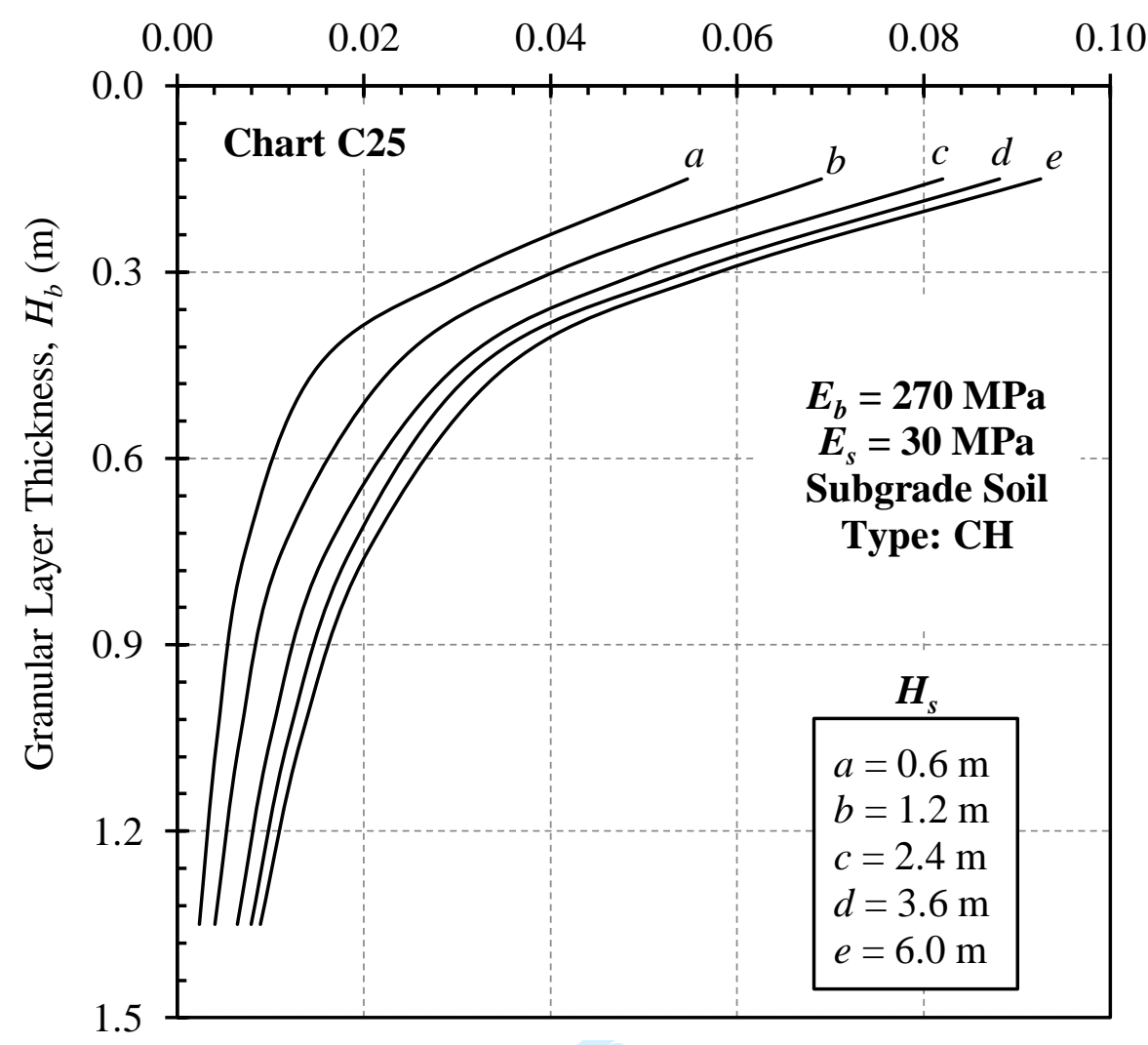

Deformation Influence Factor, $I_{\rho_{-} s}$

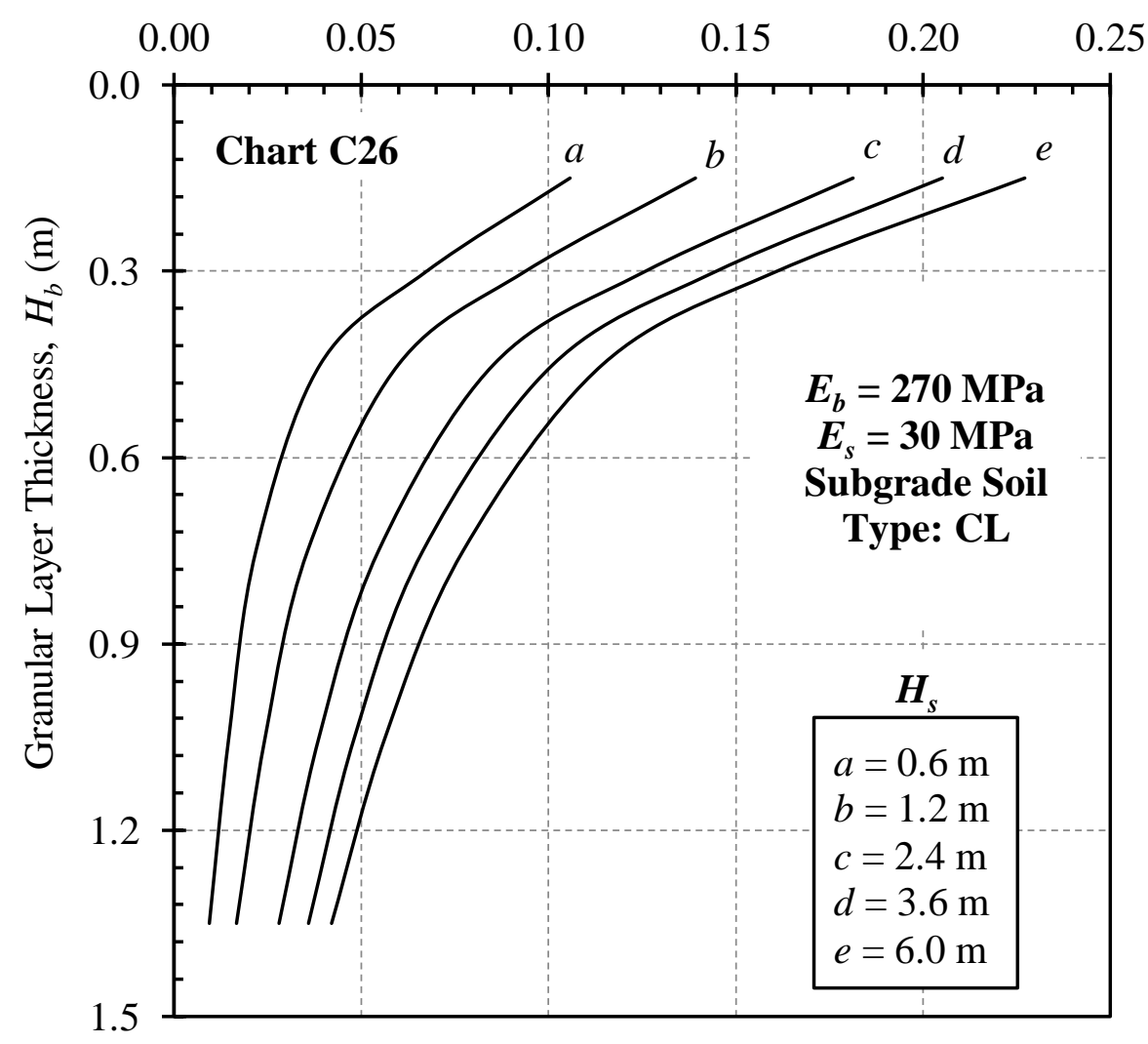


Deformation Influence Factor, $I_{\rho_{-} s}$

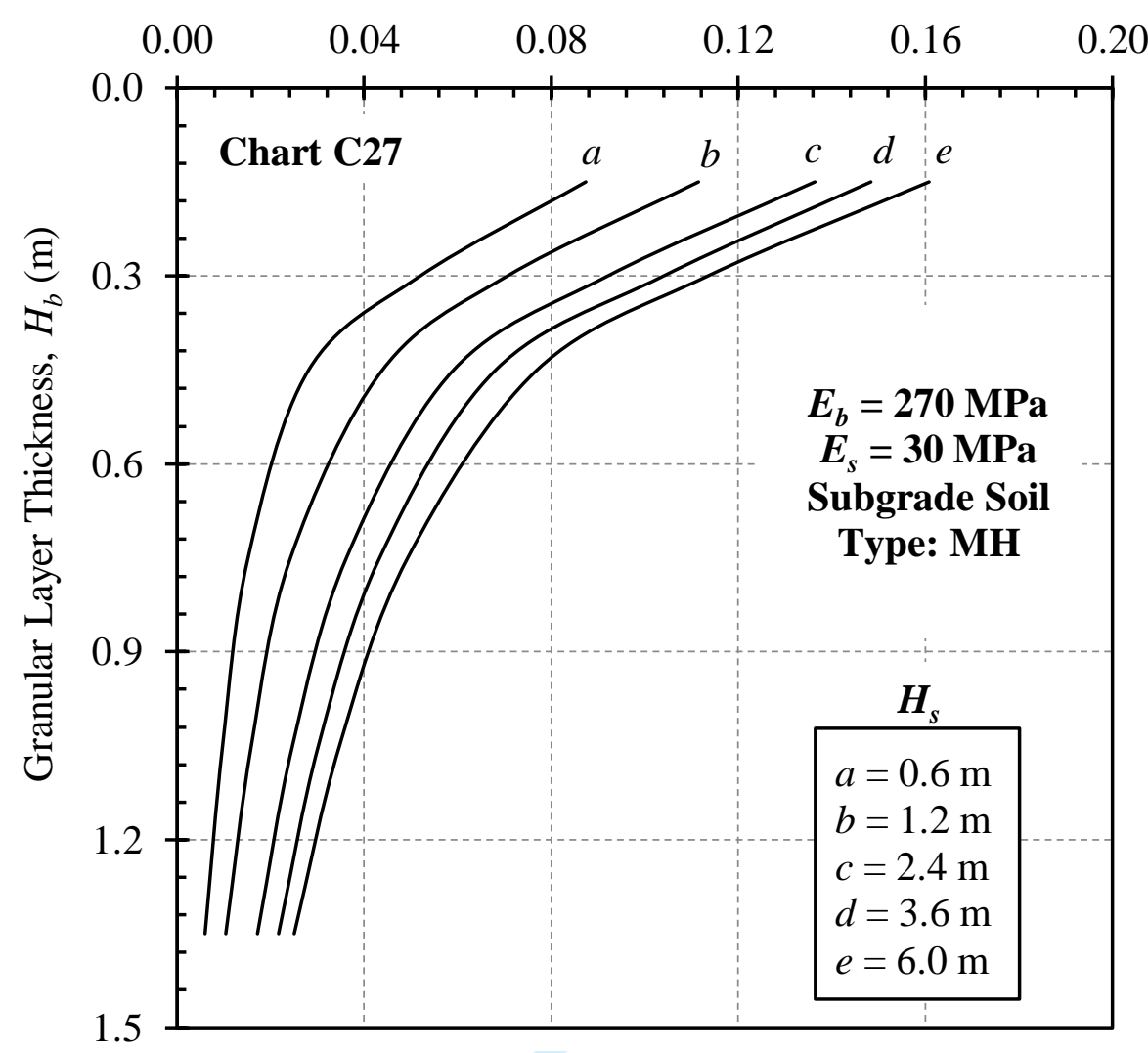

Deformation Influence Factor, $I_{\rho_{-} s}$

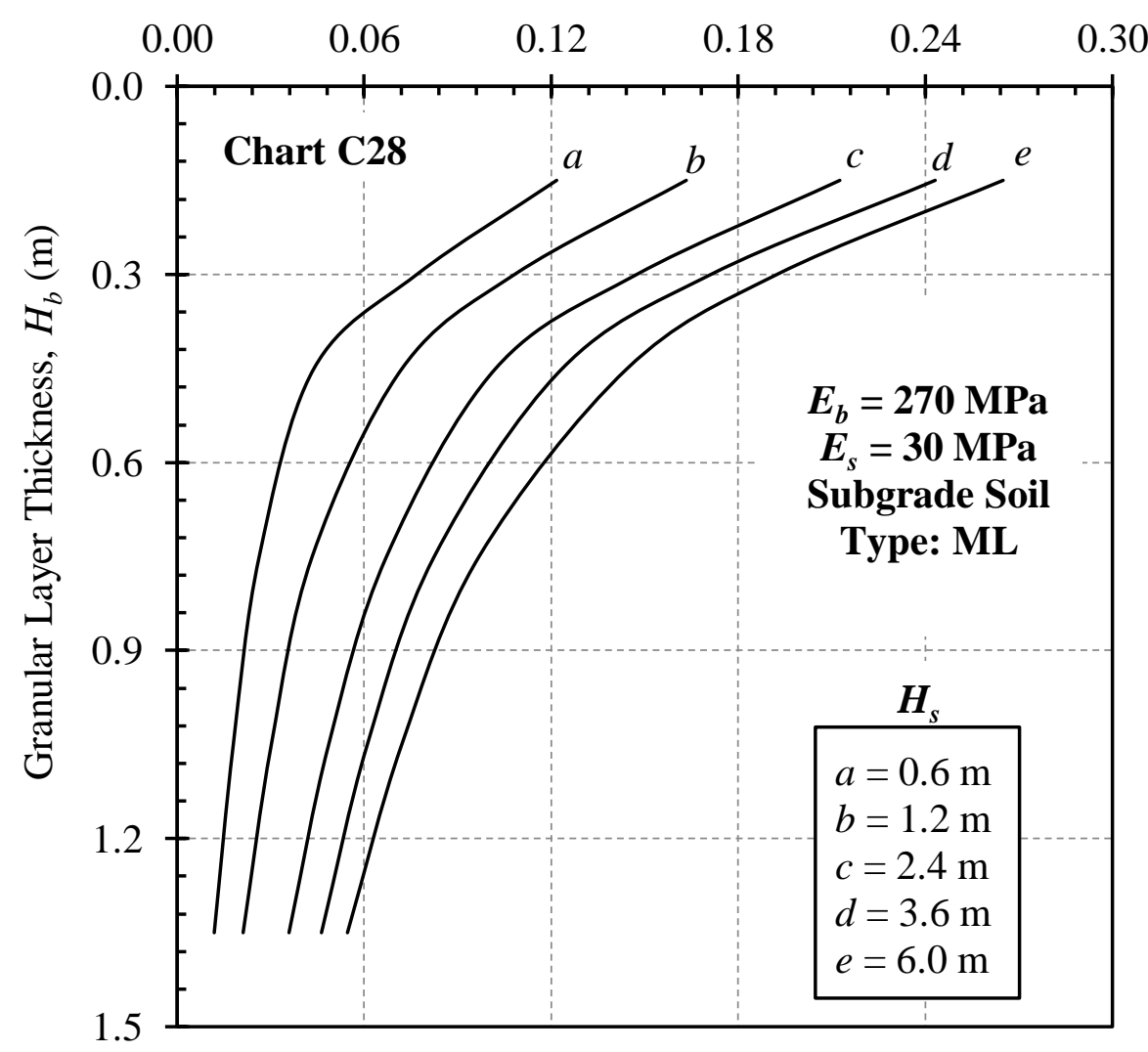


Deformation Influence Factor, $I_{\rho_{-} s}$

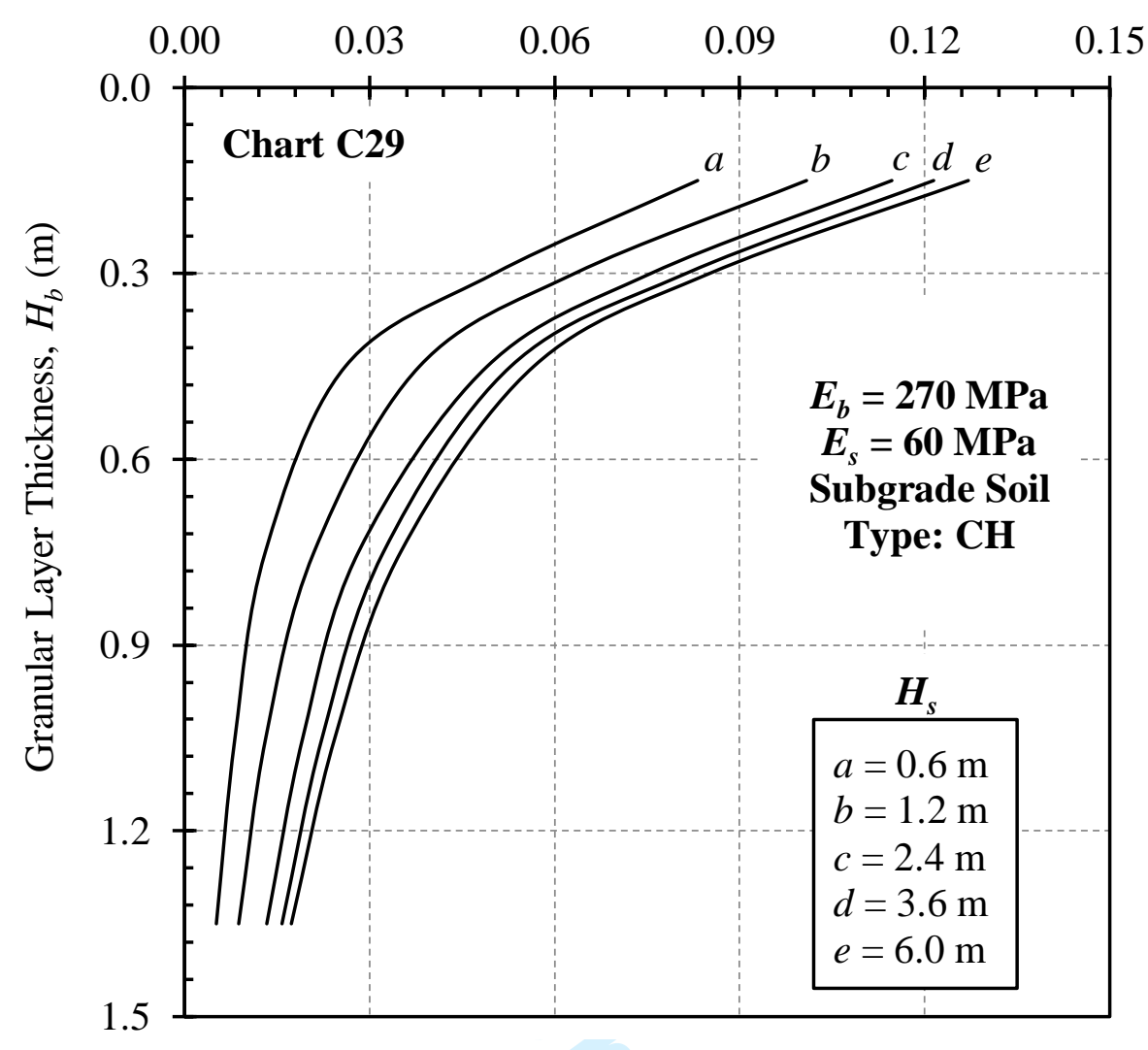

Deformation Influence Factor, $I_{\rho_{-} s}$

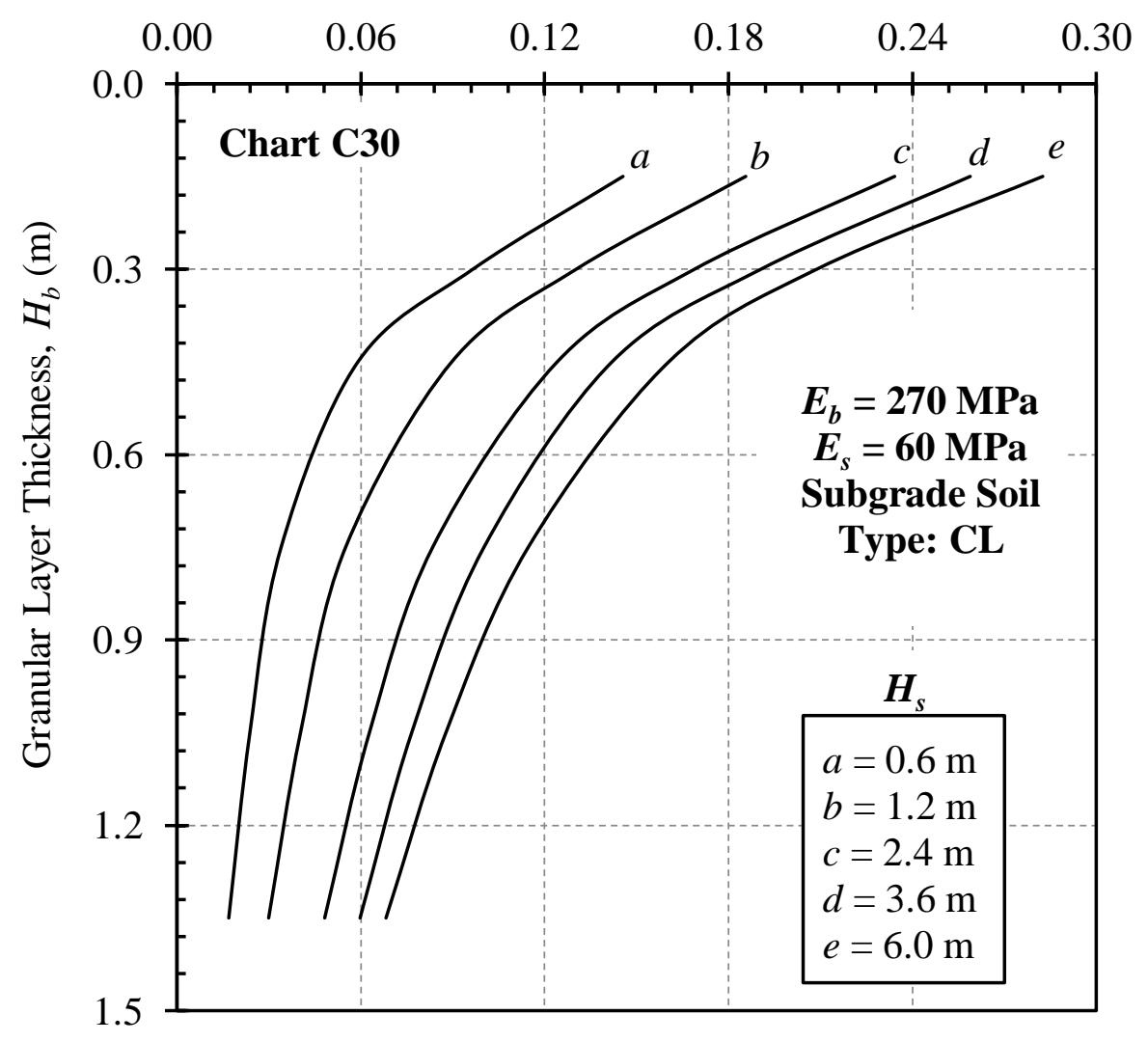


Deformation Influence Factor, $I_{\rho_{-} s}$

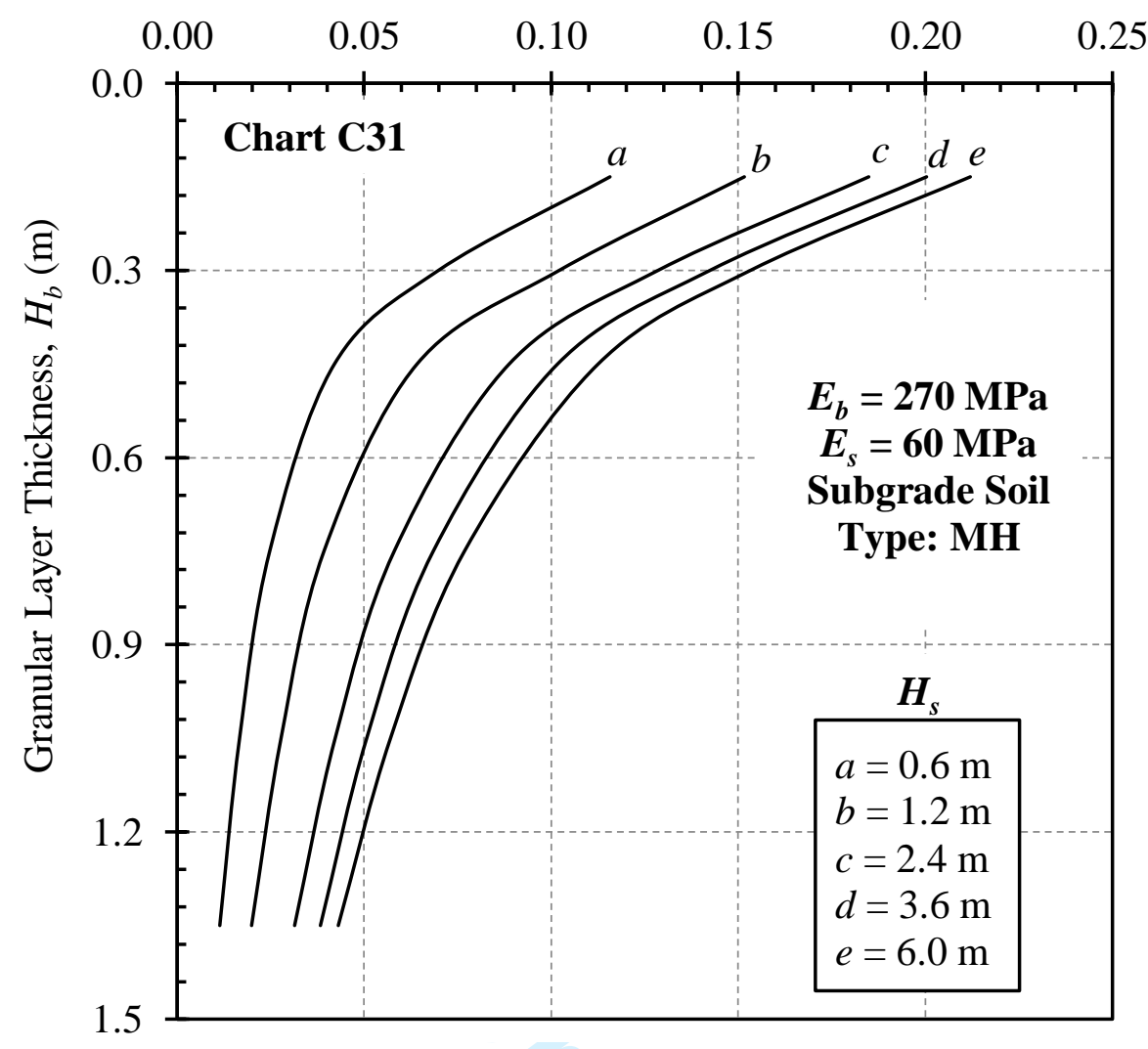

Deformation Influence Factor, $I_{\rho_{-} s}$

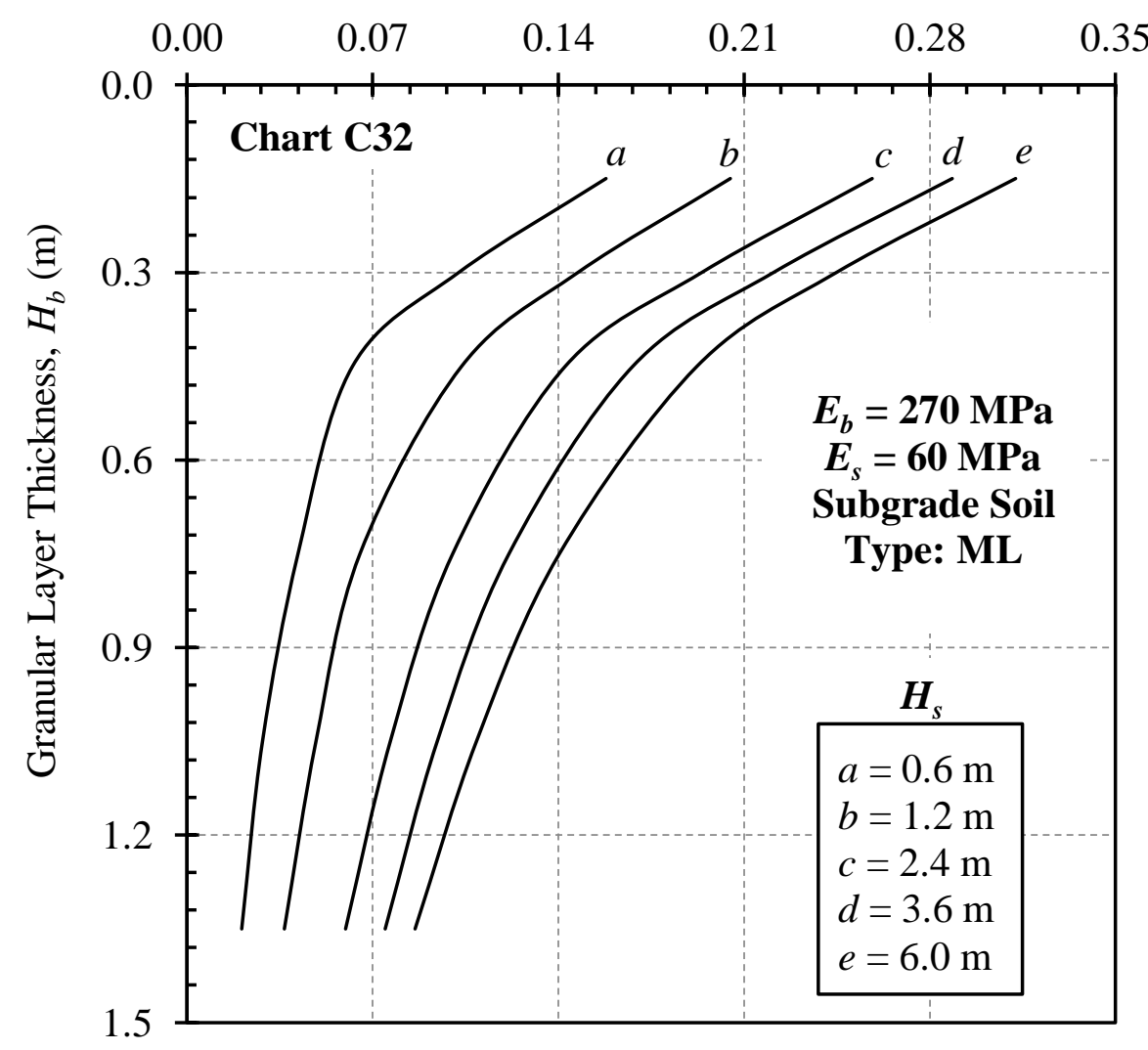


Deformation Influence Factor, $I_{\rho_{-} s}$

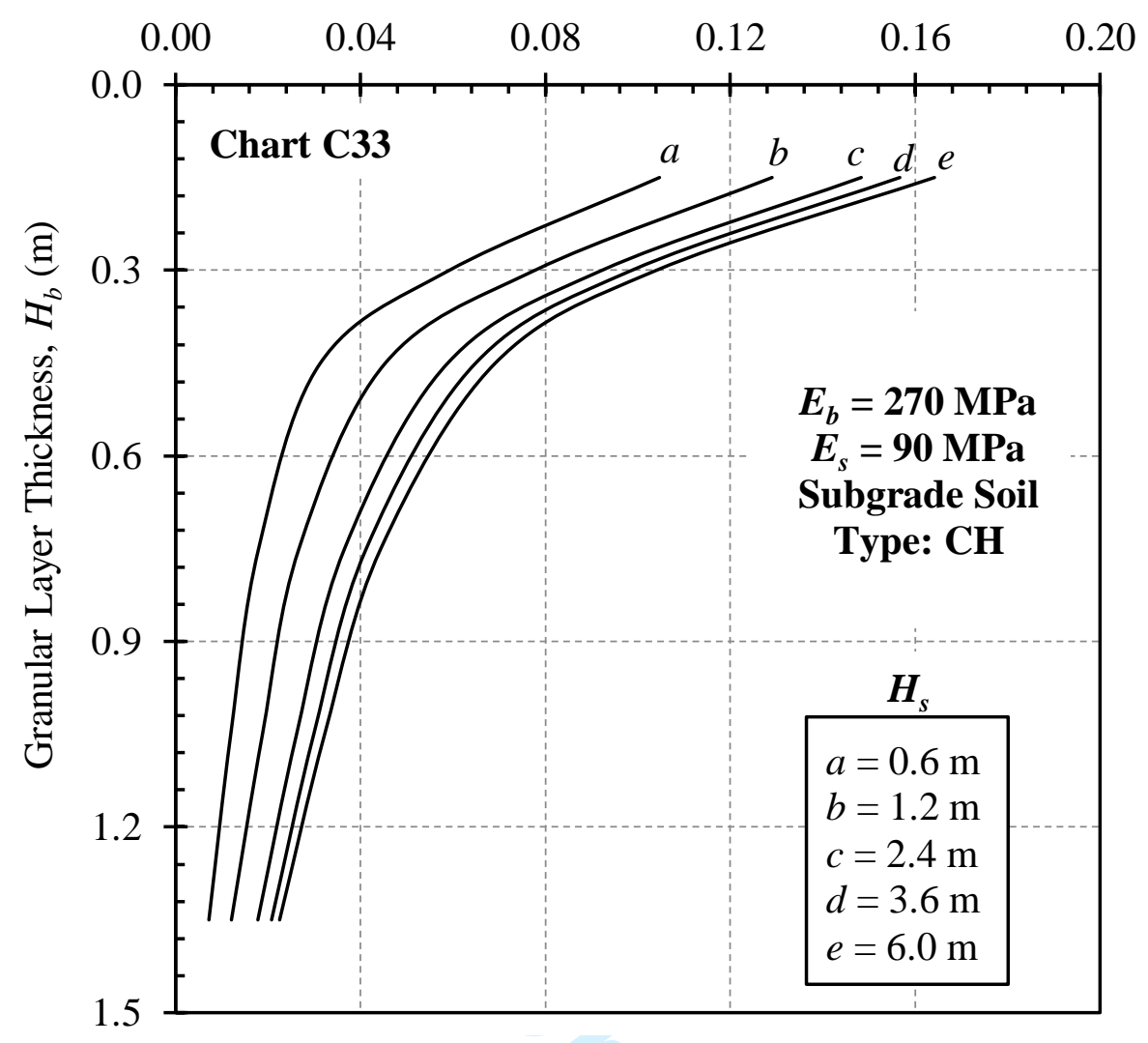

Deformation Influence Factor, $I_{\rho_{-} s}$

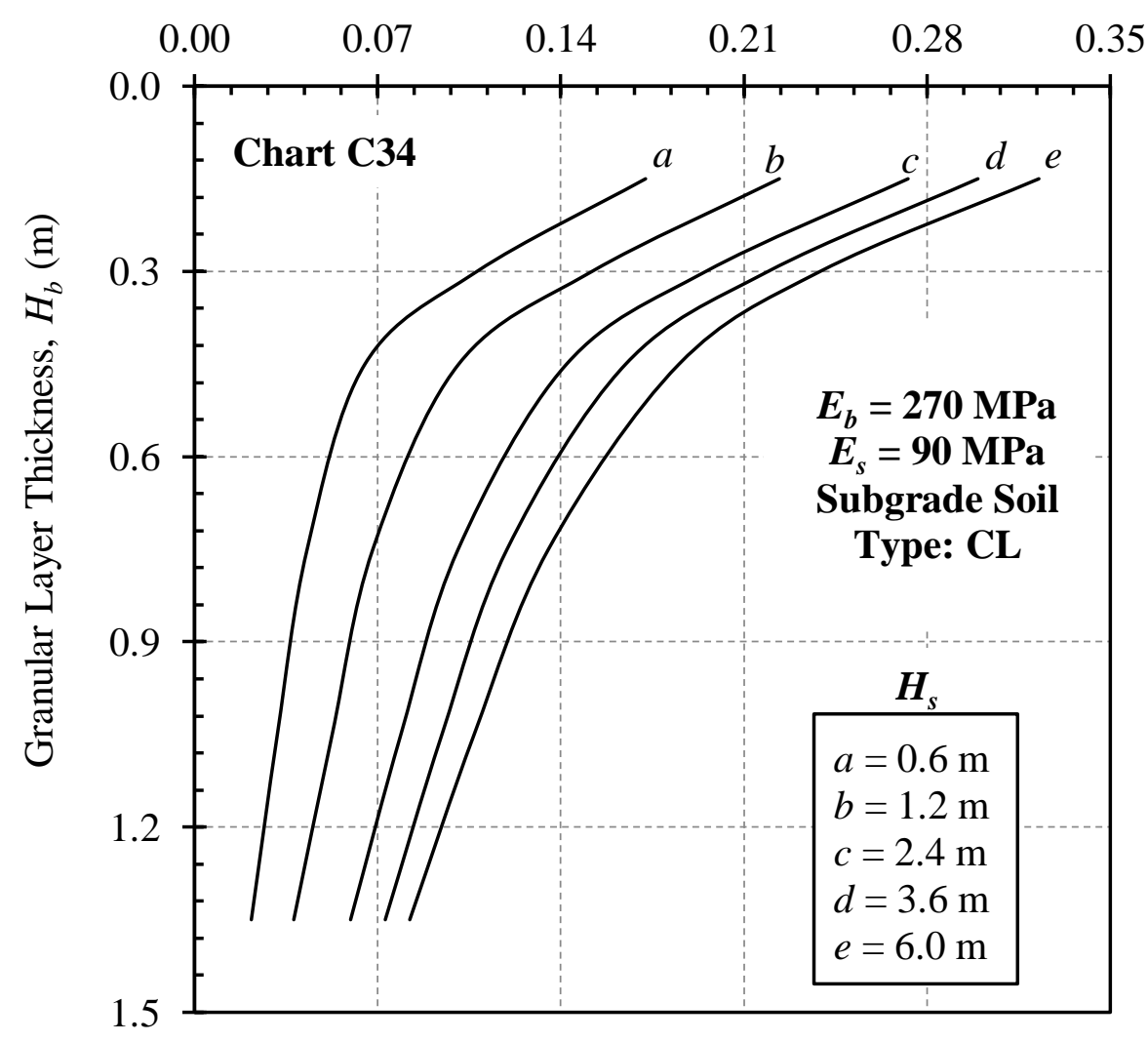


Deformation Influence Factor, $I_{\rho_{-} s}$

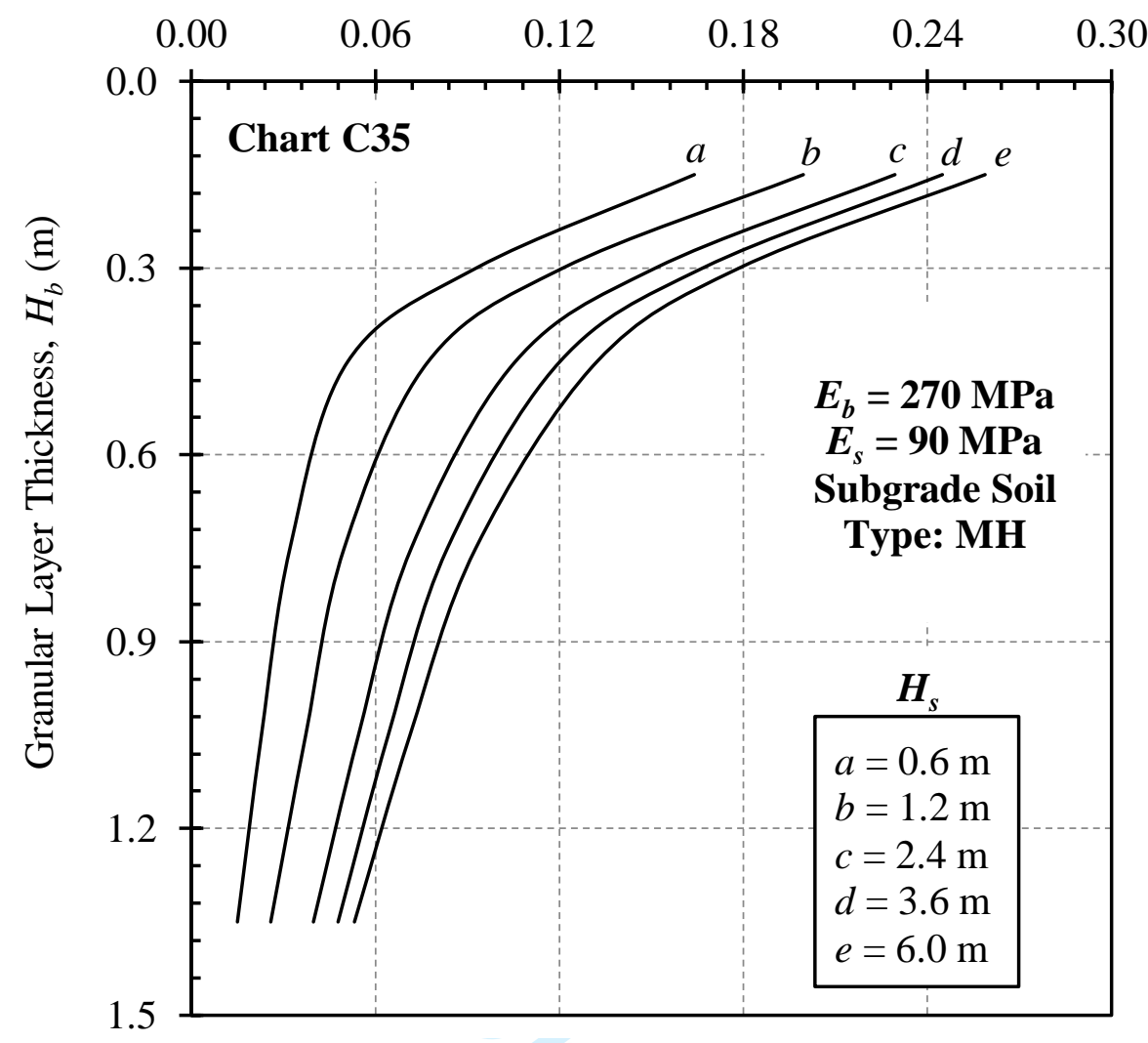

Deformation Influence Factor, $I_{\rho_{-} s}$

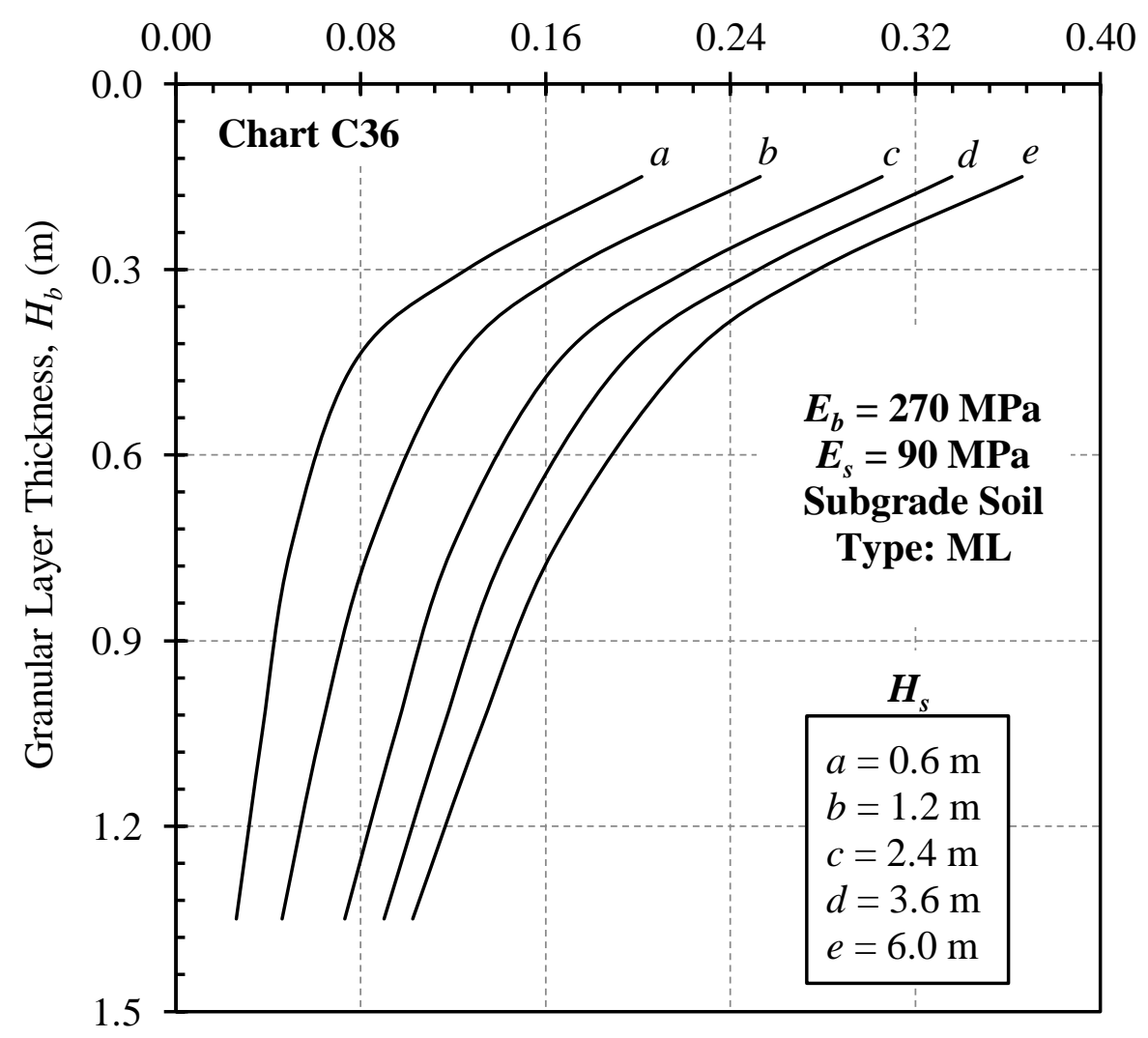


Deformation Influence Factor, $I_{\rho_{-} s}$

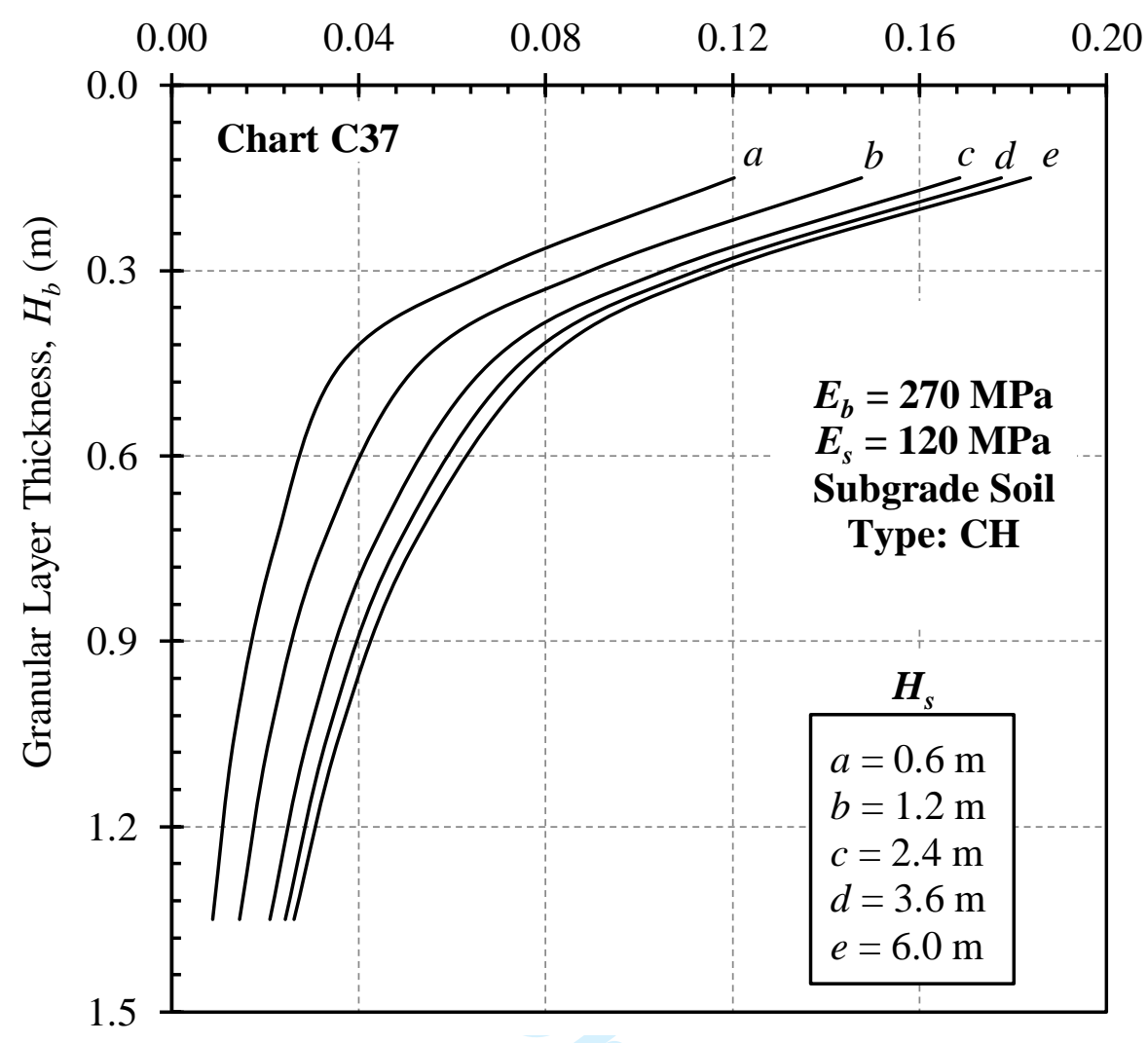

Deformation Influence Factor, $I_{\rho_{-} s}$

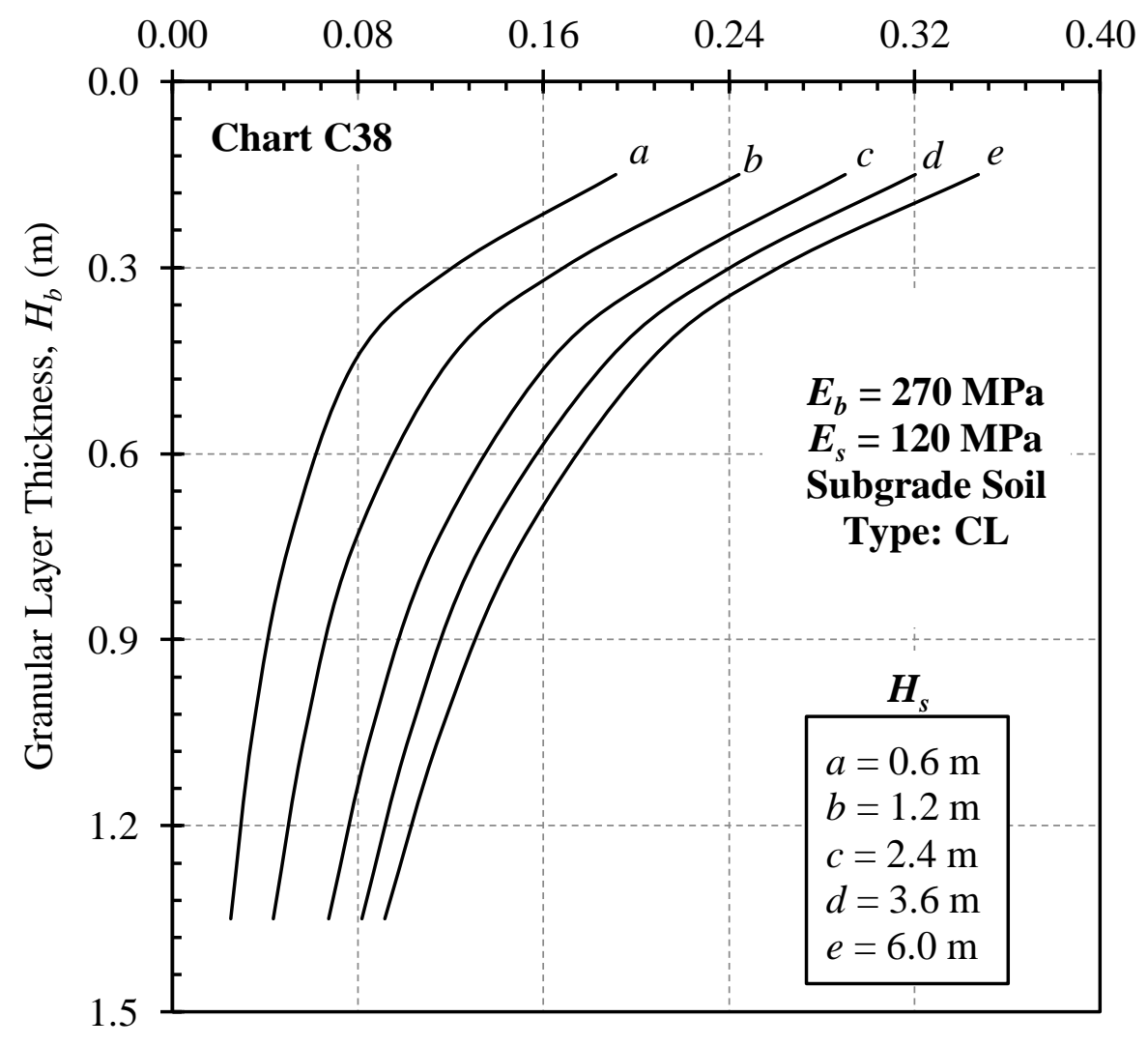


Deformation Influence Factor, $I_{\rho_{-} s}$

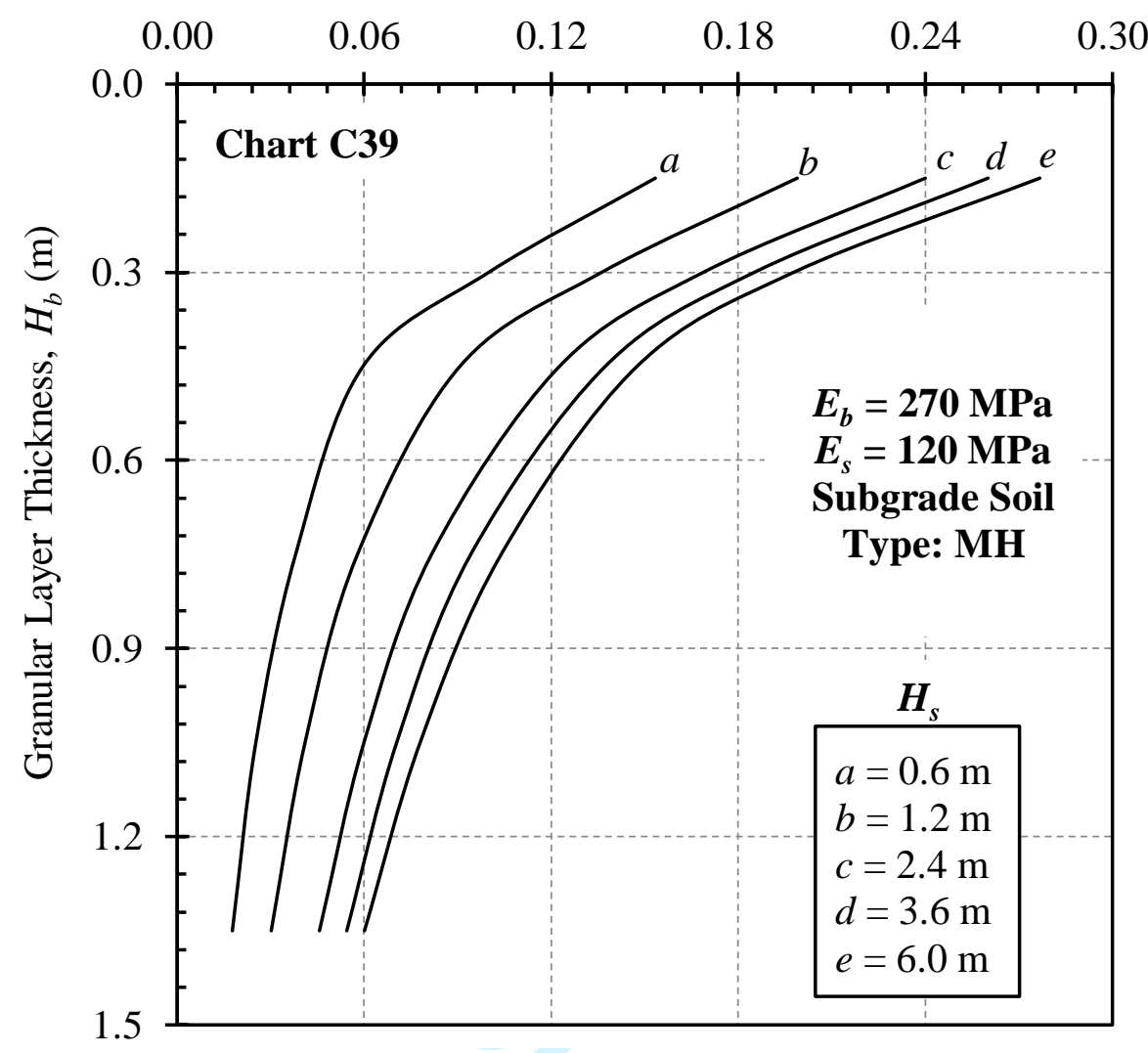

Deformation Influence Factor, $I_{\rho_{-} s}$

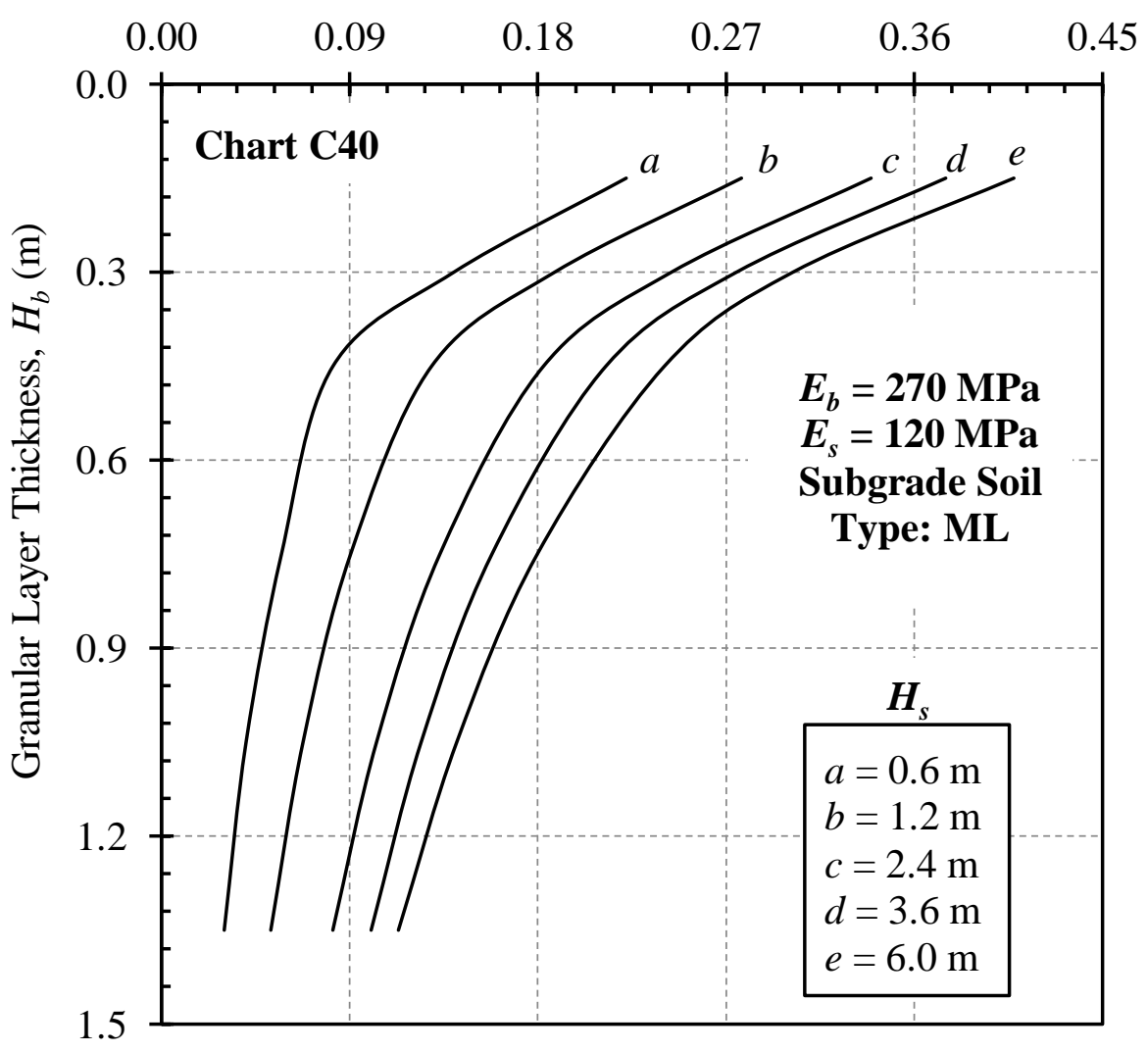


Deformation Influence Factor, $I_{\rho_{-} s}$

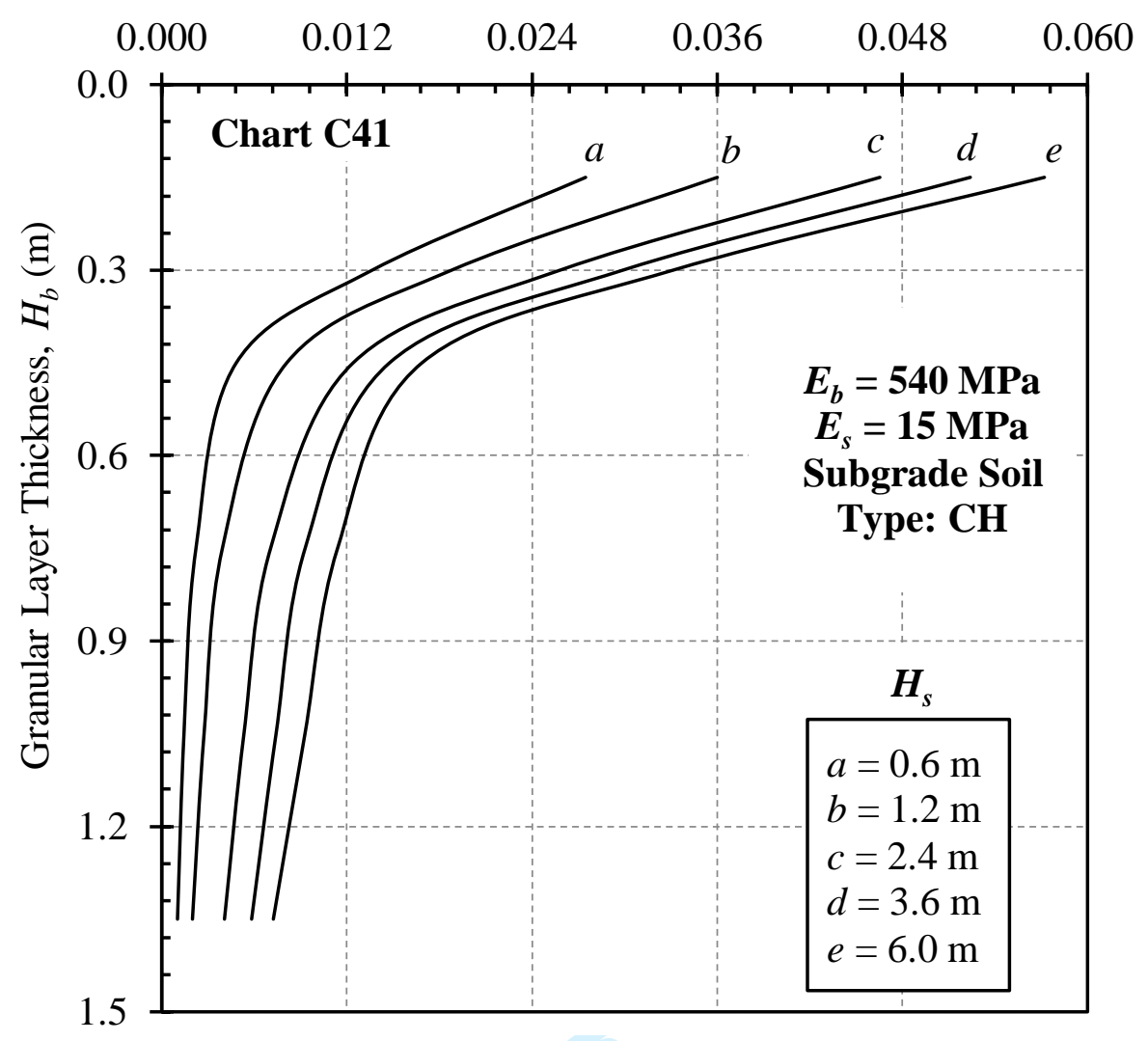

Deformation Influence Factor, $I_{\rho_{-} s}$

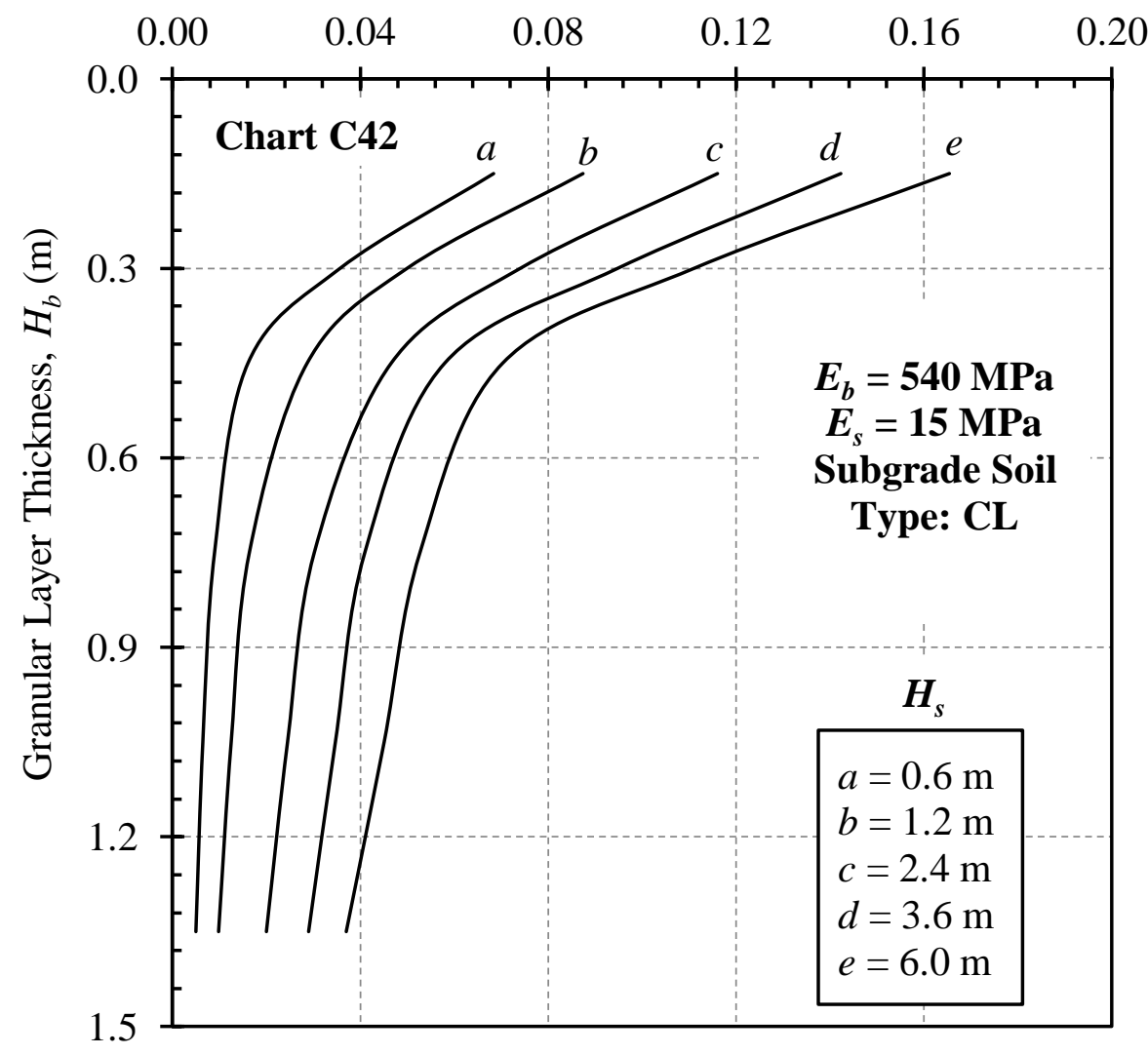


Deformation Influence Factor, $I_{\rho_{-} s}$

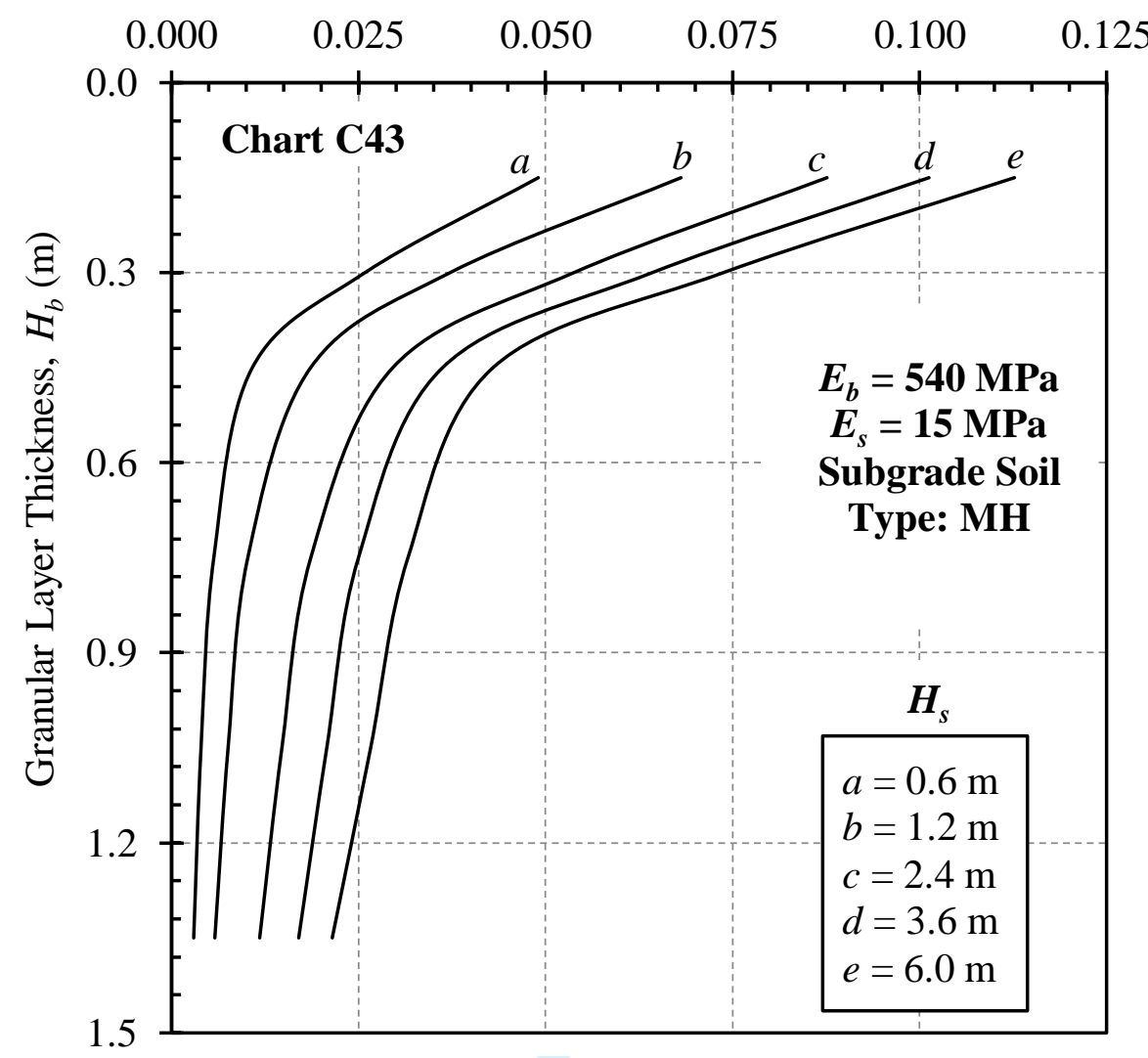

Deformation Influence Factor, $I_{\rho_{-} s}$

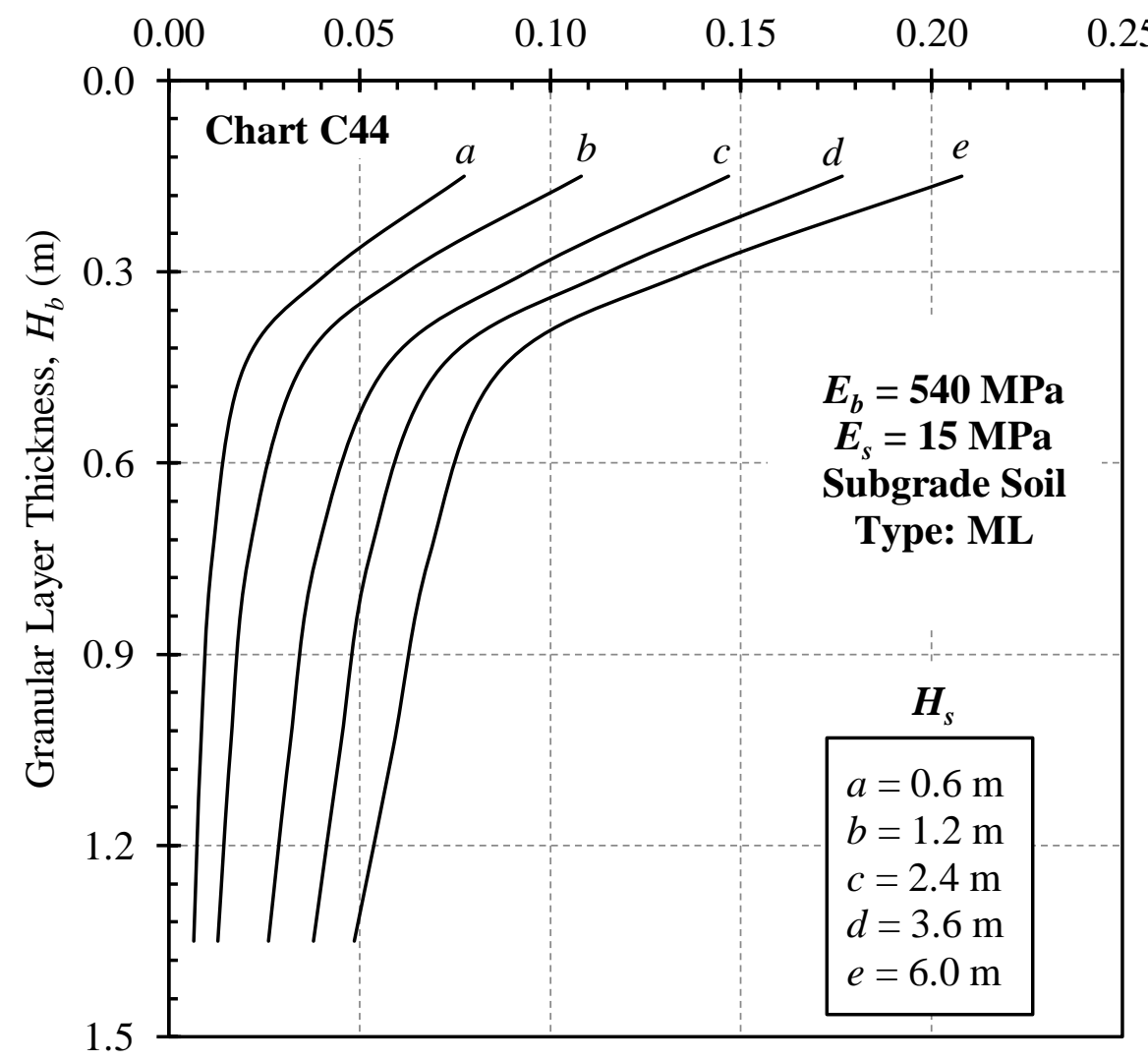


Deformation Influence Factor, $I_{\rho_{-} s}$

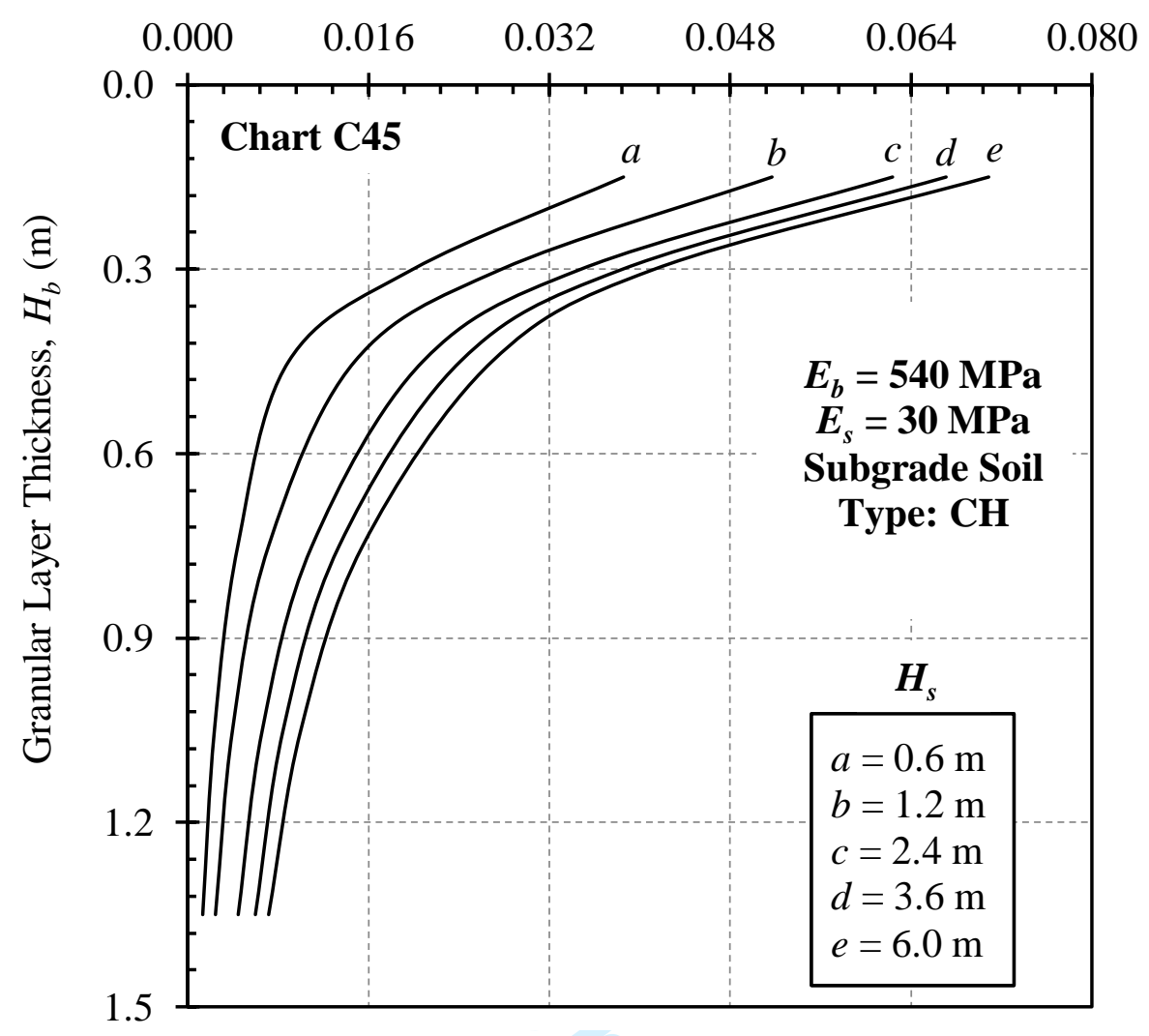

Deformation Influence Factor, $I_{\rho_{-} s}$

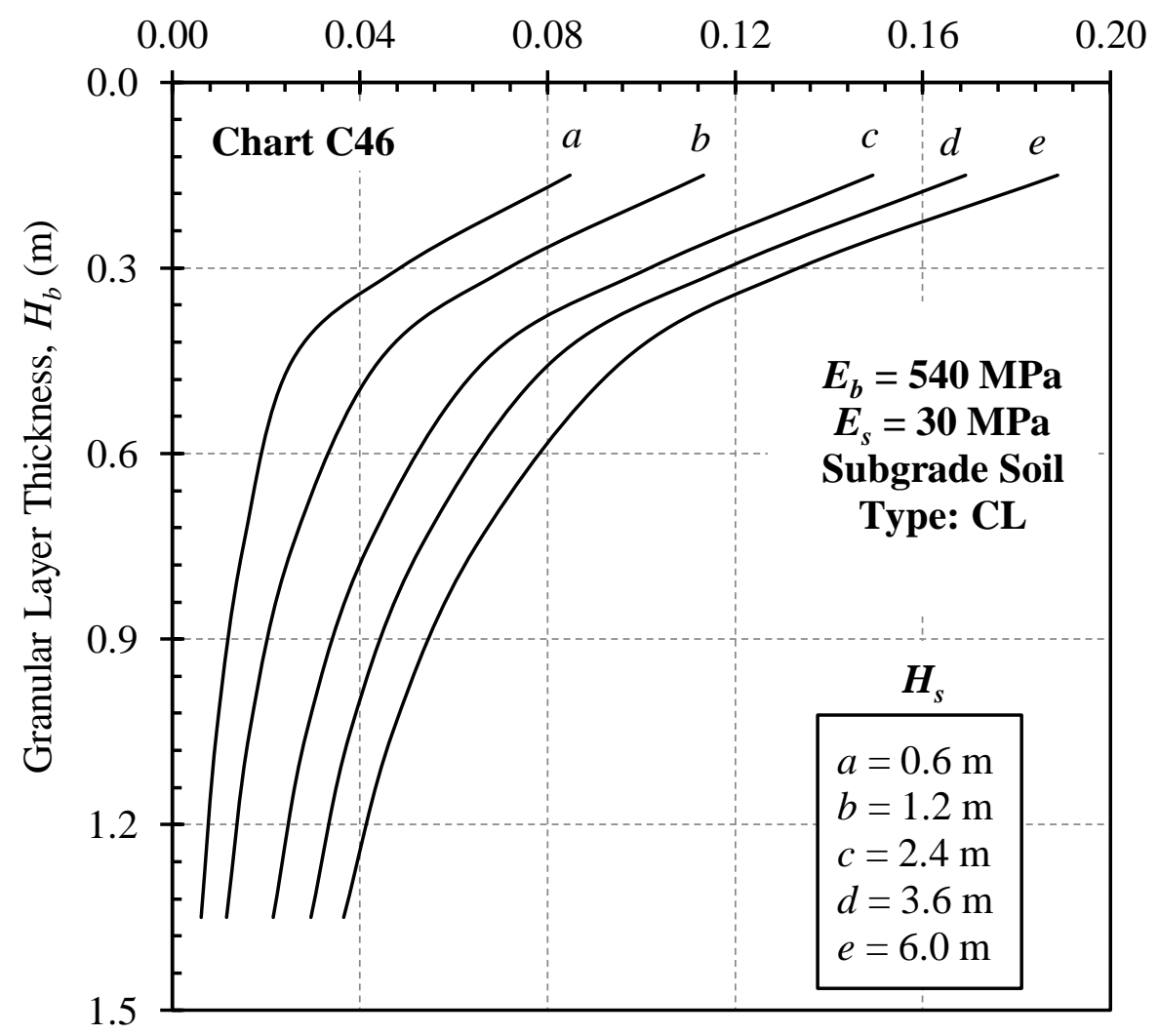


Deformation Influence Factor, $I_{\rho_{-} s}$

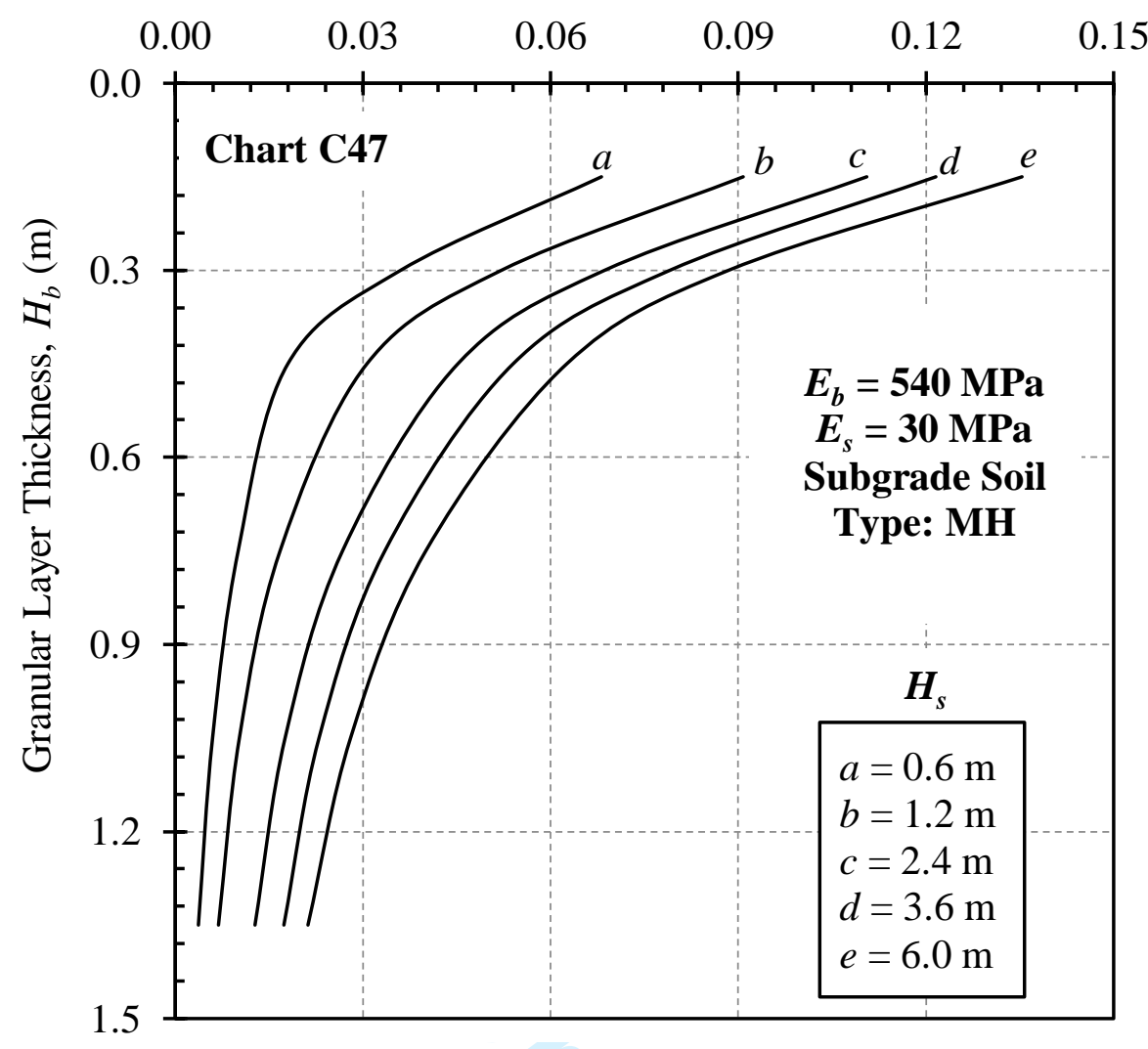

Deformation Influence Factor, $I_{\rho_{-} s}$

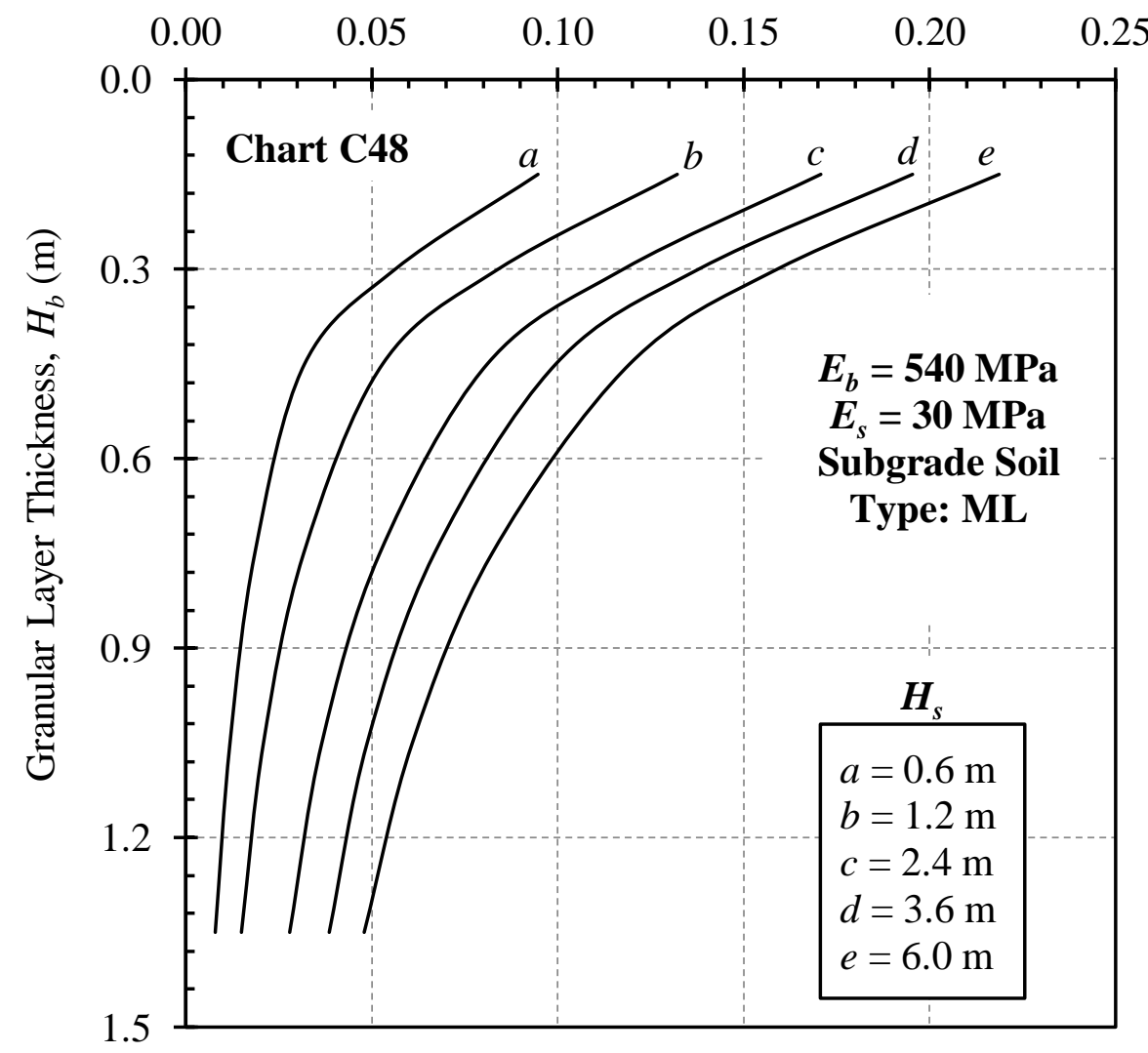


Deformation Influence Factor, $I_{\rho_{-} s}$

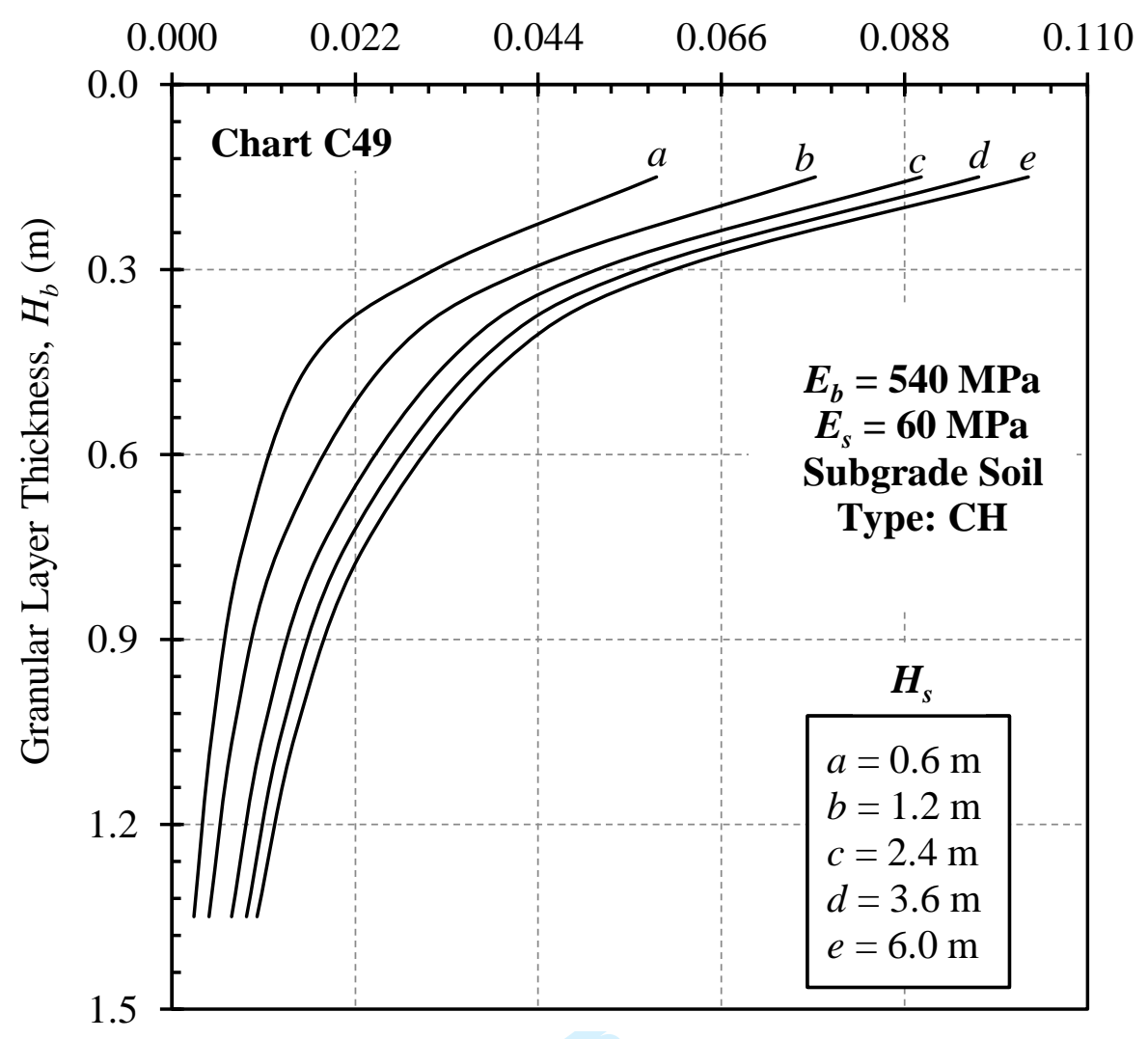

Deformation Influence Factor, $I_{\rho_{-} s}$

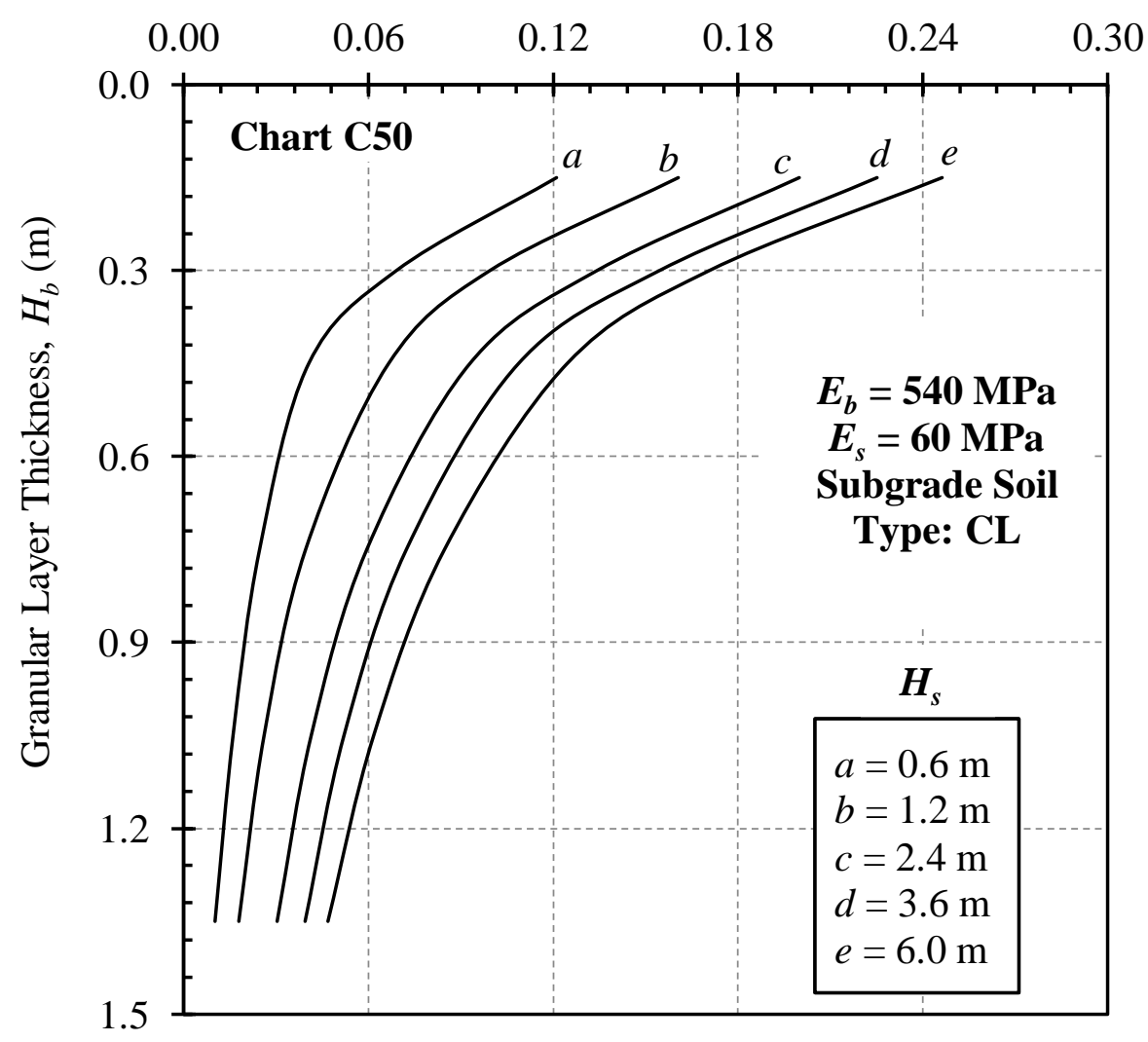


Deformation Influence Factor, $I_{\rho_{-} s}$

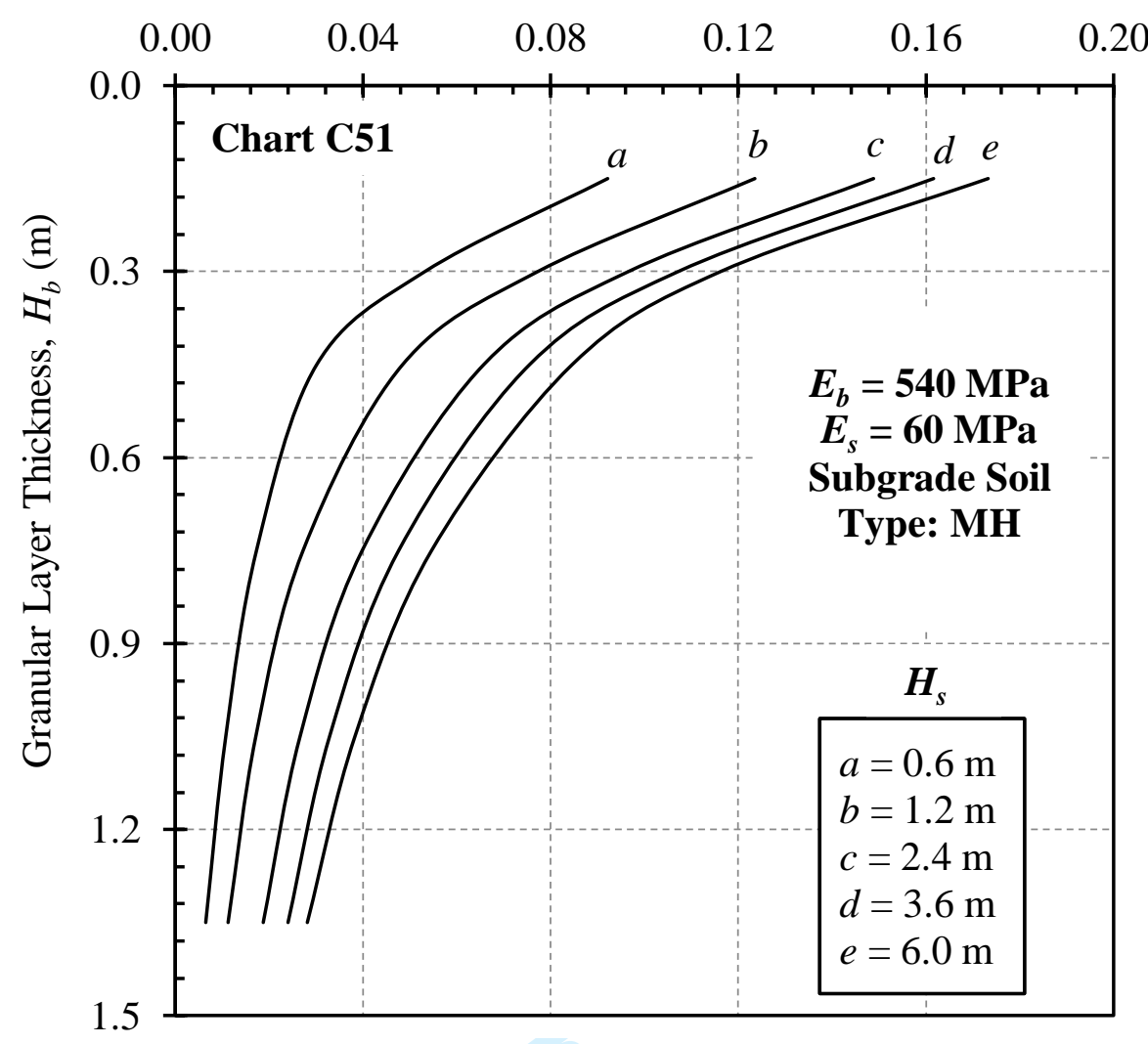

Deformation Influence Factor, $I_{\rho_{-} s}$

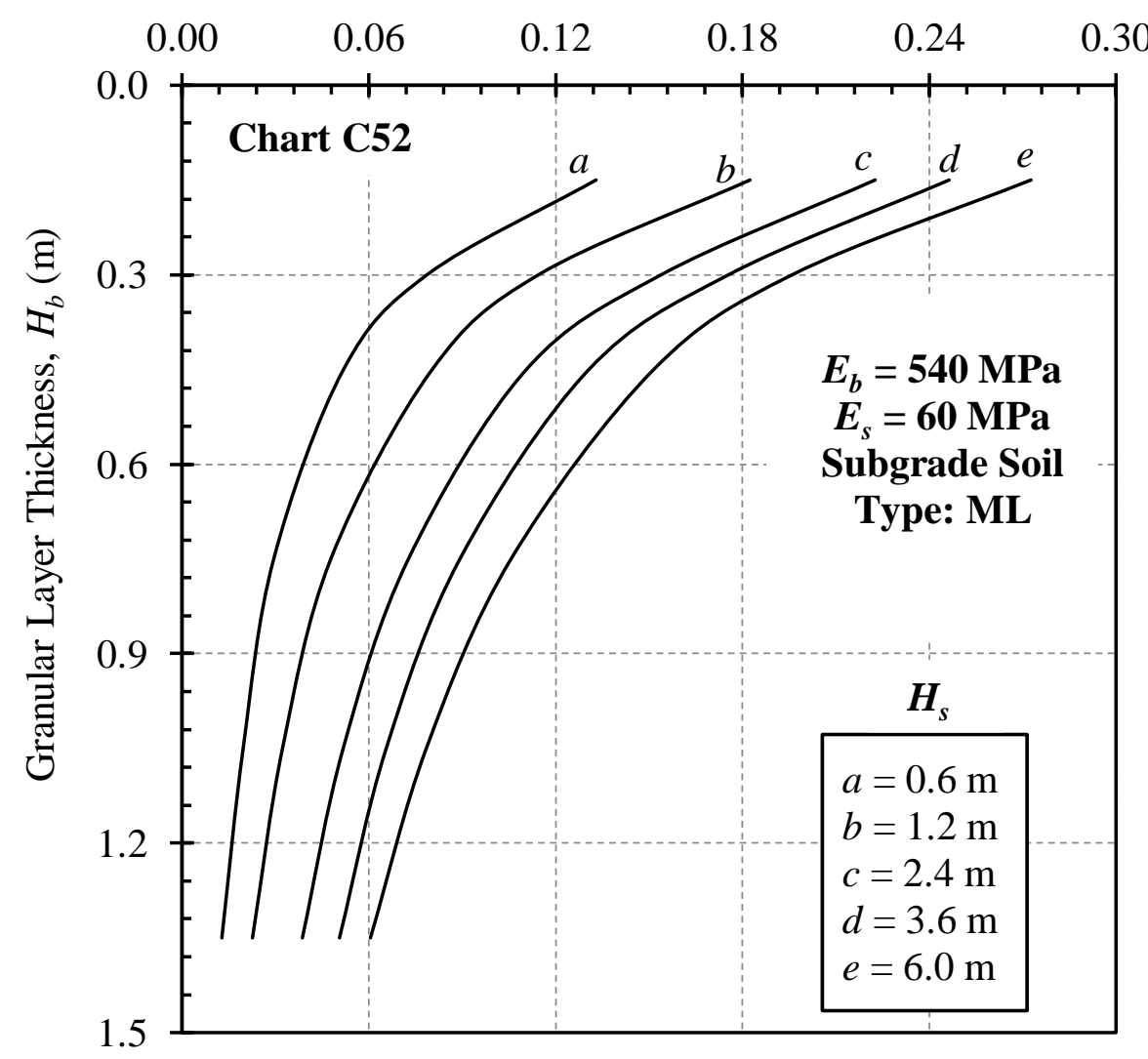


Deformation Influence Factor, $I_{\rho_{-} s}$

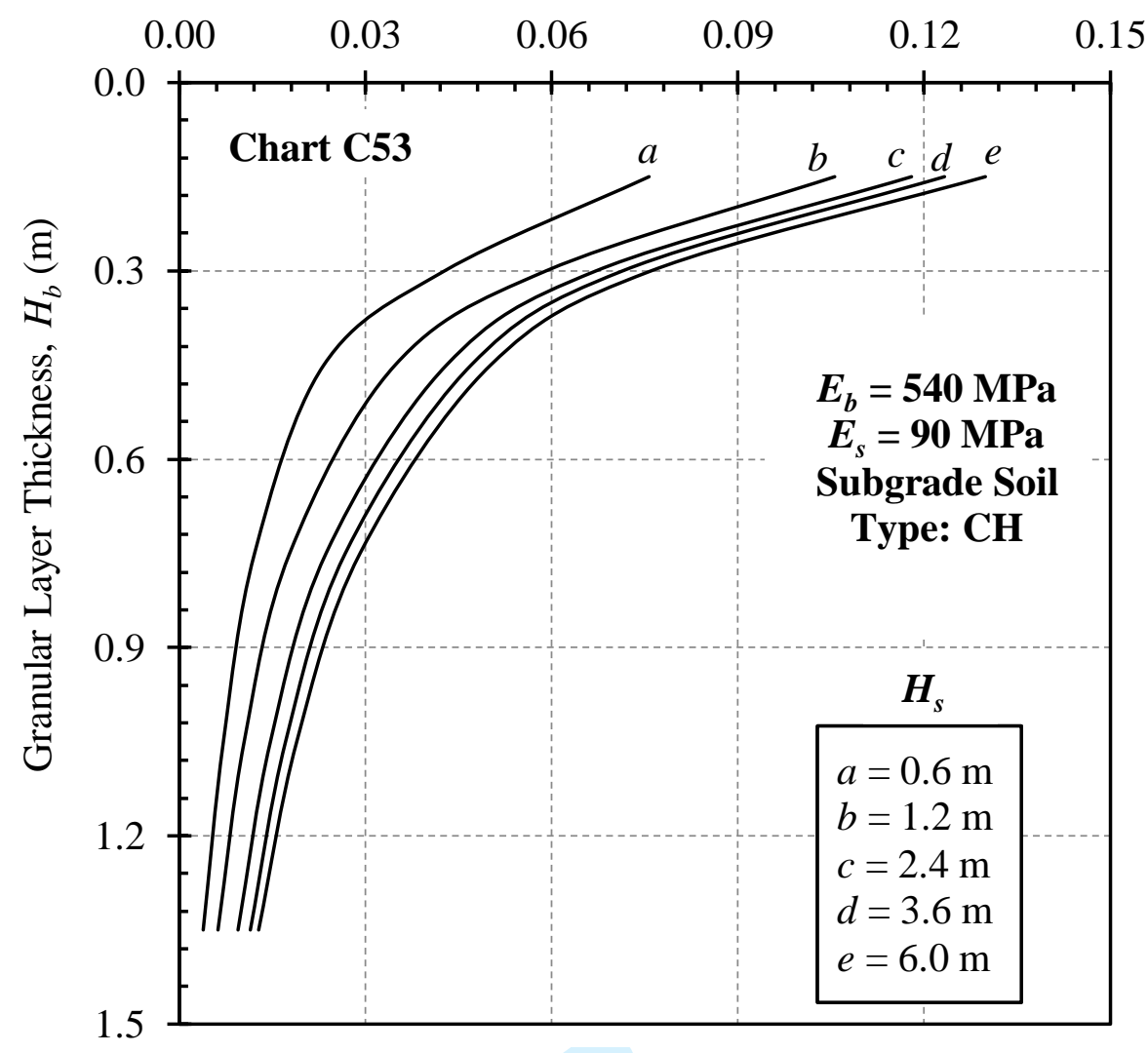

Deformation Influence Factor, $I_{\rho_{-} s}$

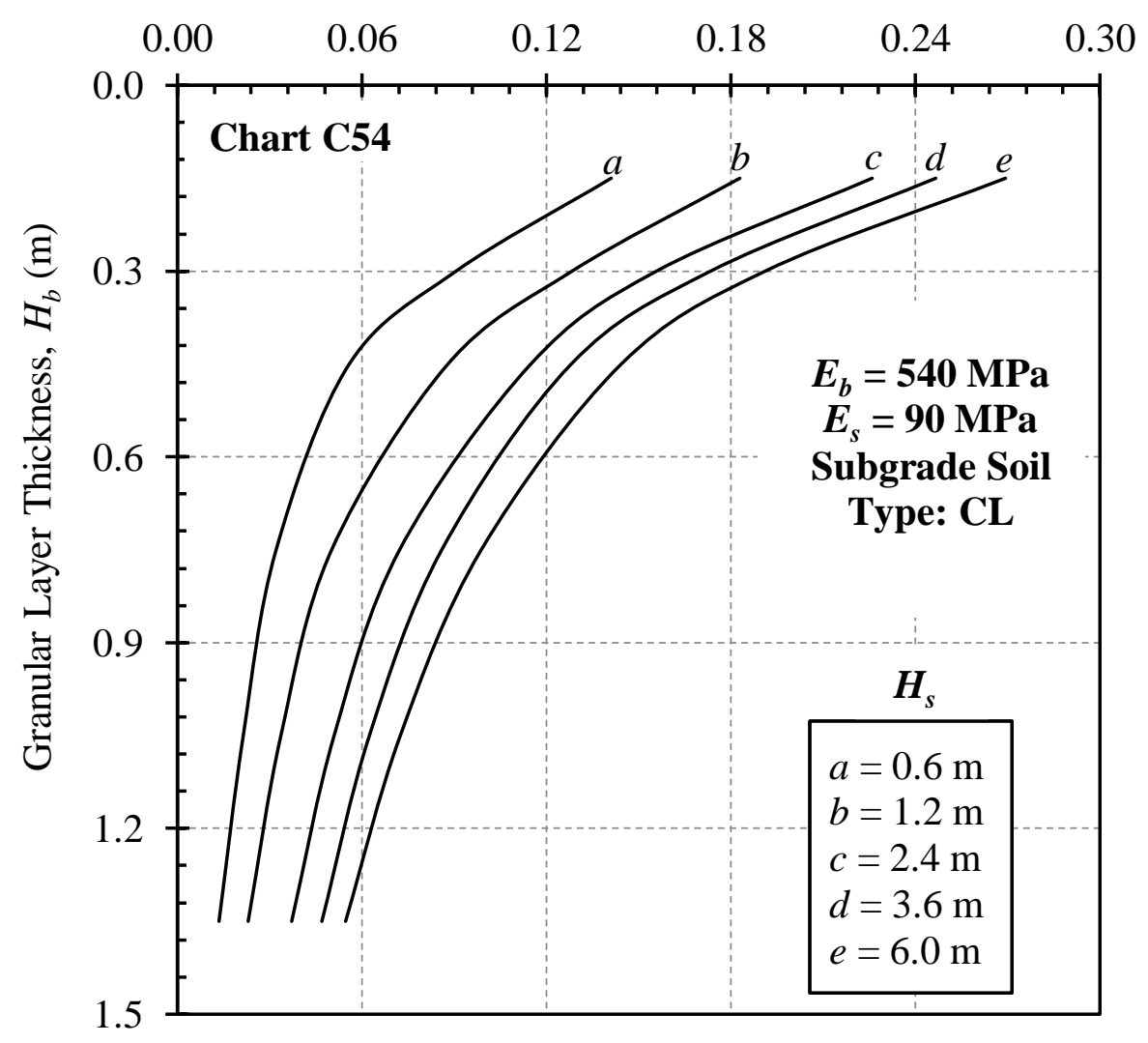


Deformation Influence Factor, $I_{\rho_{-} s}$

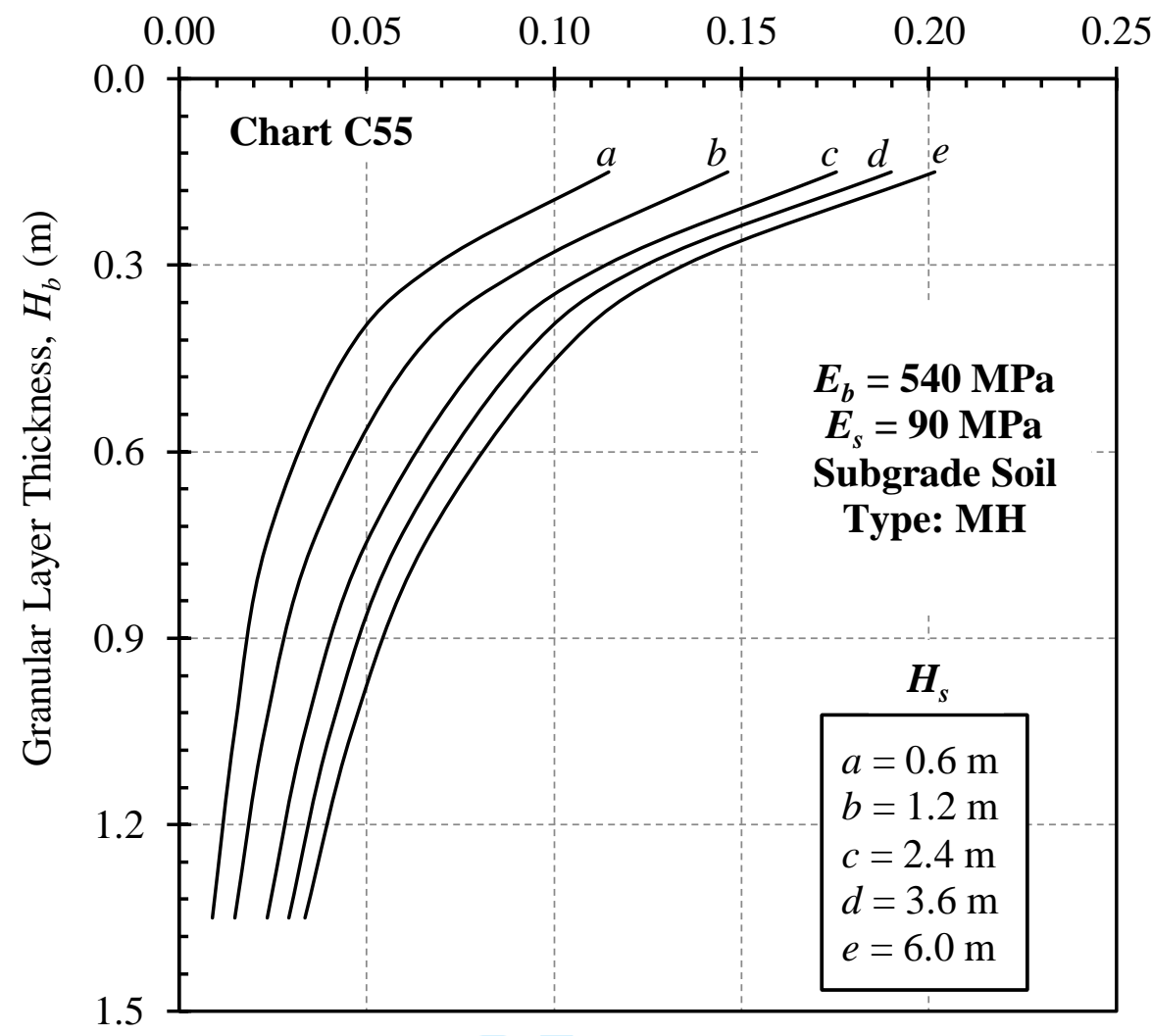

Deformation Influence Factor, $I_{\rho_{-} s}$

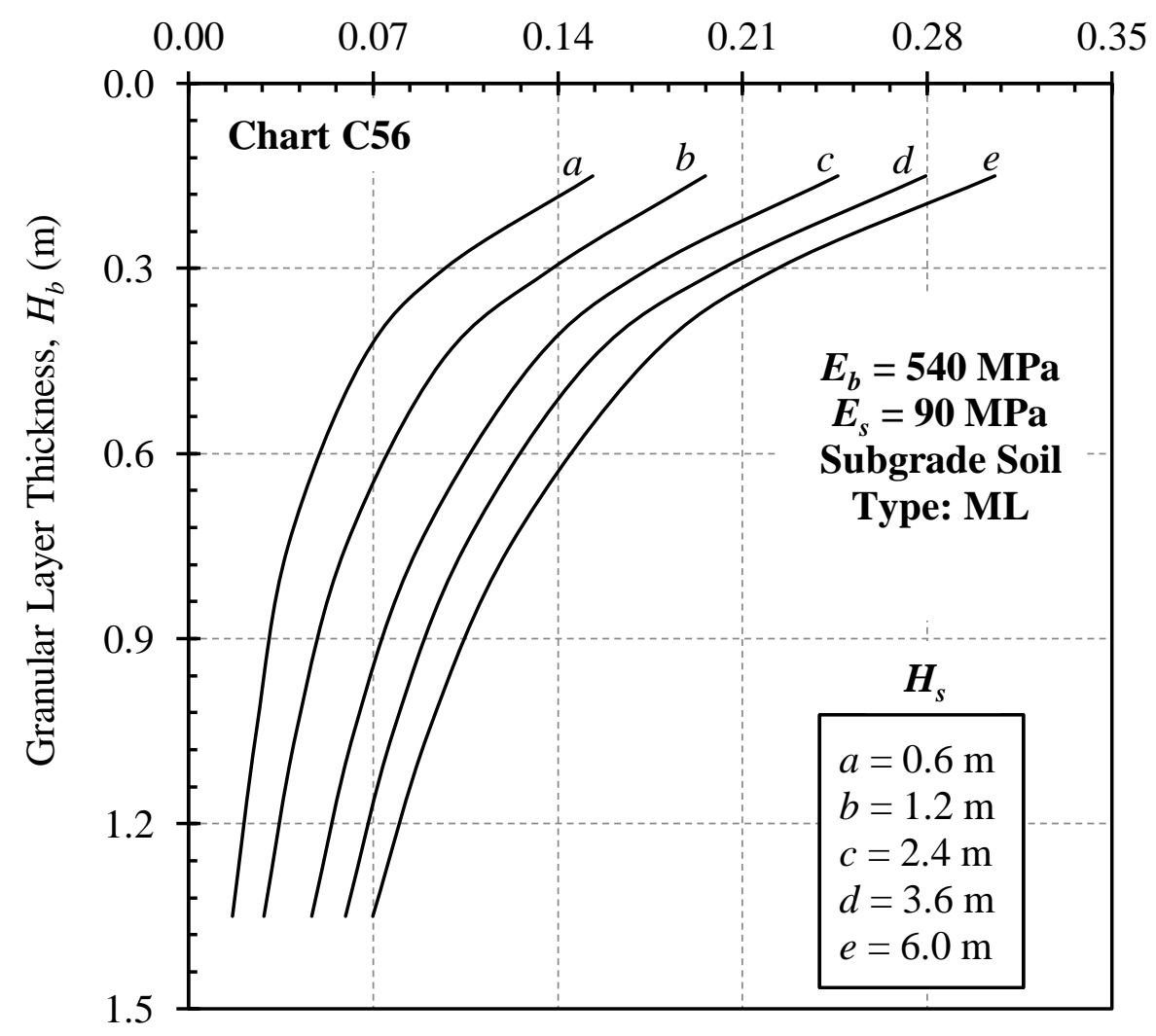


Deformation Influence Factor, $I_{\rho_{-} s}$

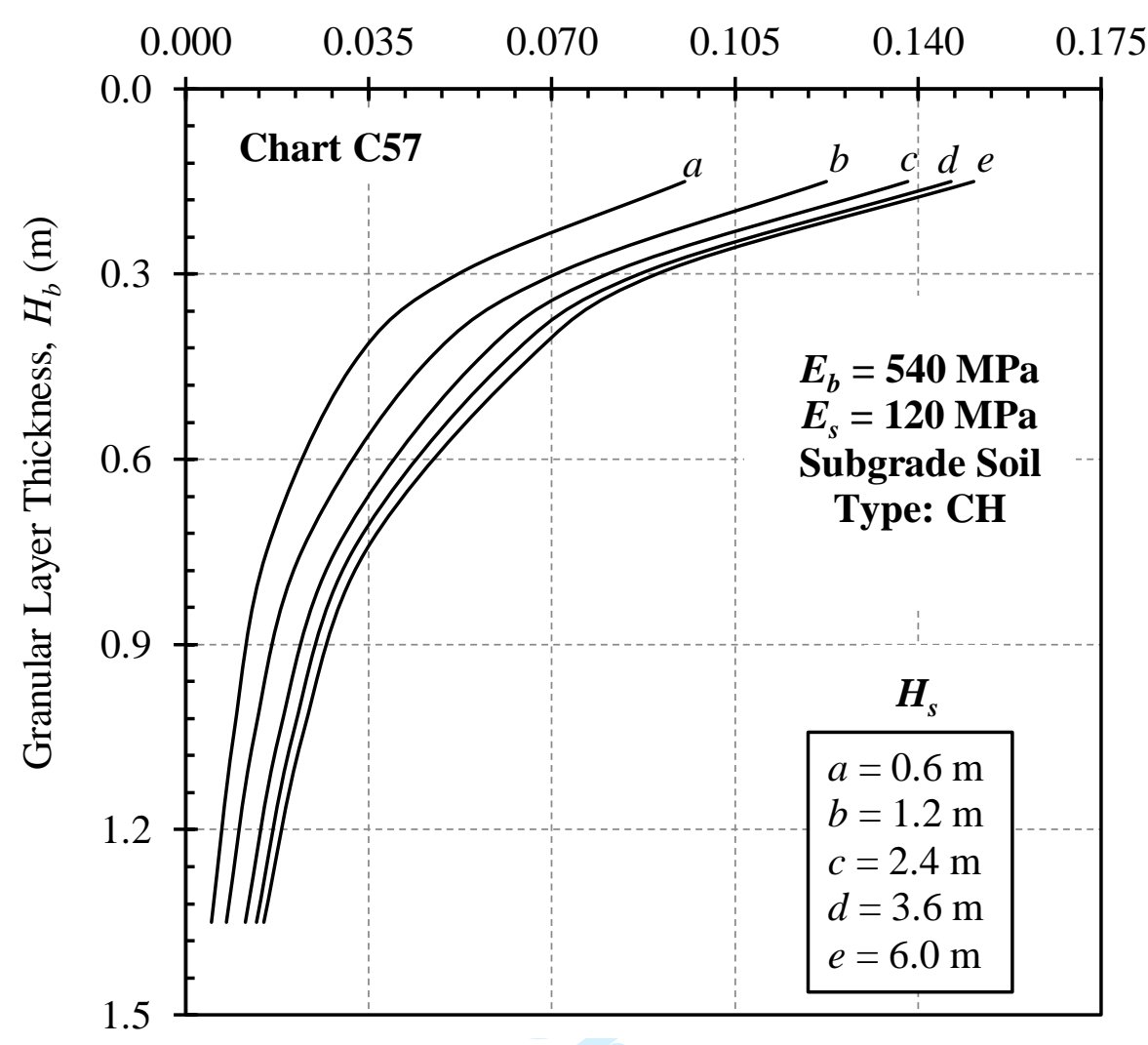

Deformation Influence Factor, $I_{\rho_{-} s}$

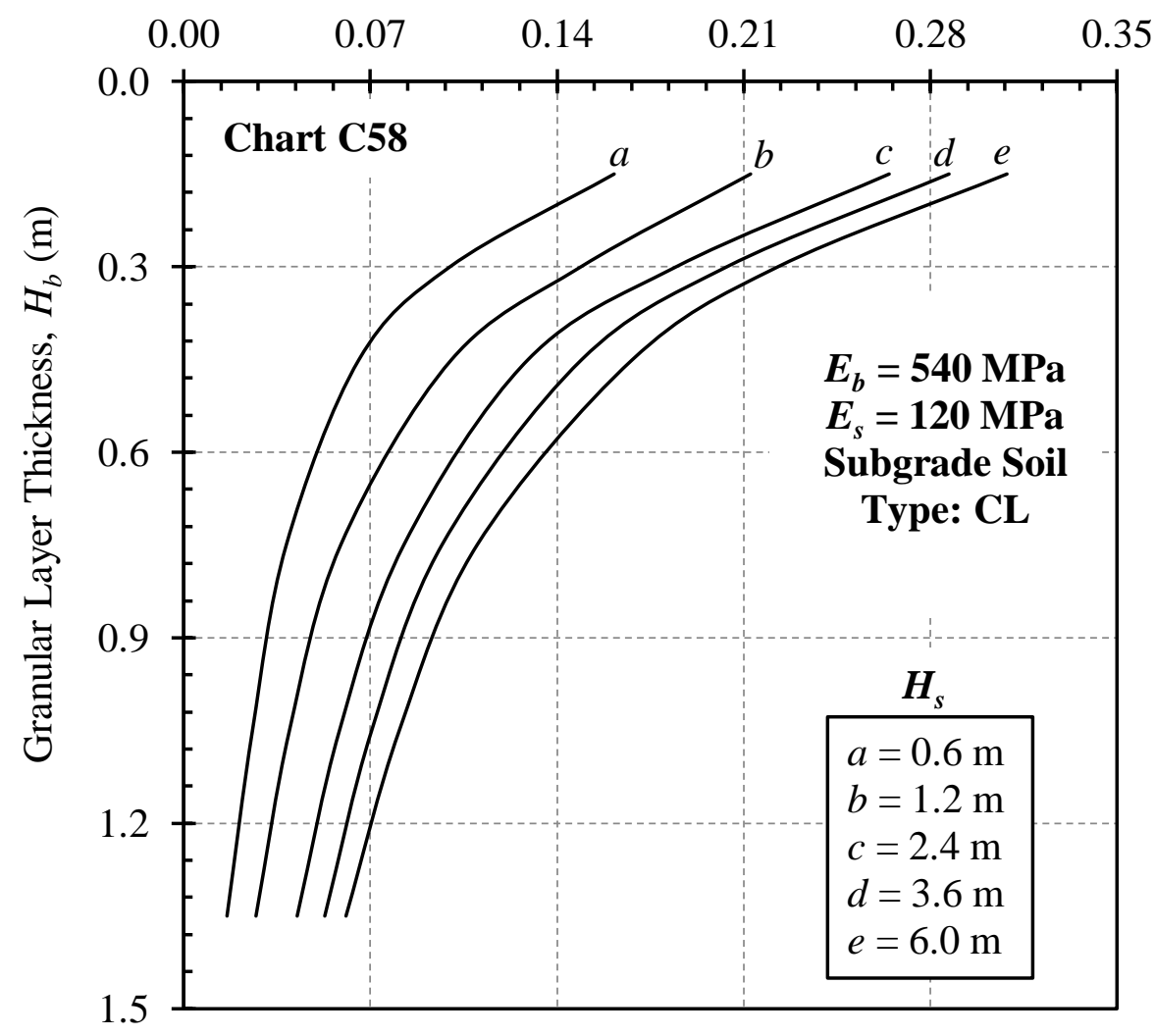


Deformation Influence Factor, $I_{\rho_{-} s}$

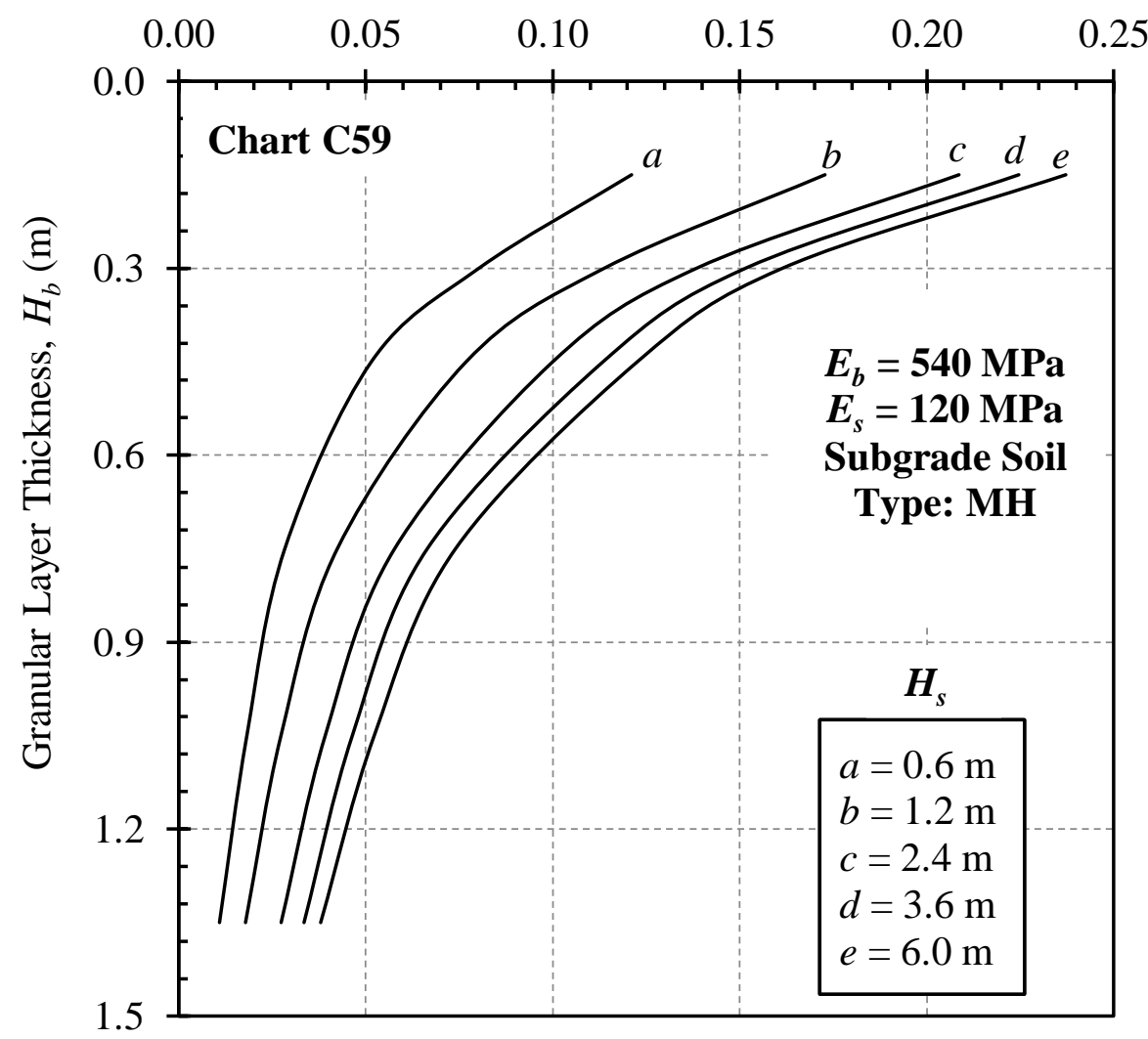

Deformation Influence Factor, $I_{\rho_{-} s}$

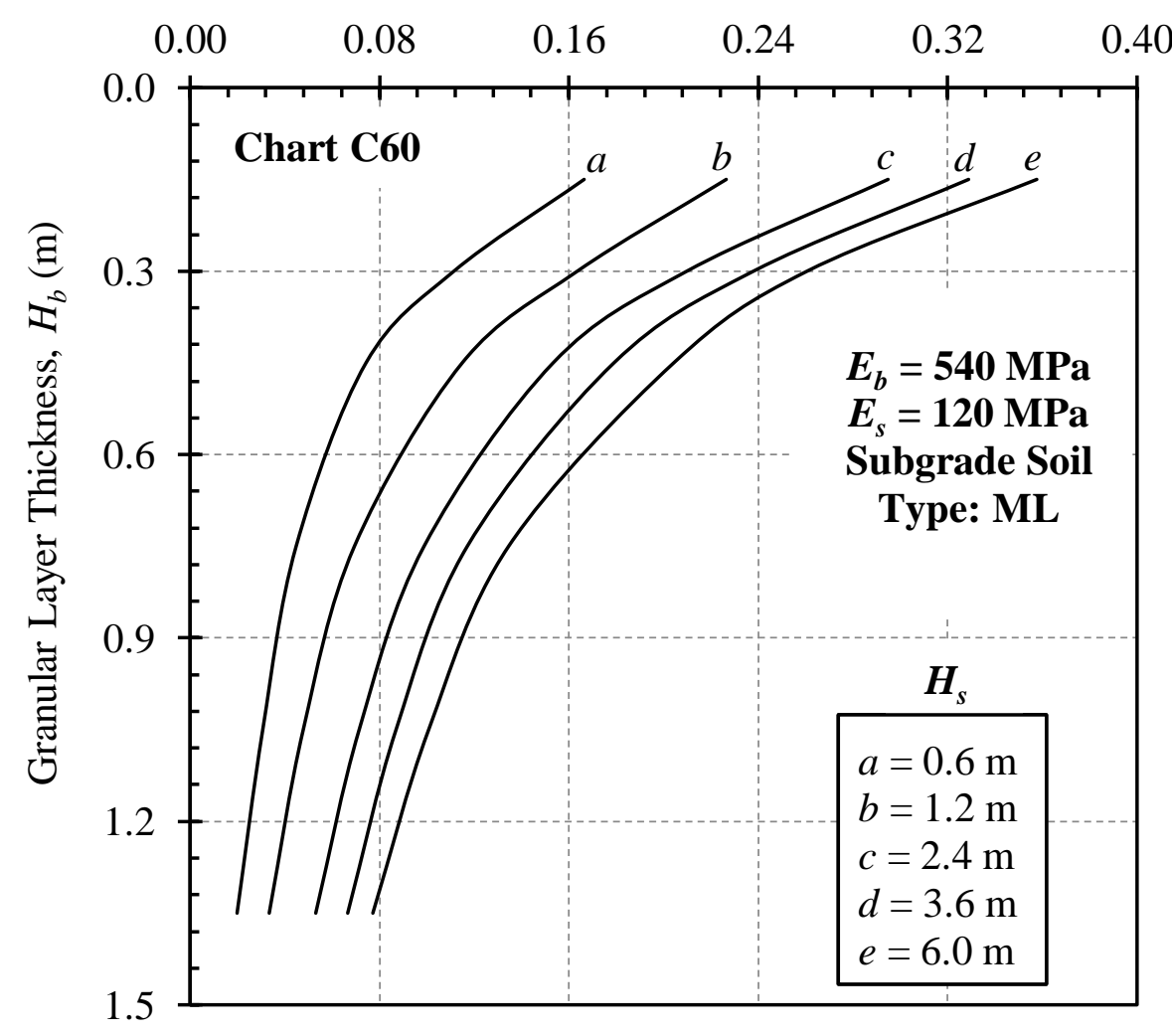

